\title{
A new Oligo-Miocene dolphin from New Zealand: Otekaikea huata expands diversity of the early Platanistoidea
}

\author{
Yoshihiro Tanaka and R. Ewan Fordyce
}

\begin{abstract}
The New Zealand fossil dolphin Otekaikea huata (latest Oligocene to earliest Miocene, in the range 22.28 to $24.61 \mathrm{Ma}$ ) is here identified as an early new species in the clade Platanistoidea, which includes the endangered Ganges River dolphin (Platanista gangetica). Otekaikea huata is known only from the holotype, which comprises a partial skeleton from the marine Otekaike Limestone of the Hakataramea Valley, South Island. Otekaikea huata has multiple procumbent tusks passing back to otherwise near-homodont and polydont teeth, and an elevated face for the nasofacial muscles implicated in production of echolocation sounds. The skull vertex is asymmetrical and strongly left-skewed. Phylogenetic analyses based on morphological features place Otekaikea huata in the clade Platanistoidea. The new species adds to the diversity of the superfamily Platanistoidea near the Oligocene-Miocene boundary.
\end{abstract}

Keywords: fossil; dolphin; stratigraphy; morphology; feeding

Yoshihiro Tanaka. Department of Geology, University of Otago, 360 Leith Walk, PO Box 56, Dunedin 9054, New Zealand. yoshihiro.tanaka@otago.ac.nz

R. Ewan Fordyce. Department of Geology, University of Otago, 360 Leith Walk, PO Box 56, Dunedin 9054, New Zealand ewan.fordyce@otago.ac.nz

\section{INTRODUCTION}

Fossil cetaceans of Oligocene age reveal the dramatic early radiation of the Neoceti (Whitmore and Sanders, 1977; Fordyce, 2009). In New Zealand, one of the key productive cetacean-bearing units is the Otekaike Limestone, a late Oligocene to earliest Miocene bioclastic grainstone that was deposited largely below storm wave base in the southern Canterbury Basin. Odontocetes from the
Otekaike Limestone include Waipatia maerewhenua, Microcetus hectori and Otekaikea marplesi, as well as undescribed squalodontids and smaller platanistoid dolphins. Such fossils, and described Oligocene odontocetes from elsewhere in the world, show disparate morphologies (Abel, 1914; Allen, 1921; Fordyce, 1981; Fordyce, 2002) that are consistent with a major early radiation of odontocetes during the Oligocene. The reported fossils have led to quite different phylogenetic

http://zoobank.org/F8462823-1EC9-4C8C-8A43-1EEED202F89C

PE Article Number: 18.2.23A

Copyright: Palaeontological Association May 2015

Submission: 16 October 2014. Acceptance: 31 March 2015

Tanaka, Yoshihiro and Fordyce, R. Ewan 2015. A new Oligo-Miocene dolphin from New Zealand: Otekaikea huata expands diversity of the early Platanistoidea. Palaeontologia Electronica 18.2.23A: 1-71

palaeo-electronica.org/content/2015/1161-fossil-platanistoid-dolphin 
TABLE 1. Measurements in mm of holotype, OU 22306, Otekaikea huata: skull and mandibles. Dimensions follow Fordyce et al. (2002) and Perrin (1975). Measurements are rounded to the nearest $0.5 \mathrm{~mm}$. For skull and mandible, distances are either horizontal or vertical, unless identified as point to point. + means measurements of preserved distances of broken part.

\begin{tabular}{|c|c|}
\hline Skull & \\
\hline total length, from the most anterior point to posterior of occipital condyles & $790.0+$ \\
\hline Cranial length & $222.0+$ \\
\hline width of premaxillae at a line across posterior limits of antorbital notches & $39.0+$ \\
\hline maximum width of premaxillae & 127.5 \\
\hline preorbital width, at level of frontal-lacrimal suture & $209.0+$ \\
\hline postorbital width, across apices of postorbital processes & $252.0+$ \\
\hline maximum width across narial aperture & 68.5 \\
\hline median length of nasals on vertex, point to point & 7.5 \\
\hline maximum length of right nasal on vertex & 31.5 \\
\hline median length of frontals on vertex & 35.0 \\
\hline greatest width of right temporal fossa, measured to external margin of raised suture & 60.5 \\
\hline greatest width of right temporal fossa at right angle to greatest length & 114.0 \\
\hline mediolateral diameter of right temporal fossa proper & 82.0 \\
\hline anteroposterior diameter of right temporal fossa proper & 64.5 \\
\hline distance from posterior of occipital condyle to anterior apex of supraoccipital & 38.5 \\
\hline $\begin{array}{l}\text { vertical external height of skull, from most ventral part of braincase on basioccipital crest, to dorsal } \\
\text { extremity of frontal at vertex }\end{array}$ & 160.0 \\
\hline bizygomatic width & 265.0 \\
\hline bicondylar width & 85.5 \\
\hline Mandibles & \\
\hline maximum preserved length of left mandible & $533.0+$ \\
\hline maximum preserved height of left mandible & $116.0+$ \\
\hline height of condyloid process & - \\
\hline width of condyloid process & - \\
\hline
\end{tabular}

hypotheses (Fordyce, 1994; Geisler and Sanders, 2003; Uhen, 2008; Steeman et al., 2009; Geisler et al., 2011; Murakami et al., 2012b; Aguirre-Fernández and Fordyce, 2014; Geisler et al., 2014) with implications for the origin of modern families, taxonomy above genus level, and understanding of ecological patterns amongst clades. Most of the named Oligocene odontocetes listed by Uhen (2008, Table 1) are based on fragmentary specimens that give little insight into body form and function or, in some cases, phylogenetic relations. The description of associated partial skeletons, as below, will improve understanding of the early history of odontocetes (Tanaka and Fordyce, 2014).

Recently, another New Zealand species, "Prosqualodon" marplesi Dickson, was placed in a new genus as Otekaikea marplesi (Tanaka and Fordyce, 2014). Here, a second species of
Otekaikea is described from a naturally associated skull, ear bones and forelimb materials. Such preservation is not common for early odontocetes. This informative specimen expands the taxonomic and structural diversity of early odontocetes, with implications for ecology and resource partitioning.

\section{MATERIAL AND METHODS}

Material was prepared by A. Grebneff using pneumatic chisels and hand tools, and finished by Y. Tanaka and R.E. Fordyce under a Zeiss SR binocular microscope. The positions of most sutures were confirmed using the binocular microscope. Dilute $(5 \%)$ acetic acid was used to free the articulated periotic from the squamosal and to remove concretionary carbonate. Bone was glued with cyanoacrylate and/or polyvinyl butyral solution, the lat- 
ter also used as a consolidant. Photographs were taken with a Nikon D700 DSLR camera and a 105 $\mathrm{mm}$ micro lens. Most views show the specimen coated with sublimed ammonium chloride, with lighting from the upper left.

No permits were required for the described study, which complied with all relevant New Zealand regulations.

\section{Acronyms}

AMNH - American Museum of Natural History, New York, USA; OU - Geology Museum, University of Otago, Dunedin, New Zealand; USNM - Department of Paleobiology, National Museum of Natural History, Smithsonian Institution, Washington, DC, USA. All these institutions are accessible, permanent repositories.

\section{Geological Setting}

The fossil dolphin OU 22306 was collected in a single plaster jacket from the upper part of the Otekaike Limestone at the Hakataramea Lime Quarry, informally known as Haughs' Quarry, in the Hakataramea Valley, South Canterbury, around 16 $\mathrm{km}$ northeast of the nearest town of Kurow, North Otago (Figure 1). Latitude $44^{\circ} 39^{\prime} 39.82 " \mathrm{~S}$, longitude $170^{\circ} 38^{\prime} 57.22 " \mathrm{E}$. The Geosciences Society of New Zealand fossil record number is 140/f0219B.

The sequence at Haughs' Quarry includes three formations, from base to top: the Kokoamu Greensand, the Otekaike Limestone, and the Mt. Harris Formation. The Kokoamu Greensand (Gage, 1957) is a bioturbated massive (lower, and top) to diffusely $\mathrm{dm}$-bedded (middle) fossiliferous calcareous greensand. The Kokoamu Greensand grades up into the Otekaike Limestone (Gage, 1957), which is a massive, fossiliferous, mostly soft grainstone, yellow-brown bioclastic limestone with fine glaucony grains and sometimes-abundant shell fragments. In the Waitaki Valley region in general, there are three members of Otekaike Limestone, from bottom to top: Maerewhenua Member (soft to cemented massive, glauconitic limestone), Miller Member (yellow or brown calcareous silt or bioclastic sandstone, sometimes with large lowangle cross-beds), and Waitoura Marl (massive, calcareous silt) (Gage, 1957; Ayress, 1993; Graham et al., 2000). At Hakataramea Lime Quarry, only the Maerewhenua Member is present. A diffuse shellbed with conspicuous Protula, about 20 $\mathrm{cm}$ thick, lies in upper part of the Maerewhenua Member, 2-3 $\mathrm{m}$ below the gradational boundary with the more-glauconitic and muddy Mt. Harris Formation.

The matrix of OU 22306 is yellow shelly glauconitic bioclastic silty-muddy sandstone with occasional calcareous concretions. The horizon is a few $\mathrm{cm}$ below the diffusely-bounded Protula-dominated shellbed in the upper Maerewhenua Member. A strontium isotope $\left({ }^{87} \mathrm{Sr} /{ }^{86} \mathrm{Sr}\right)$ determination from a smooth-shelled scallop Lentipecten hochstetteri, recovered by Fordyce from the top of the Protula shellbed, is $0.708294( \pm 2$ SE 0.000013$)$ (D.A. Teagle, personal commun., 2005), equivalent to 22.28 \pm 0.13 (22.41 to 22.15) Ma (lookup table of McArthur et al., 2012). Given that Vandenberghe et al. (2012) cited the Chattian-Aquitanian boundary as $23.03 \pm 0.1 \mathrm{Ma}$, the $\mathrm{Sr} / \mathrm{Sr}$ date puts the upper limit for $O$. huata in the lowermost Aquitanian, earliest Miocene.

Foraminifera in matrix taken from the fossil dolphin braincase include rare small specimens of the planktic foraminiferan Globoturborotalita woodi, indicating the $G$. woodi woodi planktic foraminiferal zone of Jenkins (1965), in the middle of the New Zealand Waitakian stage. The next younger zonal species, Globoturborotalita connecta, was not found. For the Otiake Trig Z section $18 \mathrm{~km}$ to the south southwest, Graham, Morgans et al. (2000) identified the incoming of $G$. woodi woodi in the range 23.99 to $24.61 \mathrm{Ma}$, earlier than the ChattianAquitanian boundary. Thus, the age from strontium isotope and planktic foraminifera is in the range 22.28 to $24.61 \mathrm{Ma}$, straddling the Oligocene/Miocene boundary.

The locality is an important vertebrate fossil source in New Zealand (Fordyce and Maxwell, 2003; Fordyce, 2014). Two Waitakian penguins (Fordyce and Jones, 1990) and a Duntroonian billfish (Gottfried et al., 2012) from the Otekaike Limestone have been reported from the quarry. Several undescribed mysticetes also are known (Fordyce, 2009). The paleoenvironment is probably below storm wave base, in a sheltered middle shelf setting, with warm paleotemperature indicated by bivalve taxa (Fordyce and Maxwell, 2003). Rich mollusc-dominated invertebrate assemblages are also known from the locality.

\section{SYSTEMATIC PALEONTOLOGY}

Order CETACEA Brisson, 1762

Unranked taxon NEOCETI Fordyce and de Muizon, 2001

Suborder ODONTOCETI Flower, 1867

Superfamily PLATANISTOIDEA Gray, 1863 


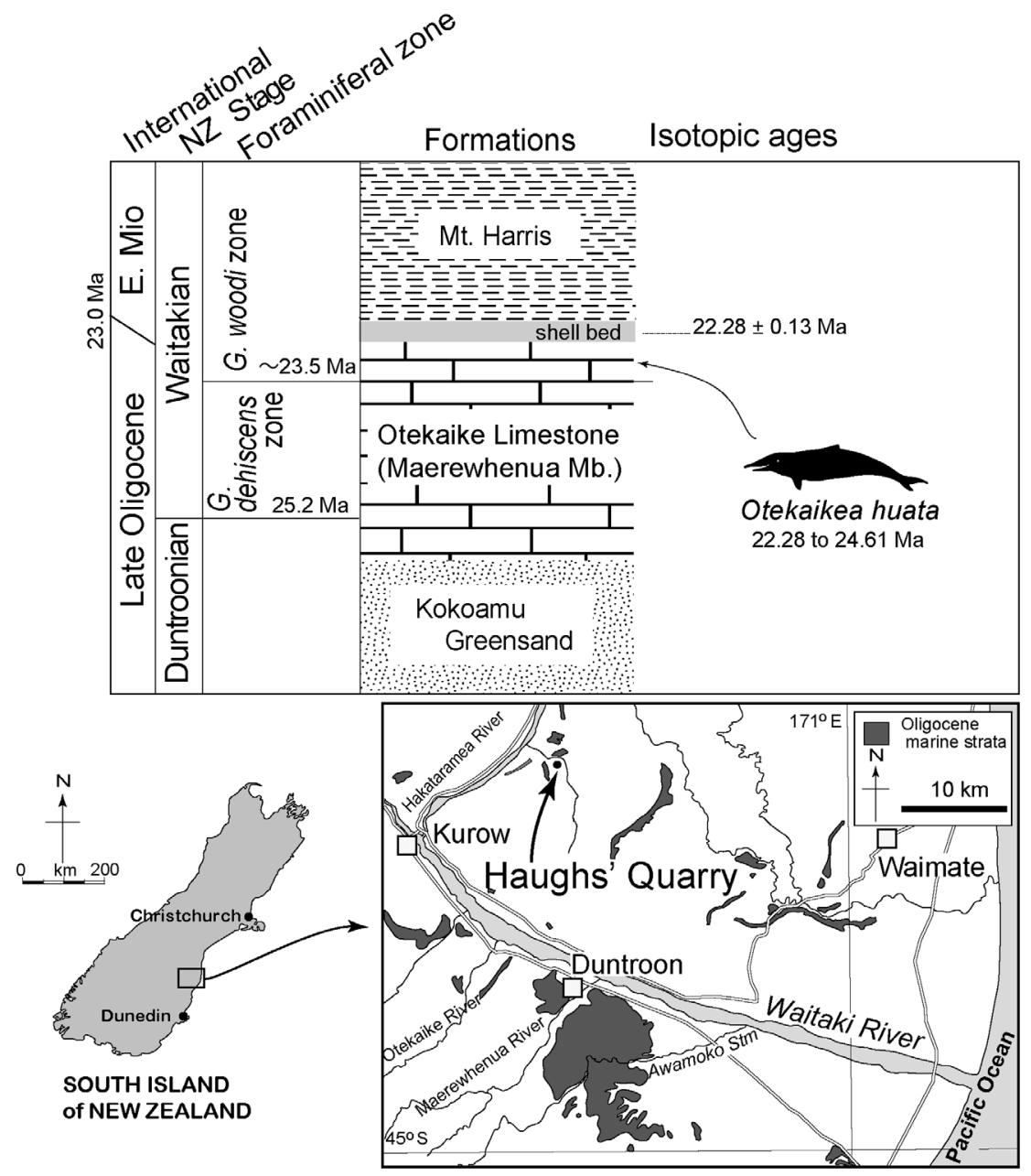

FIGURE 1. Locality map and stratigraphic sections of the Otekaikea huata type locality. Arrow shows type locality. Foraminiferal zonation and geochronology are based on Graham et al. (2000).

Family not specified

Genus OTEKAIKEA Tanaka and Fordyce, 2014

Type species. Prosqualodon marplesi Dickson, 1964 = Otekaikea marplesi (Dickson, 1964) sensu Tanaka and Fordyce (2014).

Included species. O. marplesi (Dickson, 1964) and O. huata n. sp.

Diagnosis. Genus Otekaikea includes longirostral odontocetes with: condylobasal length around $790+\mathrm{mm}$; procumbent tusks; presence of an intrapremaxillary foramina in each premaxilla; large and rounded carotid foramen; and a deep voluminous facial fossa. Otekaikea has the following synapomorphies: ventromedial edge of the internal opening of infraorbital foramen is formed by both the maxilla and palatine; both nasals have a point on the midline and gap with the premaxillae; nasals are relatively narrow; and accessory ossicle is fused on the periotic. Otekaikea differs from Waipatia in skull features that include: rostrum is relatively longer; premaxillary sac fossa is more elevated; posterolateral plate and posteromedial splint of the premaxilla are more distinct, with an infra-premaxillary foramen on the right or bilaterally; vertex is less symmetrical, with nasals subrhomboidal rather than transversely oval; ascending process of the maxilla is less-rounded; frontal on the vertex is anteroposteriorly shorter; postglenoid process is tapered rather than squared in lateral view; zygomatic process is more robust in ventral view; and paroccipital process has a medially-developed tongue-like articulation for the stylohyal. The teeth are near-homodont, and the cheekteeth mostly lack denticles; the mandibles have a fused symphysis. The periotic differs from Waipatia in that: anterior keel is less distinct; accessory ossicle is fused; a less-strongly project- 
ing lateral tuberosity; a wider and more-circular internal acoustic meatus; posterior process is longer and subrectangular rather than elongate comma-shaped, and angled relative to the axis of the periotic from ventral or dorsal views. The posterior process of the bulla has less prominent sutures for the periotic, posterior meatal ridge, and posttympanic process.

Otekaikea differs from Squalodontidae and Prosqualodon in lacking large robust heterodont cheekteeth. Differs from Notocetus, Squalodelphis, Huaridelphis, and Platanistidae in lacking: orbital fossae for extensions of pterygoid sinuses; thickened maxilla or elevated maxillary crest over orbit.

Otekaikea differs from other archaic Odontoceti including Xenorophidae, Simocetus, Agorophius, Patriocetus, Prosqualodon, Squalodontidae, and Waipatia, in the unique combination of apomorphies involving: broad dished face; nasals elevated, nodular, and subrhomboidal; frontals elevated; premaxillary sac fossae smooth-surfaced, without prominent premaxillary sulci developed posteriorly; premaxillae bifurcated posteriorly, each with an intra-premaxillary foramen at the junction between posterolateral plate and posteromedial splint, and elevated crests on the maxillae; periotic with long, slender, parallel-sided posterior process. Otekaikea differs from crown odontocetes other than Platanistoidea in lacking: the supracranial basin of Physeteriidae and Kogiidae; an enlarged hamular fossa of Ziphiidae; medially located aperture for the cochlear aqueduct of Eurhinodelphinidae; and the orbital fossae for extensions of pterygoid sinuses, parabullary ridge of periotic, and saddle-shaped involucrum of the bulla of Delphinida.

Comment on higher taxonomy. Gray (1863) was the first to use the family-group name Platanistidae. The content of the family varied in later years, to include species of Platanista, and also Inia and Pontoporia, and finally Lipotes. Simpson (1945) used a new rank in the family group, Superfamily Platanistoidea, to encompass a single family, Platanistidae Gray, 1863. He justified the superfamily rank in general terms with the comment "The number of genera and families [amongst Odontoceti] has become so large that I have introduced superfamilies for the association of families that appear to be specially related" (Simpson, 1945, p. 215). According to the International Code of Zoological Nomenclature (1999), Article 50.3, Gray (1863) remains the author. This authorship for Platanistoidea follows Fordyce and de Muizon (2001).
Otekaikea huata, new species

Figures 2-20, Tables 1-3

\section{zoobank.org/CFD7D54E-00B2-40F1-830E-E60644595463}

Diagnosis. Otekaikea huata is an odontocete with: a skull of medium size (bizygomatic width $265 \mathrm{~mm}$, cranial length $222+\mathrm{mm}$, likely condylobasal length $790+\mathrm{mm})$; apical teeth procumbent with a large tusk $(197+\mathrm{mm}$ in length, not including broken crown); more-posterior teeth near-homodont and polydont, with subconical crowns and at least one tooth with vestigial denticles; supraoccipital depressed; condyles prominent; zygomatic processes robust; and cervical vertebrae unfused. Otekaikea huata is slightly larger than the holotype of 0 . marplesi in terms of bizygomatic width $(8 \mathrm{~mm}$ larger), maximum anteroposterior length of the periotic parallel to dorsal margin ( $7 \mathrm{~mm}$ larger) and also all measurements of preserved postcranial elements (each several $\mathrm{mm}$ larger). The one cheek-tooth known for 0 . marplesi has double roots, whereas the cheekteeth in $O$. huata are all single-rooted, including at least one with a vestigial longitudinal groove as if separating two fused roots. Otekaikea huata also differs from O. marplesi in: ascending process of the premaxilla is reduced, stopping at the level of the nasal (character 58); lateral expansion of the maxillae roofs the temporal fossa (character 101); nasal has an anterolateral process; fenestra rotunda of the periotic is very narrow and slit-like (character 174); caudal tympanic process of the periotic is posteroventrally projecting (character 178); and a prominent fold separates the infraspinous fossa and teres fossa on the scapula (character 236).

Etymology. From the Maori language: huata, a spear, alluding to the long tusk of the holotype specimen.

Material. Holotype only: OU 22306; the skull, right periotic and sigmoid process of left bulla, fused mandibles, 60 isolated conical-crowned teeth, atlas, axis, three other cervical vertebrae, 12 thoracic vertebrae, two lumbar vertebrae, eight ribs, scapulae, humeri, radii, an ulna, a carpal and nine digits. Collected by R.E. Fordyce, A. Grebneff, B.V.N. Black, and O. Sarll, 15 January and 12-13 February 1996; field number REF12-2-96-2.

Type locality. Informally-named Haughs' Quarry, Hakataramea Valley, South Canterbury, New Zealand (Figure1). See details above.

Horizon. A few centimeters below the diffuse Protula shellbed in the upper part of the Maerewhenua Member, Otekaike Limestone (Figure 1). See details above. 


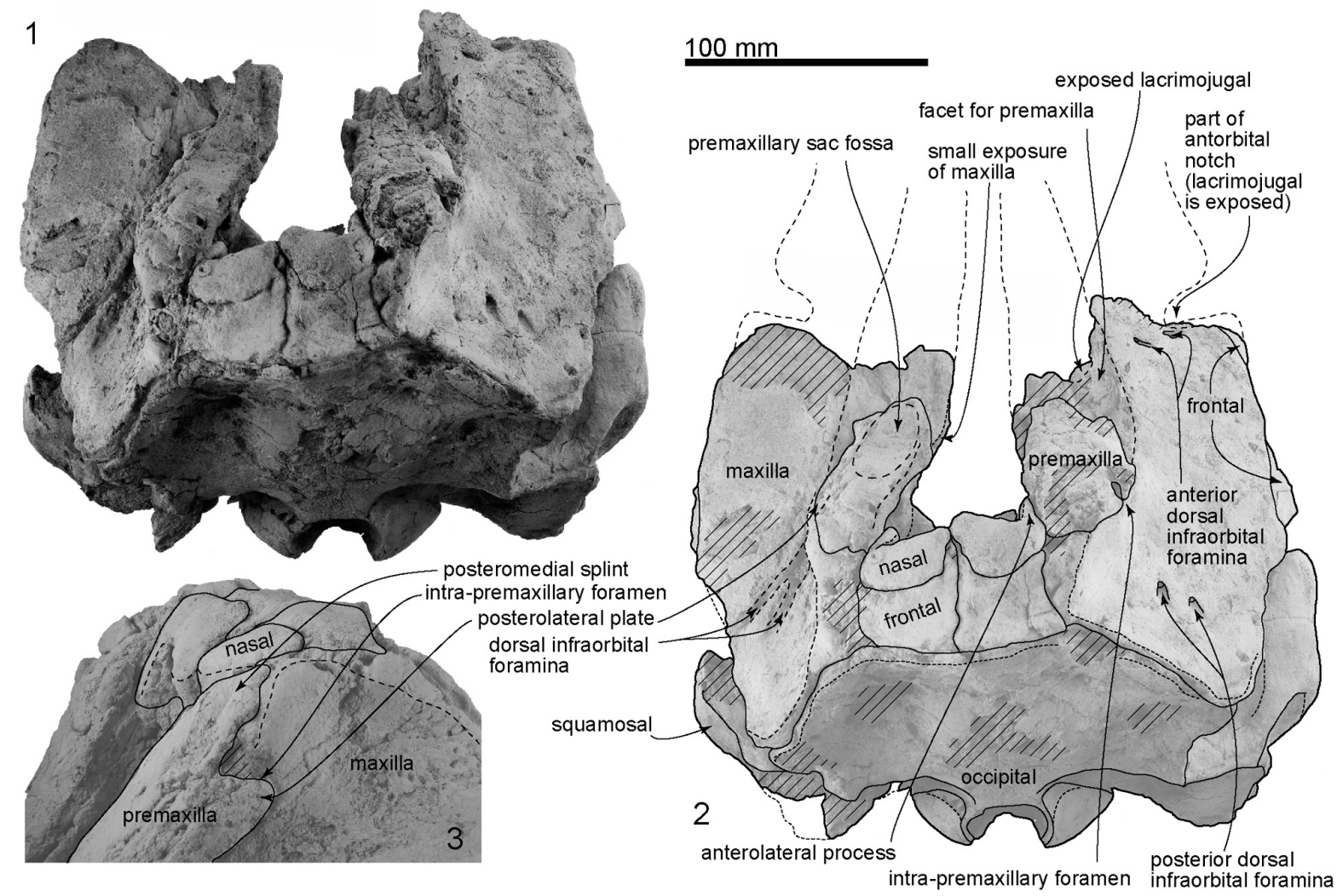

FIGURE 2. Dorsal views of the type skull, OU 22306, Otekaikea huata (1 and 2). 3, dorsolateral view, figure is not to scale.

Age. Waitakian stage, Oligo/Miocene boundary, in the range 22.28 to $24.61 \mathrm{Ma}$. See details above.

\section{General Description}

Descriptions are based on the right or left side, whichever is more informative, with differences between them mentioned only if directional asymmetry is evident. Morphological terms follow Mead and Fordyce (2009) for the skull; postcranial terms mainly follow Flower (1885a), and Evans and de Lahunta (2013). Surface detail is lost in places from bioerosion, as noted when major. Some adherent concretionary carbonate remains.

Body size. The body size of Otekaikea huata can be inferred by the Pyenson and Sponberg (2011) formula for stem Platanistoidea, $\log (L)=0.92$ * $(\log (\mathrm{BIZYG})-1.51)+2.49$. BIZYG (bizygomatic width) of $O$. huata is $26.5 \mathrm{~cm}$, giving a reconstructed body length of $2.57 \mathrm{~m}$. As with 0 . marplesi, this is a similar body length to modern Platanista gangetica: $2.6 \mathrm{~m}$ in adult female, $2.2 \mathrm{~m}$ in adult male (Jefferson et al., 2008). The gender of the type specimen of $O$. huata is uncertain. Closely related fossil species have comparable sizes: $W$. maerewhenua, bizygomatic width $24.4 \mathrm{~cm}$ (= length $2.39 \mathrm{~m}) ; 0$. marplesi, bizygomatic width $25.7 \mathrm{~cm}$ (= length around $2.5 \mathrm{~m}$ (Tanaka and Fordyce, 2014). For O. huata, the minimum condylobasal length of $79.0+\mathrm{cm}$ would comprise around $30 \%$ of the BIZYG-predicted body size of $2.57 \mathrm{~m}$, implying a long rostrum and large cranium with a short trunk. Not enough postcranial material is known to provide independent evidence of body length.

Ontogenetic age. Skull sutures are mostly closed but distinct. All preserved vertebral epiphyses (in the atlas, axis, three cervical, 12 thoracic, and two lumbar vertebrae) are fused. These features suggest that $O$. huata is equivalent in ontogenetic age to stage VI, physically mature adult, in Stenella attenuata as proposed by Perrin (1975, p. 42). The skull lacks obvious roughened or eroded bone that might indicate a gerontic age. Otekaikea huata also has an ossified carpus, which supports an adult age class based on a flipper radiograph study on Phocoena sinus by Mellor et al. (2009).

Skull topography. The cranium is moderately complete dorsally (Figures 2-9), while the separated rostrum is broken and represented by dorsal parts (porcelanous portions) of the isolated right 


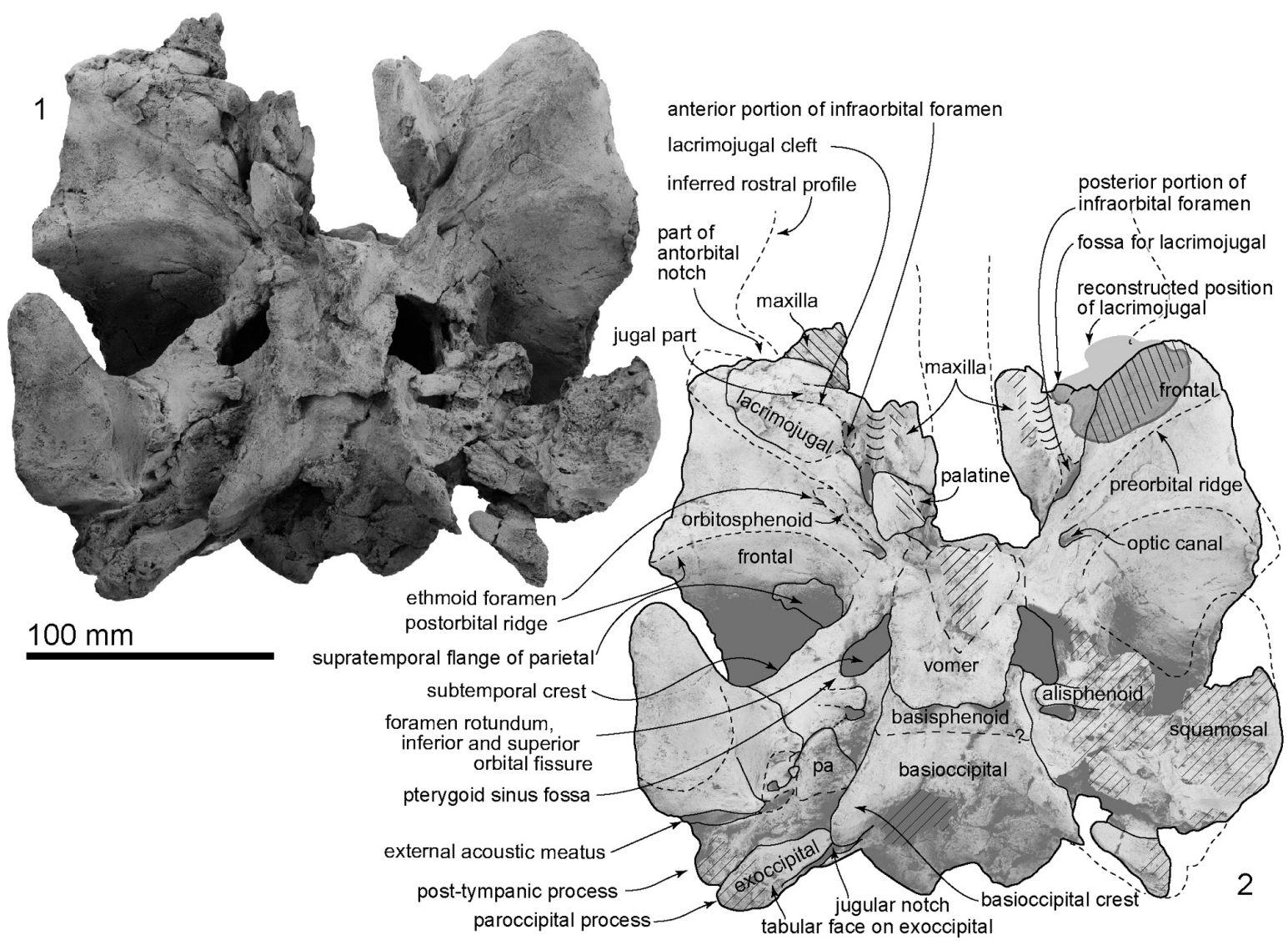

FIGURE 3. Ventral views of the type skull, OU 22306, Otekaikea huata. Pa, the parietal.

and left premaxillae, the posterior end of the right maxilla, and anterior of the vomer with the attached posterior end of the left maxilla (Figure 7). The separated rostral elements can be placed close to orig- inal articulation with the cranium, although minor burial-related distortion prevents exact matches that would allow full reassembly. The incomplete rostral left maxilla, which is sutured with the vomer

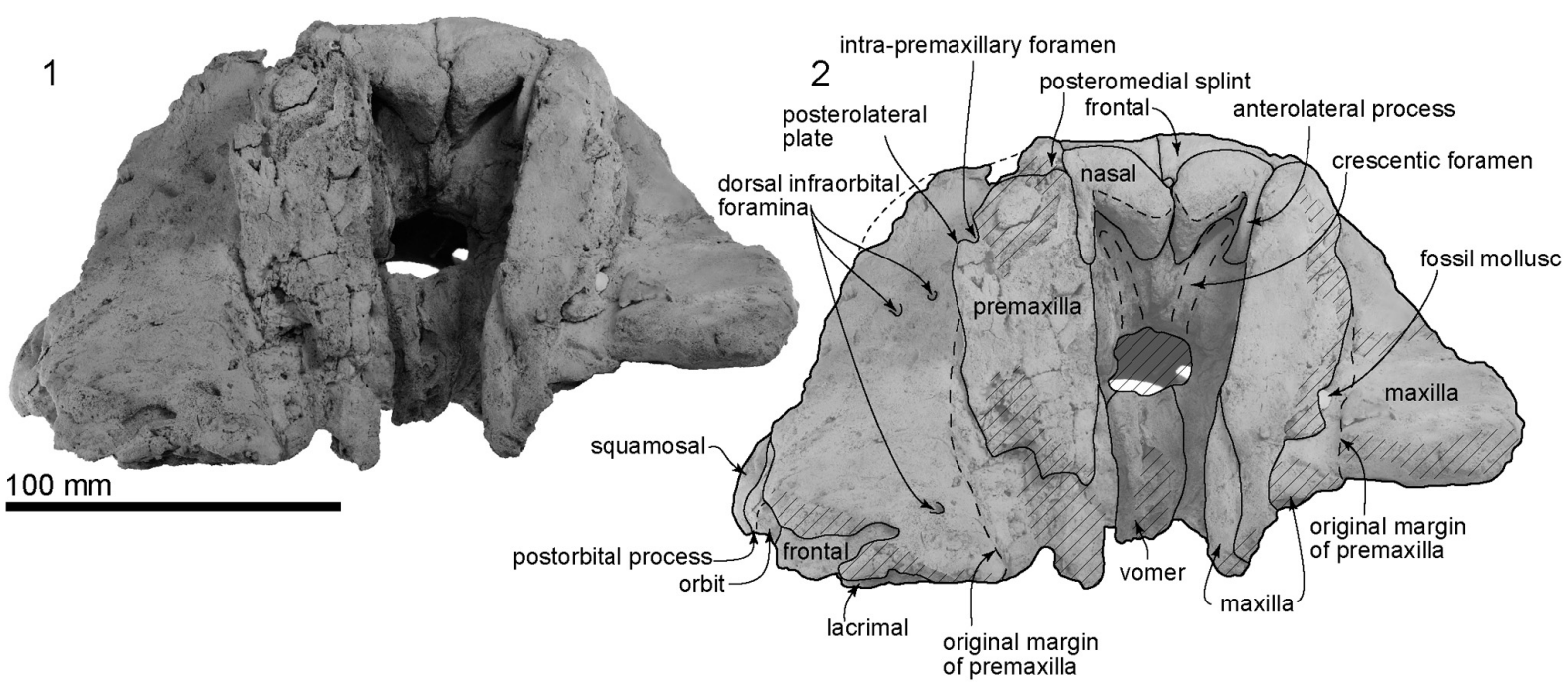

FIGURE 4. Anterior views of the type skull, OU 22306, Otekaikea huata. 

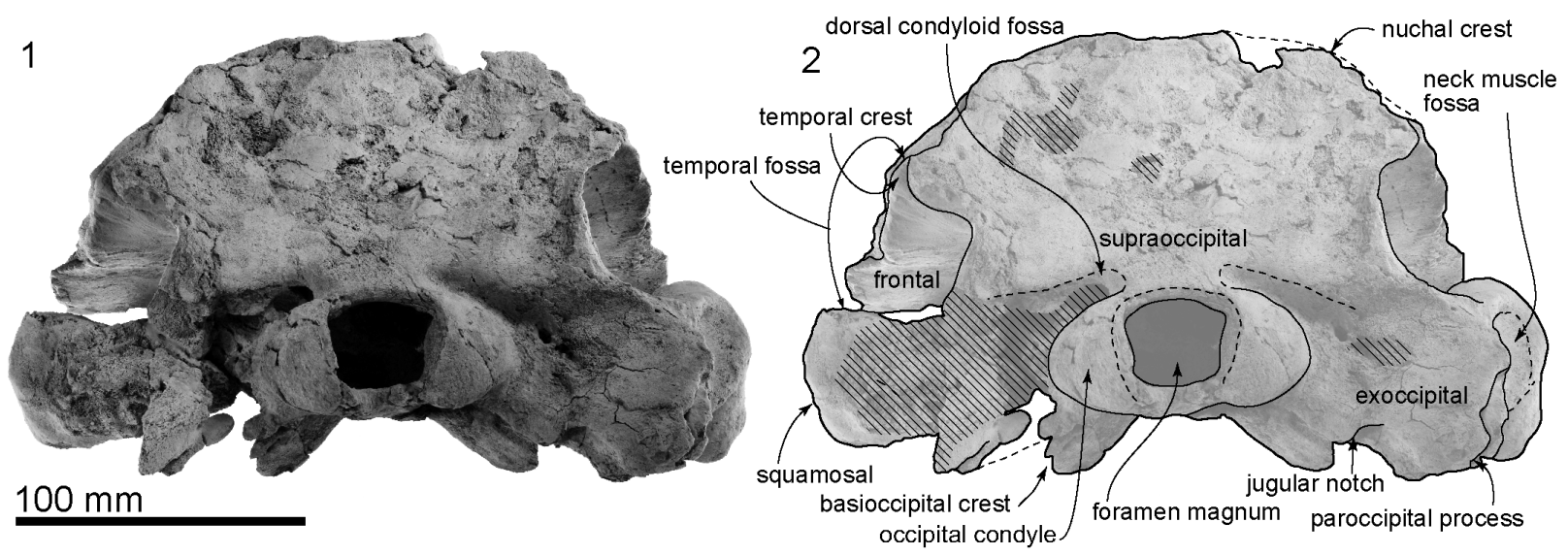

FIGURE 5. Posterior views of the type skull, OU 22306, Otekaikea huata.

and can be articulated with the cranium, preserves an elongate, flat, medially-dipping suture that matches a corresponding suture on the ventral surface of the premaxilla; a comparable suture is on the right. Both premaxillae (porcelanous parts) can be articulated with the flat sutures on the maxillae to indicate approximate life position on the rostrum (below). To reconstruct the skull, the right premaxilla was positioned to match the left; there was no independent evidence of bilateral asymmetry in the rostral sections of premaxilla. The face has a wide hexagonal shape in dorsal view, is flat anteriorly and rises steeply posteriorly. Compression slightly distorts the skull; additionally, the vertex is naturally skewed to left, as seen clearly in a posterior view, which shows the right nasal and frontal in the midline. Natural directional asymmetry affects the nasals, frontals, premaxillae, and maxillae. In lateral view (Figures 6 and 8 ), the posterior part of the face has very steep medial and posterior walls involving both maxilla and premaxilla, and these walls form a strongly elevated but anteroposteriorly short vertex comprised of the maxillae, premaxillae, nasals, and frontals. The temporal fossa is mostly invisible in dorsal view because of the laterally expanded temporal crest. The orbit is long and weakly arched, with relatively thin antorbital and postorbital processes, above which the frontal is almost fully overlapped by the maxilla. The anteriorly broken external nares open from a subvertical

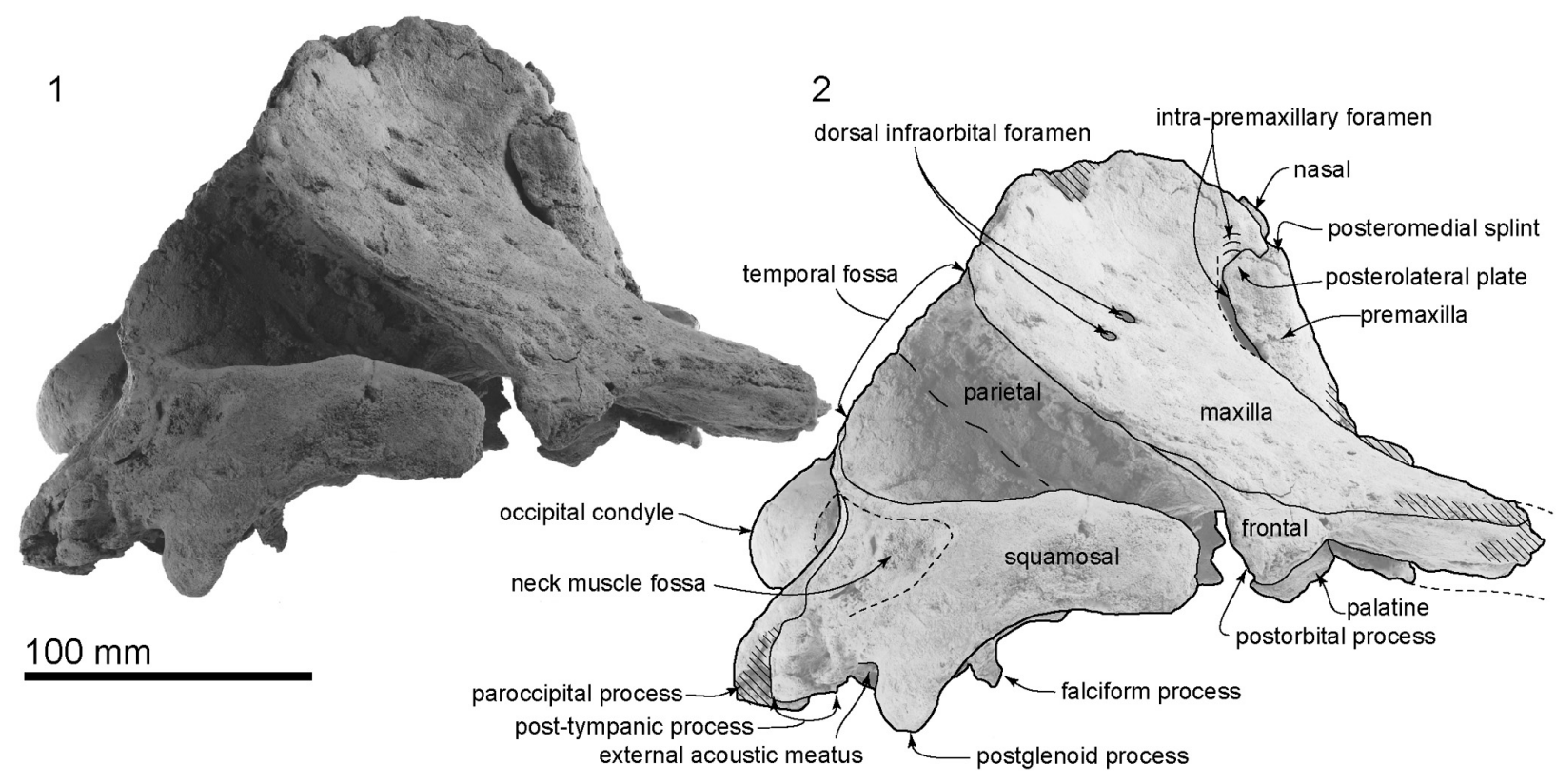

FIGURE 6. Right lateral views of the type skull, OU 22306, Otekaikea huata. 


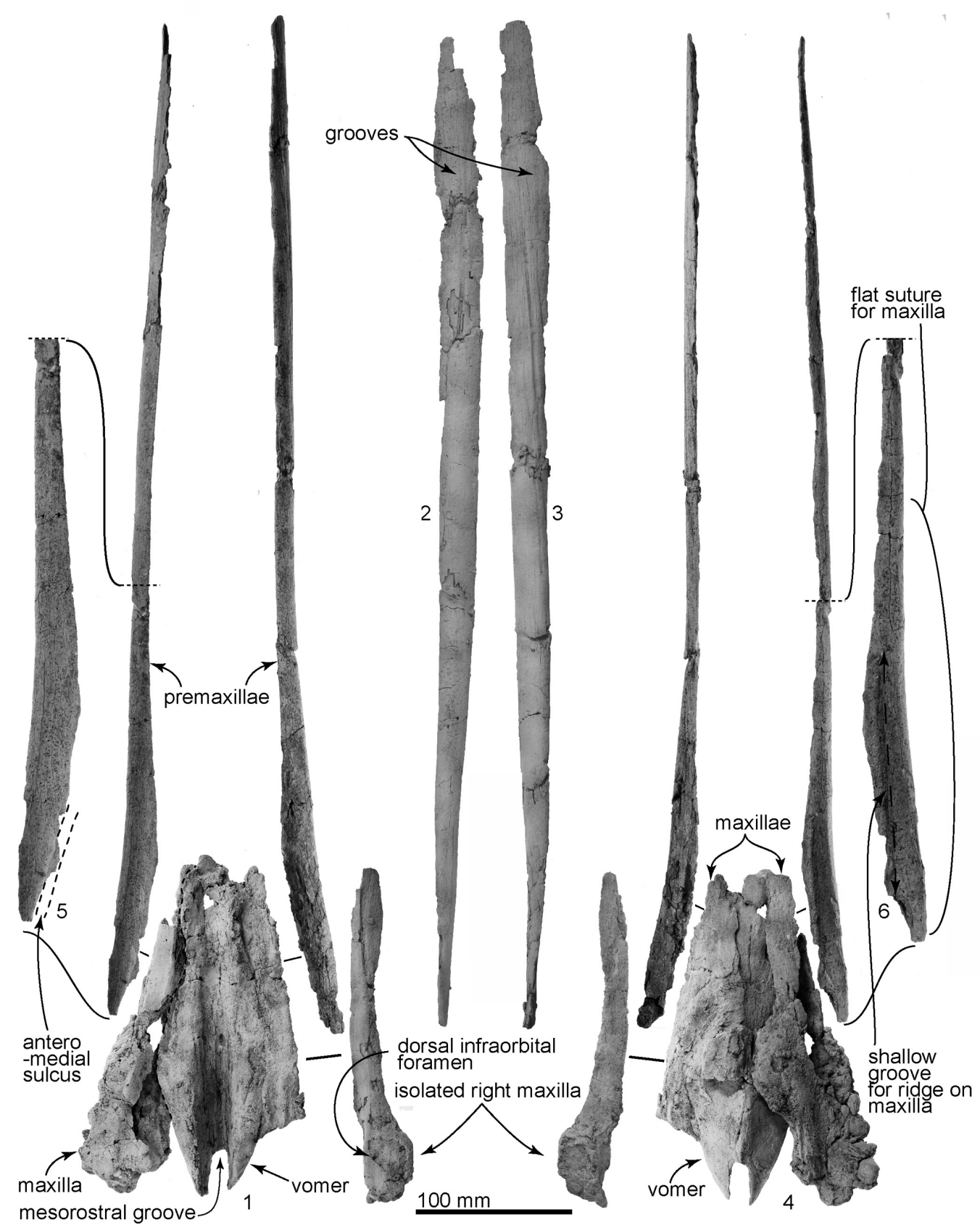

FIGURE 7. Disarticulated rostral elements, OU 22306, Otekaikea huata. 1, dorsal view. 2, left premaxilla lateral view. 3, right premaxilla lateral view. 4, ventral view. 5 and 6, detailed photos of the premaxilla.

narial passage about level with the postorbital processes. The nuchal crest is not developed. The pterygoids and most of the palatines are missing.

Rostrum. Most of the anterior part of the rostrum, comprising the maxillae and ventral parts of the premaxillae, is not preserved. The long, straight dorsal remnants of premaxillae are reconstructed based on posterior connections with the maxillae (see below). This reconstruction is consistent with a narrow, parallel-sided and deep mesorostral groove, while the broken margins of the mandible suggest a narrow elongate Y-shaped lower jaw and, by implication, a narrow rostrum. The thick posterior part of the vomer (Figure 7) sits medially, with sutured remnants of the maxillae indicating a posteriorly wide rostrum. Bone is damaged at the right antorbital notch, but the profiles of the lacrimojugal and adjacent frontal suggest an open 

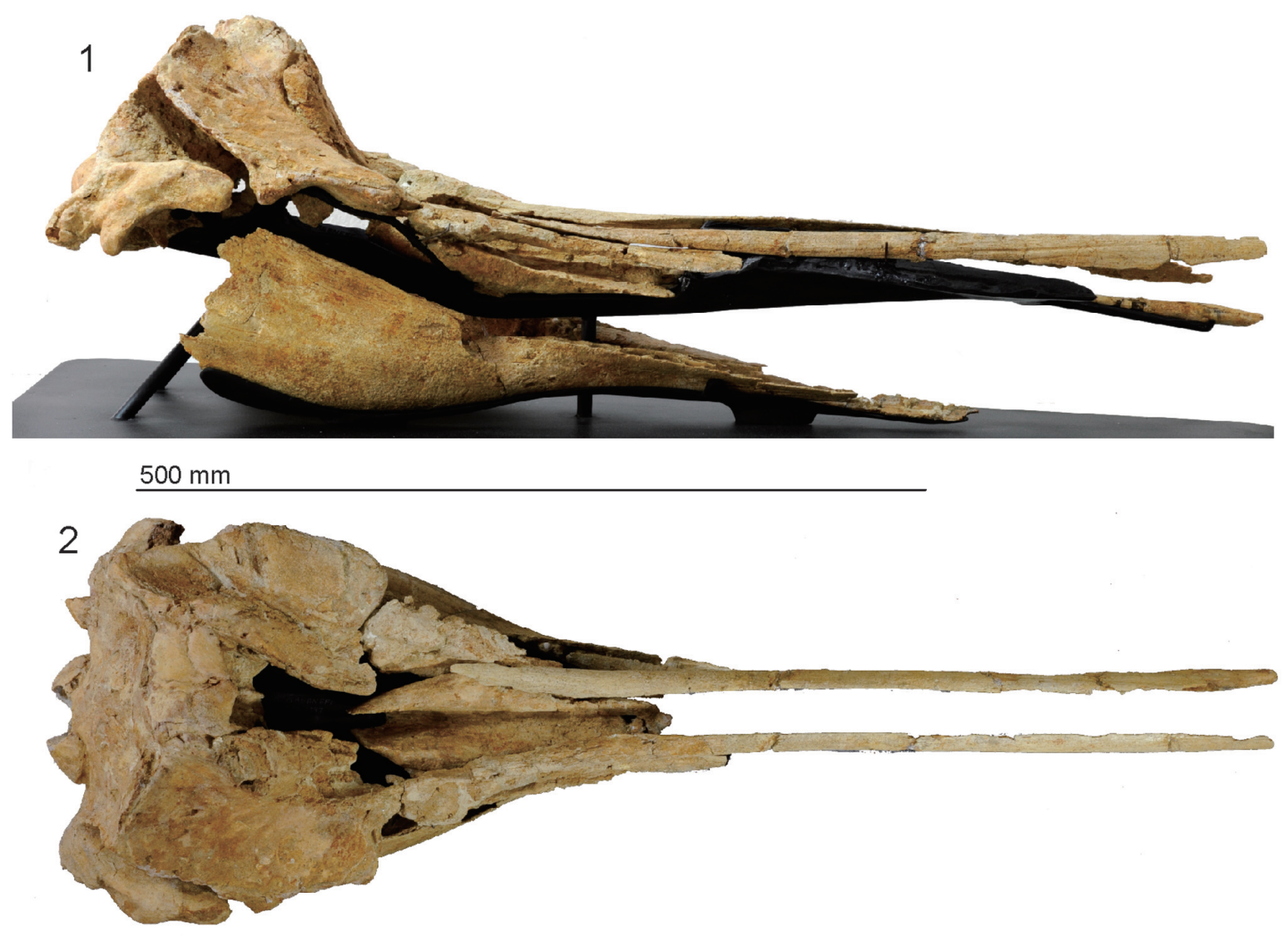

Figure 8. Skull of Otekaikea huata, OU 22306. Right 1, lateral view and 2, dorsal view.

notch with a little-projecting lateral antorbital process.

The rostral porcelanous part of each premaxilla is incomplete posteriorly; this is interpreted as postmortem break when the cranium and rostrum separated before final burial. The elongate oblique suture on the maxilla is consistent with the premaxilla passing back to merge with the cranial parts of the premaxillary sac fossae that rise steeply to the vertex. Surficial structures include the rounded dorsal surface of the premaxilla, the remnant of a shallow premaxillary sulcus at the posterior end of the rostrum, and a steep-walled mesorostral groove (see Figure 8).

Premaxilla. The rostral and cranial parts of the premaxillae are present (Figure 7), but separated post-mortem. Each bone is represented by the long, thin, posteriorly-narrowing, faintly bowed (barely concave laterally) porcelanous part of the rostral surface, each found separate from the cranium; more-ventral rostral parts of the premaxilla are lost. In life, the straight medial margin of each premaxilla would have partly roofed the mesorostral groove, converging toward each other anteri- orly, as reconstructed in Figure 8 . The left premaxilla is distorted slightly outwards and down toward the rostral apex, probably a result of burial. Both ends are incomplete for each premaxilla, and bone is missing between the posterior of the rostral part and the premaxillary sac fossa on the cranium. Anteriorly, the rounded external surface on the rostral left premaxilla (511.5+ mm long) rises steeply, facing obliquely outwards. Posteriorly, the external surface becomes narrower and more abruptly rounded, and rotates gradually to face obliquely medially at the posterior apex of the porcelanous part. The posterior $\sim 200 \mathrm{~mm}$ of the ventral surface of premaxilla is smooth at the suture for the underlying flat dorsal face of the maxilla; this flat suture on the maxilla is horizontal anteriorly on the rostrum but posteriorly it rotates to become steeply oblique by the level of the antorbital notch, facing medially and slightly dorsally. Here, each premaxilla narrows posteriorly, and is deflected slightly outwards. A broken narrow medial shelf on the left premaxilla, barely visible in dorsal view, is presumed to be part of the anteromedial sulcus, origi- 

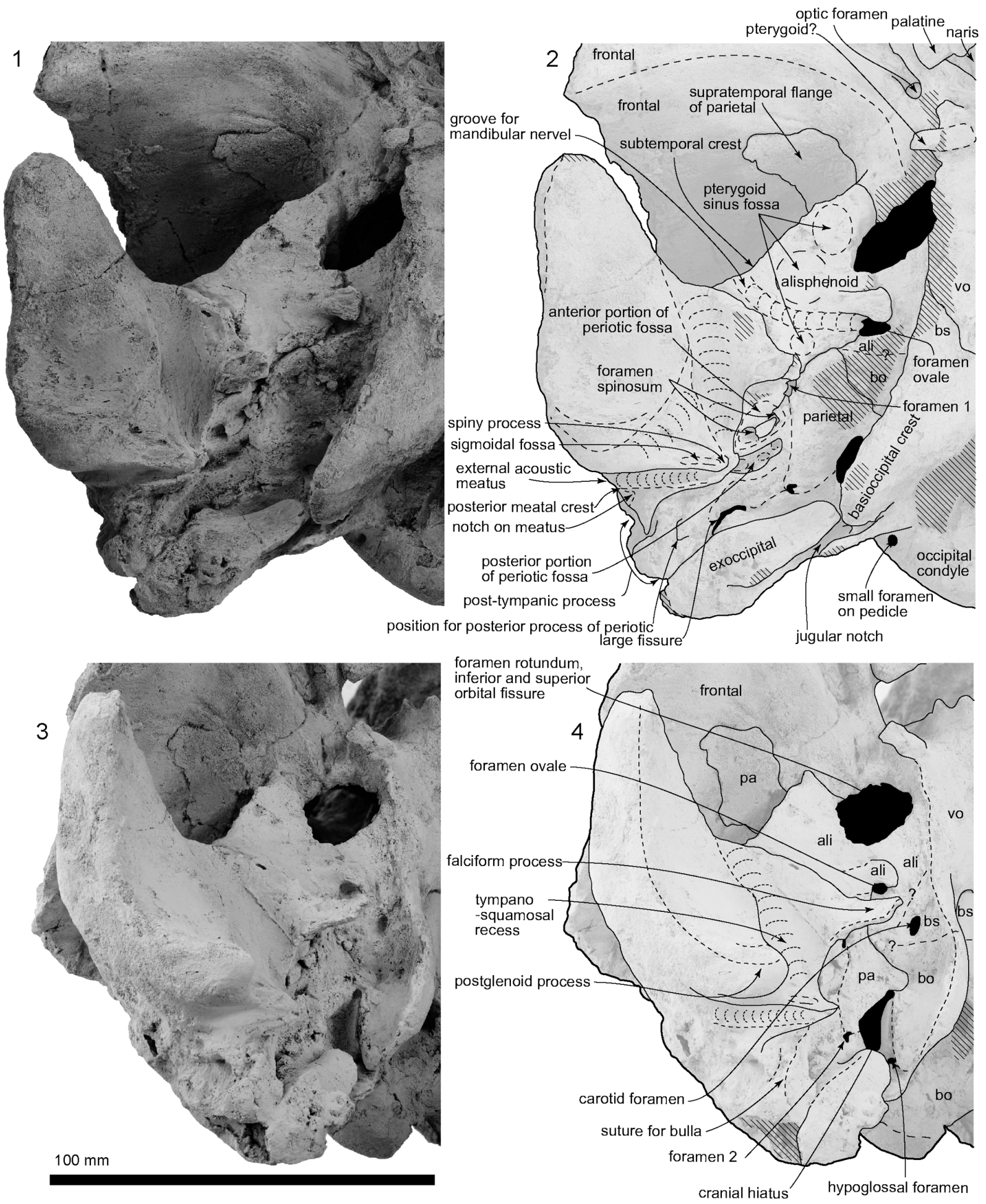

FIGURE 9. Details of right basicranium part, OU 22306, Otekaikea huata. 1 and 2, ventral view. 3 and 4, ventrolateral view. Ali, alisphenoid. Bo, basioccipital. Bs, basisphenoid. Pa, parietal. Vo, vomer. 


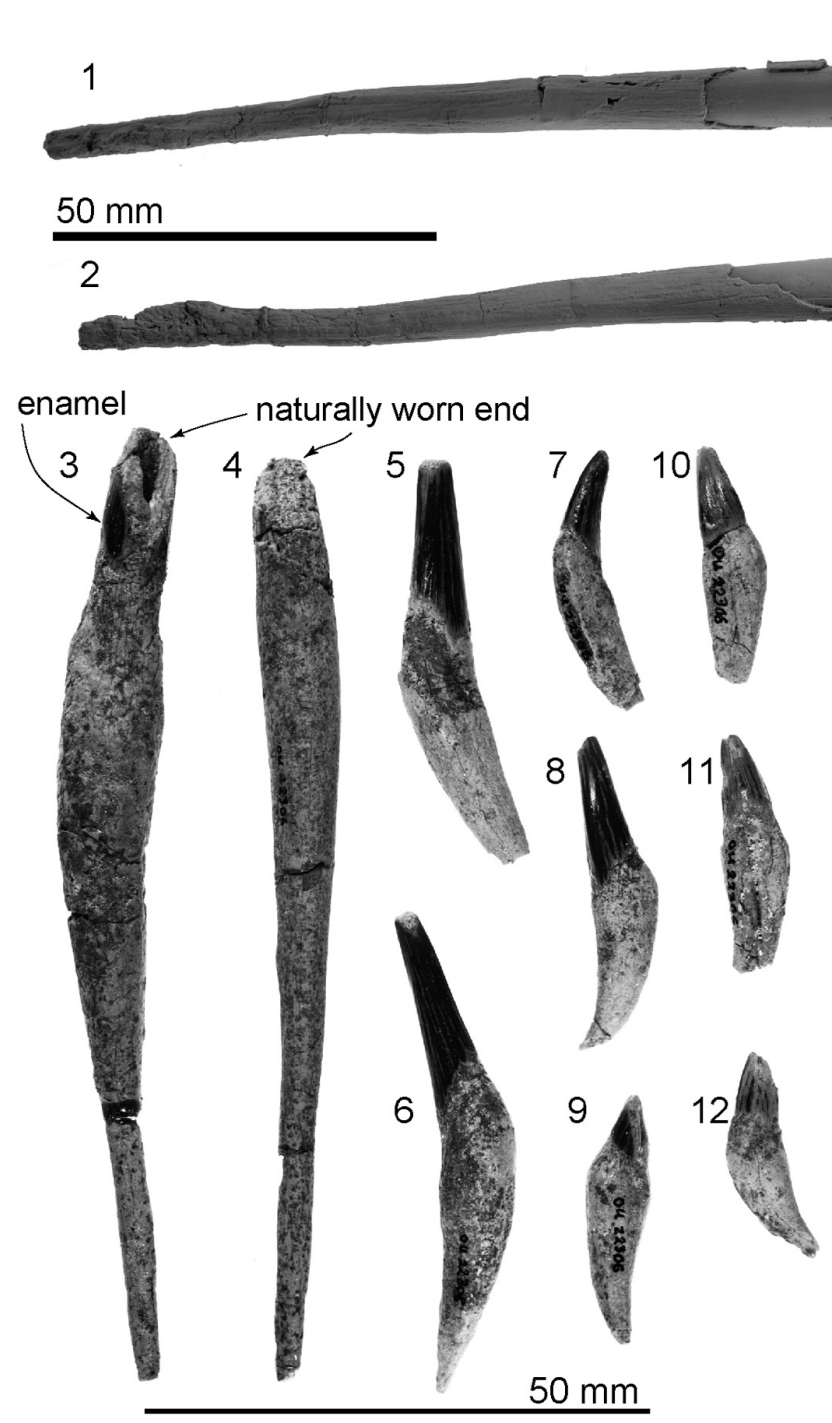

pulp cavity
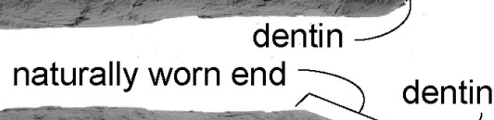

FIGURE 10. The type teeth, OU 22306, Otekaikea huata. Scales vary as indicated, depending on specimen size. 1 and 2, largest incisor. 1, worn surface view. 2, lateral view. 3 and 4, two long tusks, showing worn surface. 5 and 6 , two medium teeth. 7-9, single rooted smaller medium teeth. 10-12, buccolingually flattened teeth. 13 and 14 , tooth with small denticles. 13, buccal view. 14, lingual view.

nally arising further posteriorly from the nowmissing premaxillary foramen.

Posteriorly, each premaxilla thickens, widens, and rises upward. In dorsal view, the lateral edge of the premaxillae is widest $(125.1 \mathrm{~mm})$ at the level of the nares. In spite of some compaction crushing, there is some directional asymmetry in the cranial parts of the premaxillae: 1 , the right premaxilla is wider, lies further toward the midline, with a morelaterally flanged posterolateral plate than the left; 2 , the right intra-premaxillary foramen, which opens dorsally between the maxilla and the posterolateral plate, is larger (elliptical; $10.6 \mathrm{~mm}$ long, $4.8 \mathrm{~mm}$ wide), and the lip of the foramen is formed mostly by the premaxilla, with maxilla contributing posteromedially. The left intra-premaxillary foramen opens almost the same level with the right, and it is smaller (also elliptical; $3.0 \mathrm{~mm}$ long, $1.2 \mathrm{~mm}$ wide; occluded by cemented matrix) and formed by the premaxilla; 3 , the blunt right posteromedial splint reaches half way back along the nasal, bounded laterally by a slightly raised crest and vertical face of maxilla, whereas the left splint appears not to reach the nasofrontal suture and the adjacent maxilla is lower and more-nodular. The intra-premaxillary foramen is probably one of many foramina from the infraorbital complex, as discussed below. 


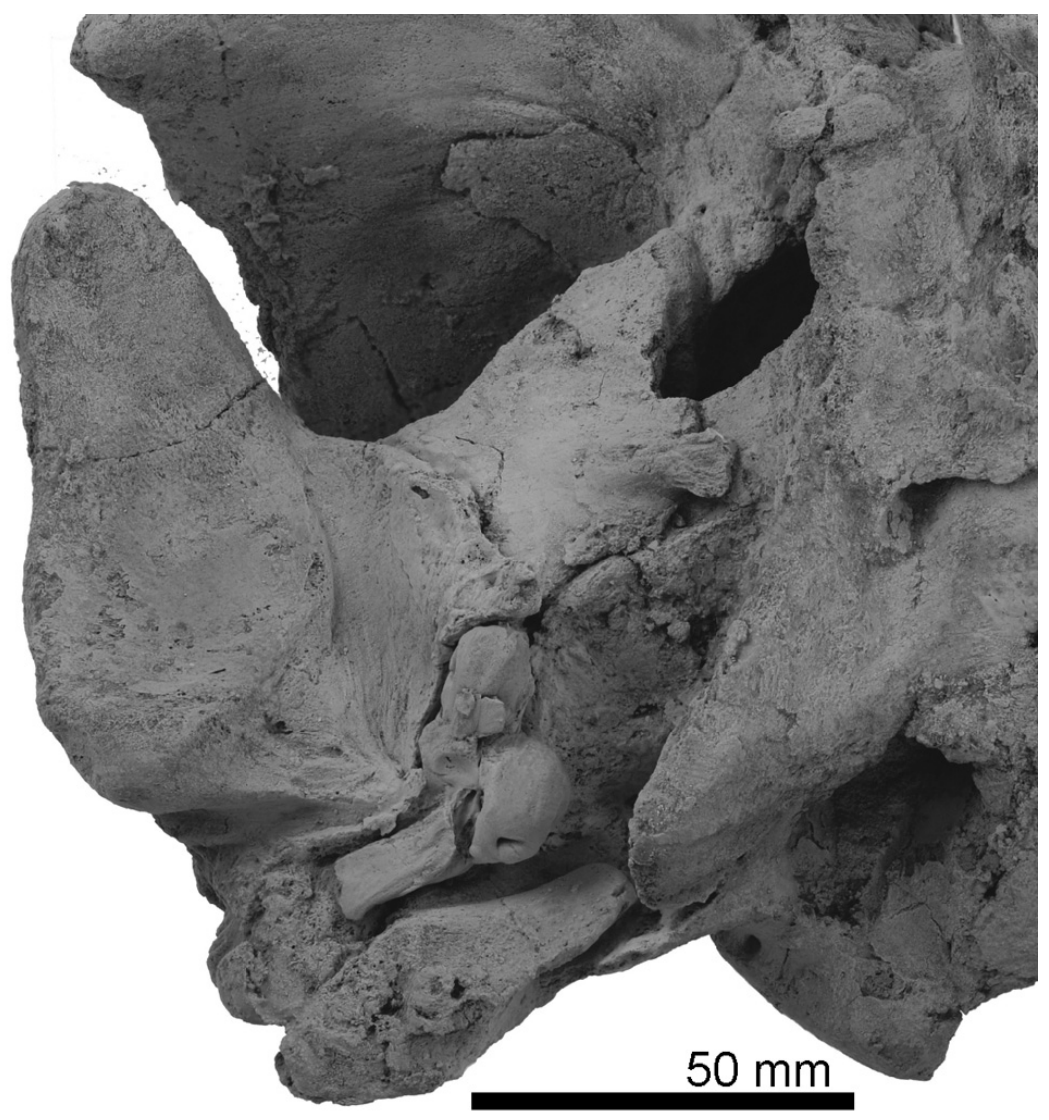

FIGURE 11. Periotic in original position in the right squamosal, ventral view, OU 22306, Otekaikea huata.

Maxilla. The rostral part of the left maxilla is firmly sutured with the vomer (possibly cemented by matrix); the two bones can be placed close to their original positions against the cranium, with the maxilla close to the antorbital notch. The rostral part of the right maxilla, not attached to the vomer (but originally sutured), can be mirrored against the left. Dorsally, each maxilla has an elongate planar suture dipping obliquely ventromedially, formed by dense rather than cancellous bone, for the premaxillae (Figures 7 and 8); the sutural face can be traced back onto the cranium. A small $(2.6 \mathrm{~mm}$ diameter) dorsal infraorbital foramen opens bilaterally, facing outwards, toward the posterior of the rostral maxilla. Ventrally, the maxillae form a medially arched palate with flattened lateral margins at the base of the rostrum.

Posteriorly, the cranial part of the maxilla is overlaid by the premaxilla, with clear sutures with the frontal and lacrimal. In places (e.g., left near the position of the maxillary-premaxillary suture), the maxillary surface is dense and porcelanous; adjacent irregular cancellous surface is interpreted as (bio) eroded. About $25 \mathrm{~mm}$ medial to the right antorbital notch, the maxilla has an anteroposteriorly long, wide and smooth trough, presumably partly for the premaxilla, extending $\sim 15 \mathrm{~mm}$ anterior and $\sim 40 \mathrm{~mm}$ posterior to the level of the antorbital notch (Figures 2.2, 7.4). This trough has a steep lateral face that passes sharply at an elongate fold onto the flat supraorbital process of the maxilla.

On the braincase, dorsally, the cranial part of the maxilla covers most of the frontal except the lateral part of the postorbital process (right side; Figure 2). The maxilla on the supraorbital process is flat and smooth; it is not obviously thickened and it lacks a pneumatic maxillary crest. At the level of the right lacrimojugal, behind the antorbital notch, a small anterior dorsal infraorbital foramen $(1.4 \mathrm{~mm}$ diameter) opens into a short oblique sulcus (Figure 2.2). The region is damaged on the left. The posteromedial surface of the maxilla is very steep; at the level of the nasal/frontal border, two posterior dorsal infraorbital foramina open on each side, which are small and rounded (right side diameters: anterior, $3.4 \mathrm{~mm}$; posterior, $4.6 \mathrm{~mm}$ ), opening into sulci that run toward the posterolateral edge of the 

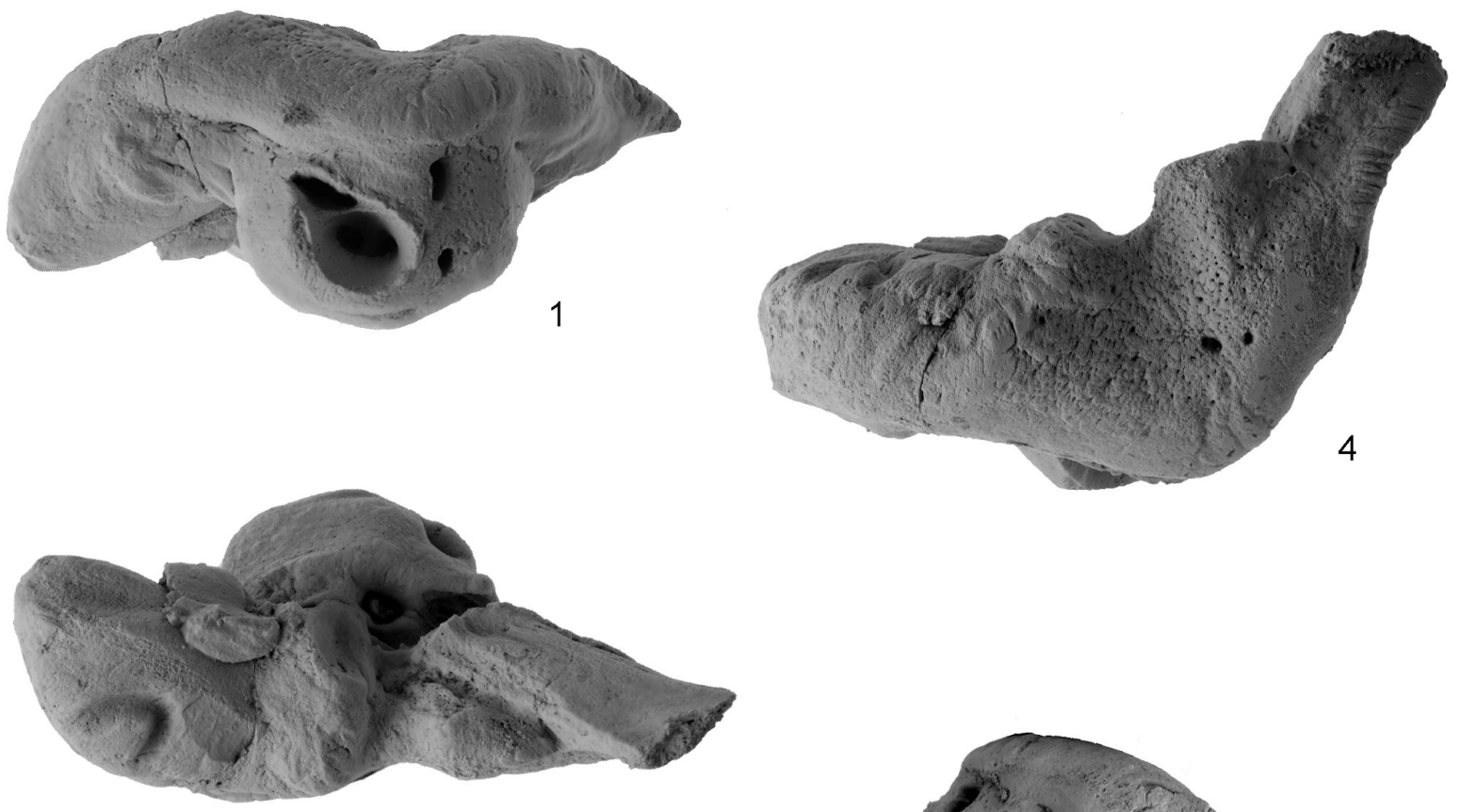

2
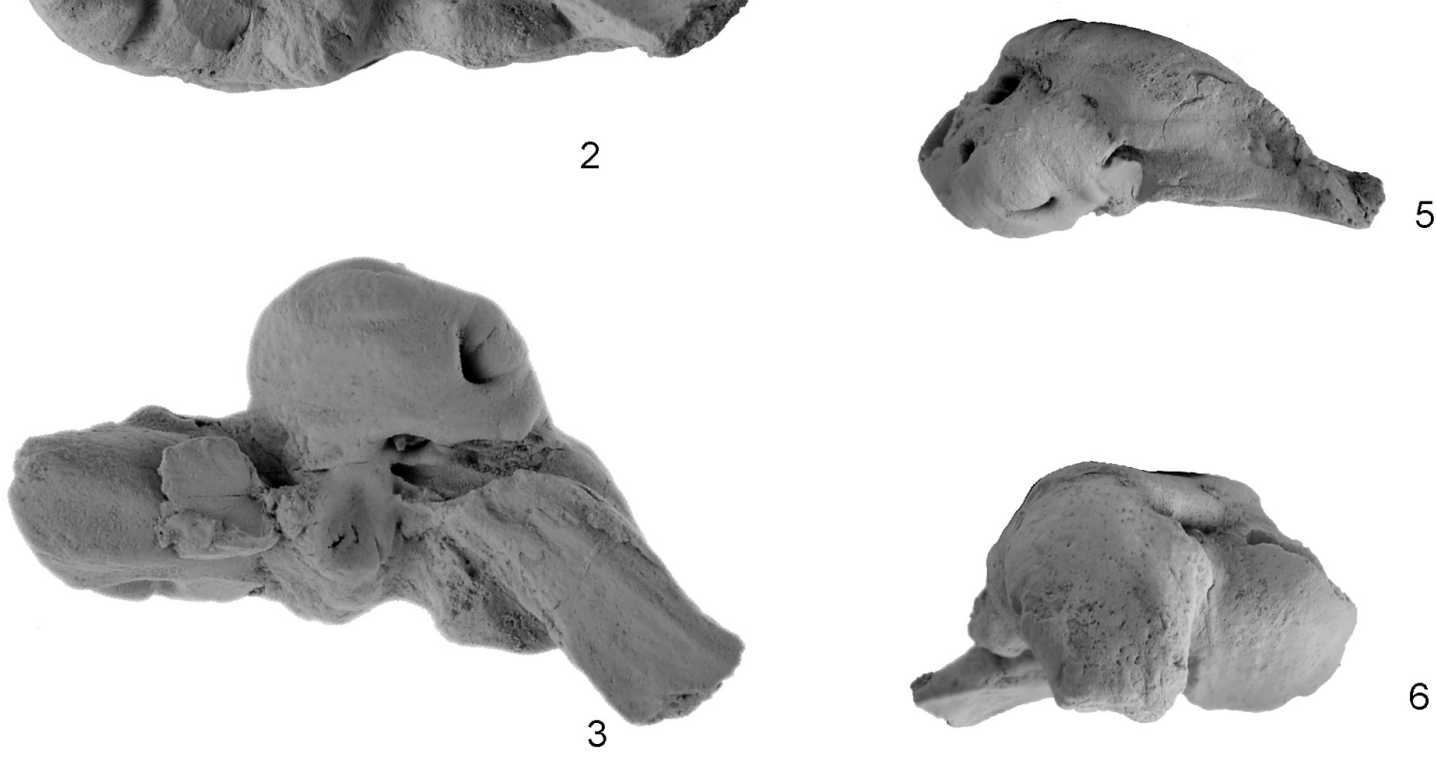

6
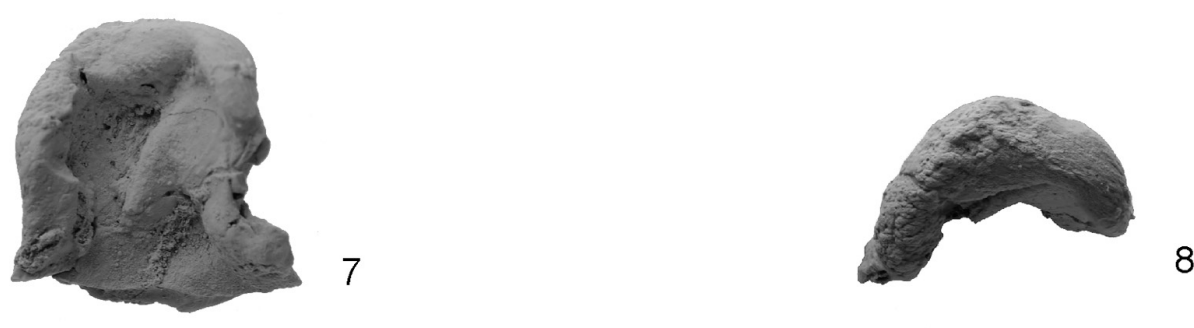

8

FIGURE 12. The type tympanoperiotics. OU 22306, Otekaikea huata. 1-6, right periotic. 7 and $\mathbf{8}$, sigmoid process of left bulla. 1, medial view. 2, lateral view. 3, ventral view. 4, dorsal view. 5, posterior view. 6, anterior view. 7, ventral view. 8, posterior view. 

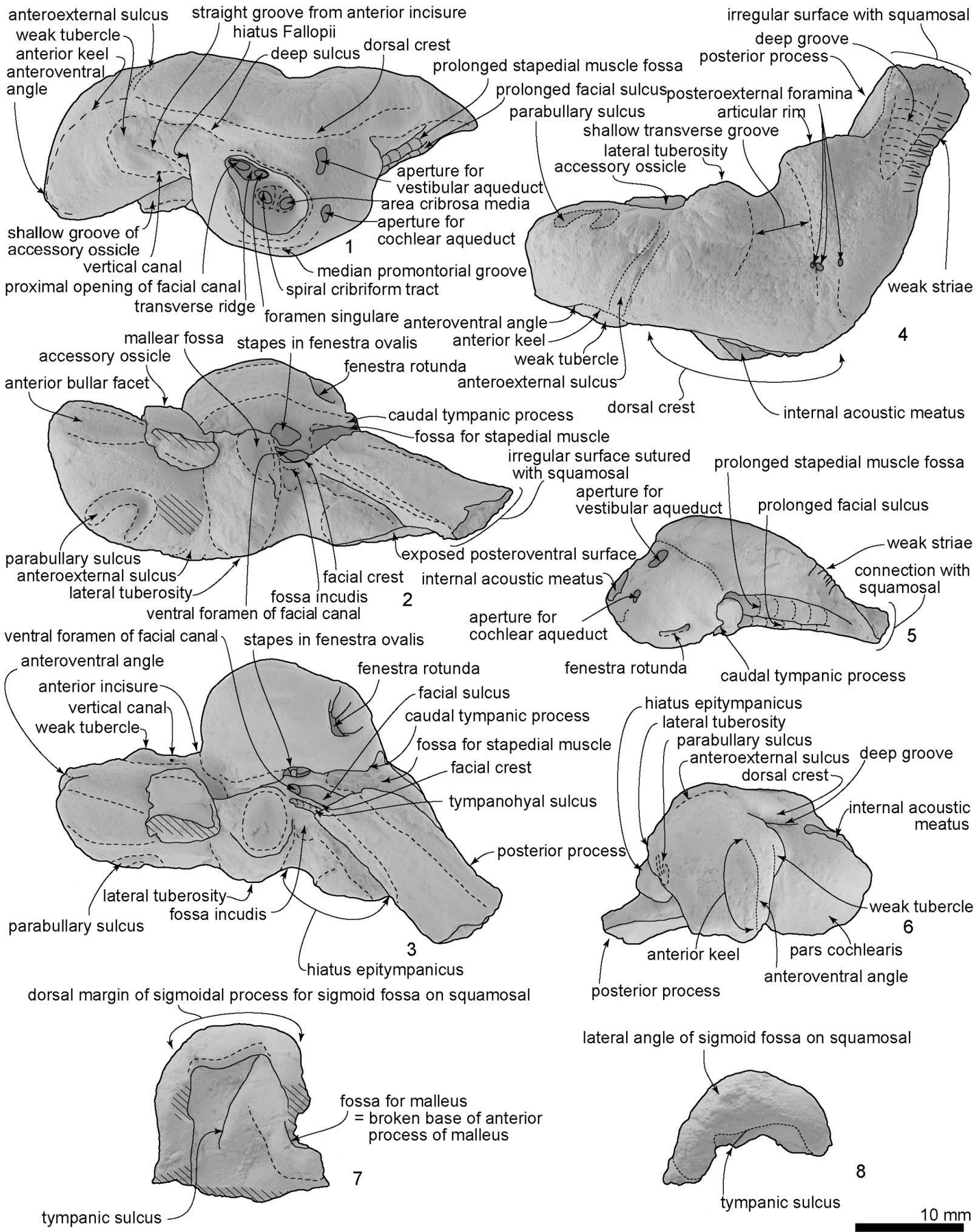

FIGURE 13. Key features of the type tympanoperiotics. OU 22306, Otekaikea huata. 1-6, right periotic. 7 and 8 , sigmoid process of left bulla. 1, medial view. 2, lateral view. 3, ventral view. 4, dorsal view. 5, posterior view. 6, anterior view. 7, ventral view. 8, posterior view. 


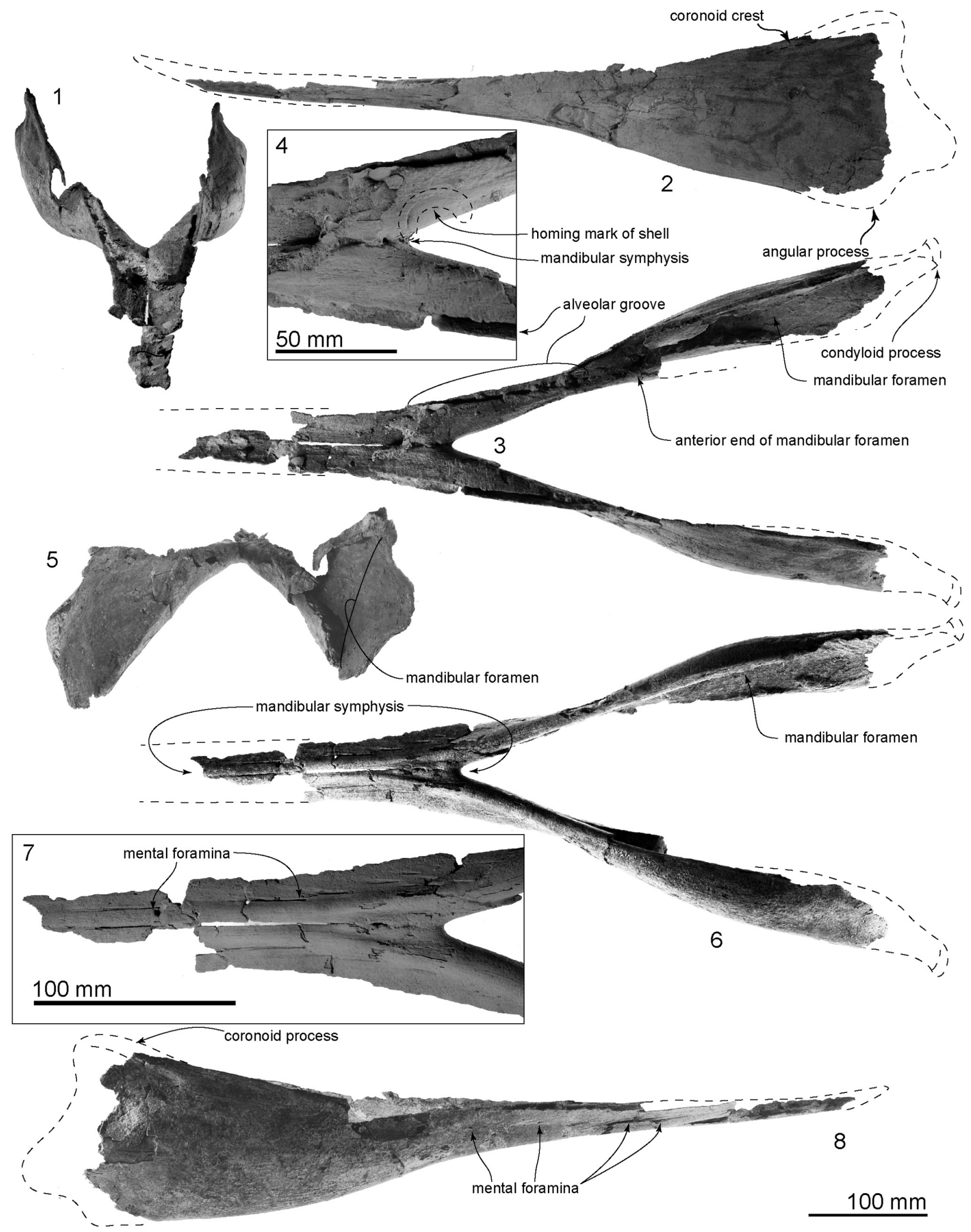

FIGURE 14. The type mandible, OU 22306, Otekaikea huata. 1, anterior view. 2, left lateral view. 3, dorsal view. 4, mandibular symphysis in dorsal view. 5, posterior view. 6, ventral view. $\mathbf{7}$, anterior end in ventral view. 8, right lateral view. 


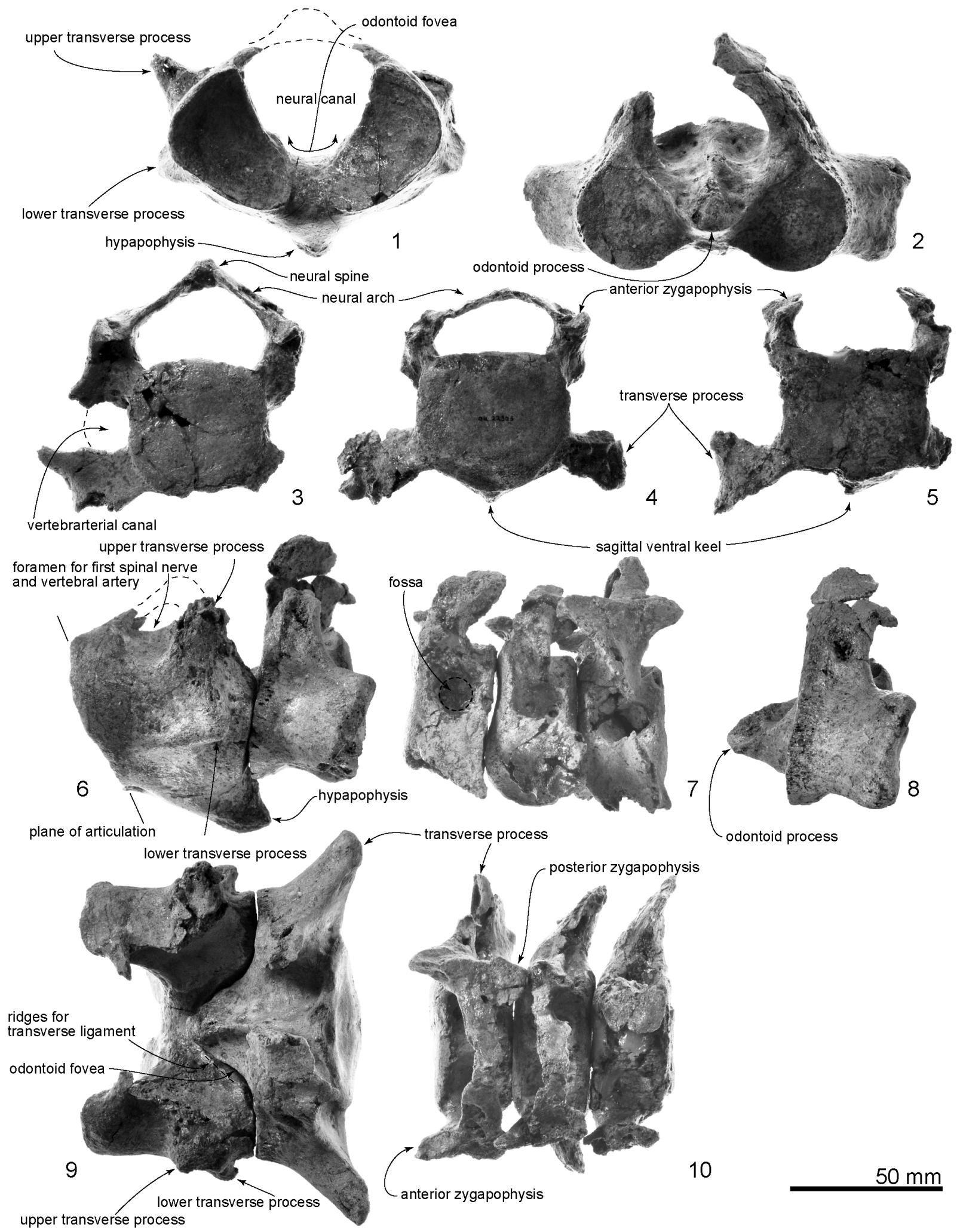

FIGURE 15. The type cervical vertebrae, OU 22306, Otekaikea huata. 1-5, anterior views. 6-8, lateral views. 9-10, dorsal views. 1, atlas. 2 and 8, axis, 3, fourth cervical vertebra. 4, fifth cervical vertebra. 5, sixth cervical vertebra. 6 and 9 , atlas and axis. 7 and 10, third to sixth cervical vertebrae. 7, mirrored image. 


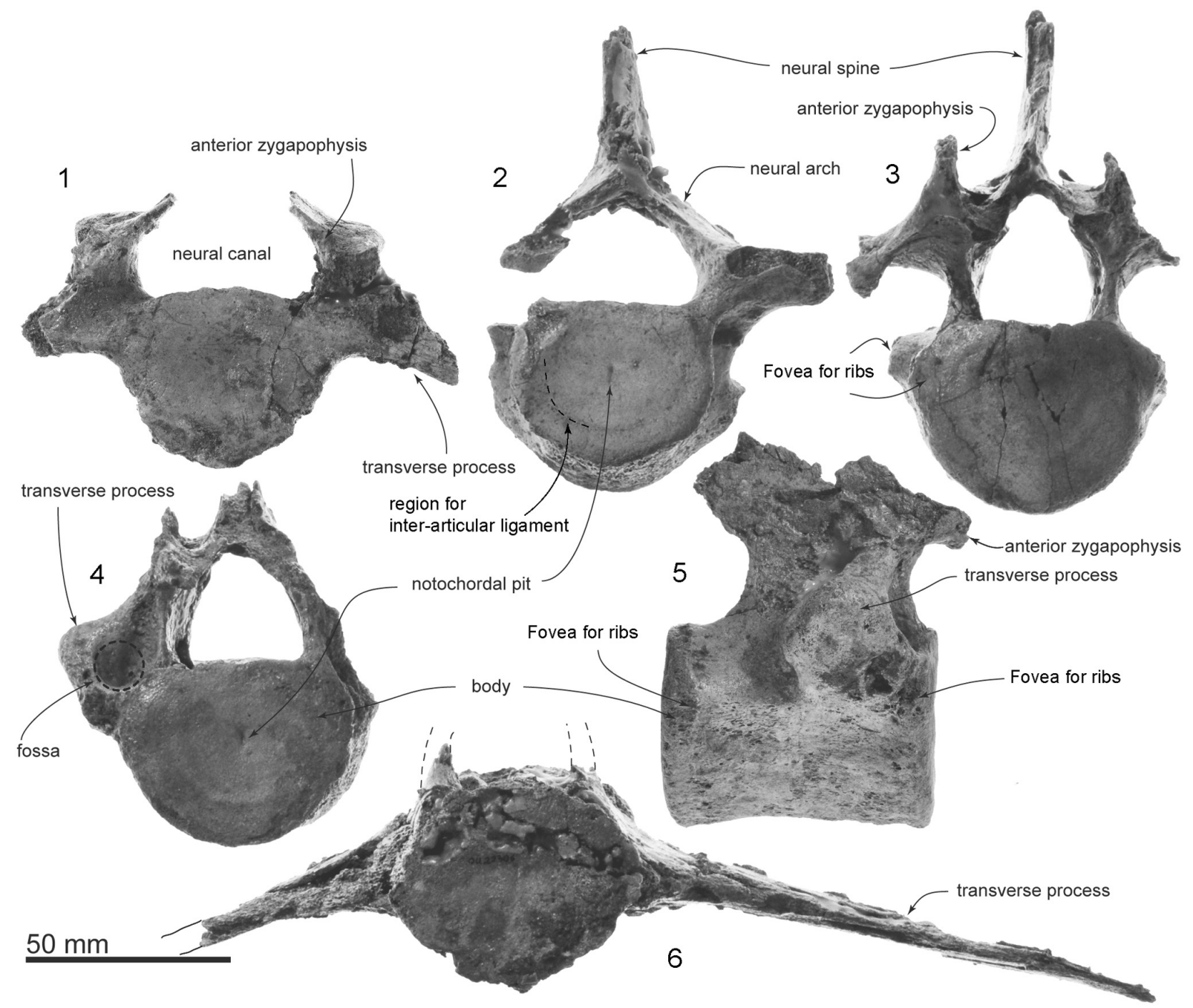

FIGURE 16. The type thoracic and lumbar vertebrae, OU 22306, Otekaikea huata. 1-3, anterior view of three thoracic vertebrae. 4 and 5, a posterior thoracic vertebra, anterior and left lateral views. 6, lumbar vertebrae from anterior view.

maxilla. The squared apex of each maxilla meets the frontal medially and the supraoccipital posteriorly. Just lateral to the nasal and frontal, the medial border of the weakly curved crest on the right maxilla rises abruptly. At the anterior end of the nares, a small area of the maxilla is exposed medially; whether this was originally covered by now-lost premaxilla, or exposed to form a maxillary intrusion (sensu Arnold and Heinsohn, 1996) is uncertain.

In ventral view (Figure 3), the better-preserved right maxilla forms the borders for two infraorbital foramina: a larger and more posteromedial foramen in the common position for odontocetes anterior to the antorbital ridge, and a smaller foramen a little anterolateral. The larger posterior foramen is bounded by frontal, palatine and maxilla, and opens anteriorly into a sulcus in the maxilla. The smaller anterior foramen is bounded mainly by maxilla and lacrimojugal, plus a small contribution of frontal; the lacrimojugal cleft is immediately lateral. It is likely that this smaller foramen was originally covered by maxilla that was lost postmortem, with the sulcus representing the infraorbital canal. On the type of Otekaikea marplesi, the single visible ventral infraorbital foramen is equivalent to the posterior foramen in O. huata.

Palatine. Ventrally, a vertical plate-like robust fragment of palatine underlies the maxilla (Figure 7), slightly posteromedial to the infraorbital foramen, and connected with the frontal posteriorly. The palatine has a smooth lateral wall and, medially, a grooved vertical surface that contributes to the lateral wall of the nares.

Pterygoid. A fragment of pterygoid is lateral to the posterior end of the vomer, posterior to the nares. Otherwise the bone is lost. A facet for the medial 


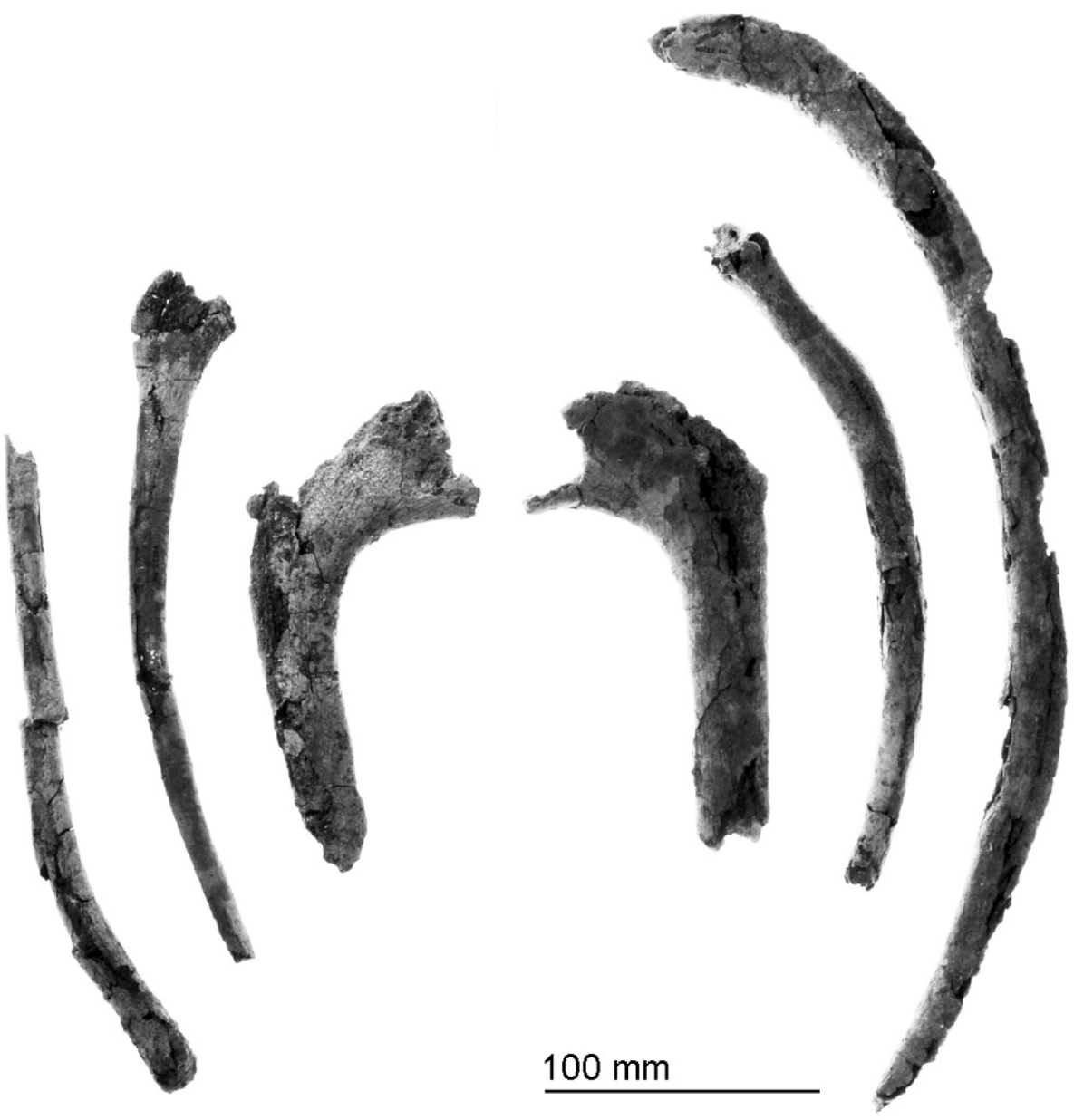

FIGURE 17. The type ribs. OU 22306, Otekaikea huata, from anterior view.

lamina of the pterygoid covers the anterior two thirds of the basioccipital crest.

Nasal. The smooth, flat, asymmetrical nasals lie just behind, rather than roofing, the nares (Figure 2 ). In anterior view, the nasals are dorsoventrally thick and nodular. The smaller left nasal is suboblong, transversely wide and anteroposteriorly narrow; the lateral and posterior margins are rounded, the anterior, straight. The sagittallyplaced larger right nasal is a rounded irregular triangle, transversely wide and anteroposteriorly longer than the left, and projected forward more than the left. Both have a prominently rounded medial corner and a semicircular posterior margin. The anterior edge of each nasal lies far posterior to the antorbital process, almost level with the posterior end of the postorbital process. The anteromedial angle projects strongly, while the posteromedial angle is displaced by the narial process of the frontal. Each nasal has a plate-like anterolateral process of the nasal [new term] laterally, $\sim 20 \mathrm{~mm}$ long and $\sim 4 \mathrm{~mm}$ wide, projecting forward to meet the posteromedial margin of the premaxilla, and separated from the main part of the nasal (anterior view) by a deep groove; the anterior margins of the two nasals form a W-shape. A slightly similar condition of the groove on the anterior surface of the nasal is seen on some kentriodontids (Pithanodelphis cornutus Abel, 1905, Delphinodon dividum True, 1912 and Kentriodon pernix Kellogg, 1927), but the grooves are much shallower and the anterolateral process less marked than in Otekaikea huata. An undescribed platanistoid OU 22126, from the Otekaike Limestone of Waitaki district (Fordyce, 2003), shows an anteroposteriorly thin nasal without a groove on the anterior surface, but the platelike anterolateral process of the nasal projects well anteriorly. The internarial, nasofrontal, nasopremaxillary, and nasomaxillary sutures are deep and wide. The internarial suture is invaded by narrow fingers of frontal, forming the narial process. In 


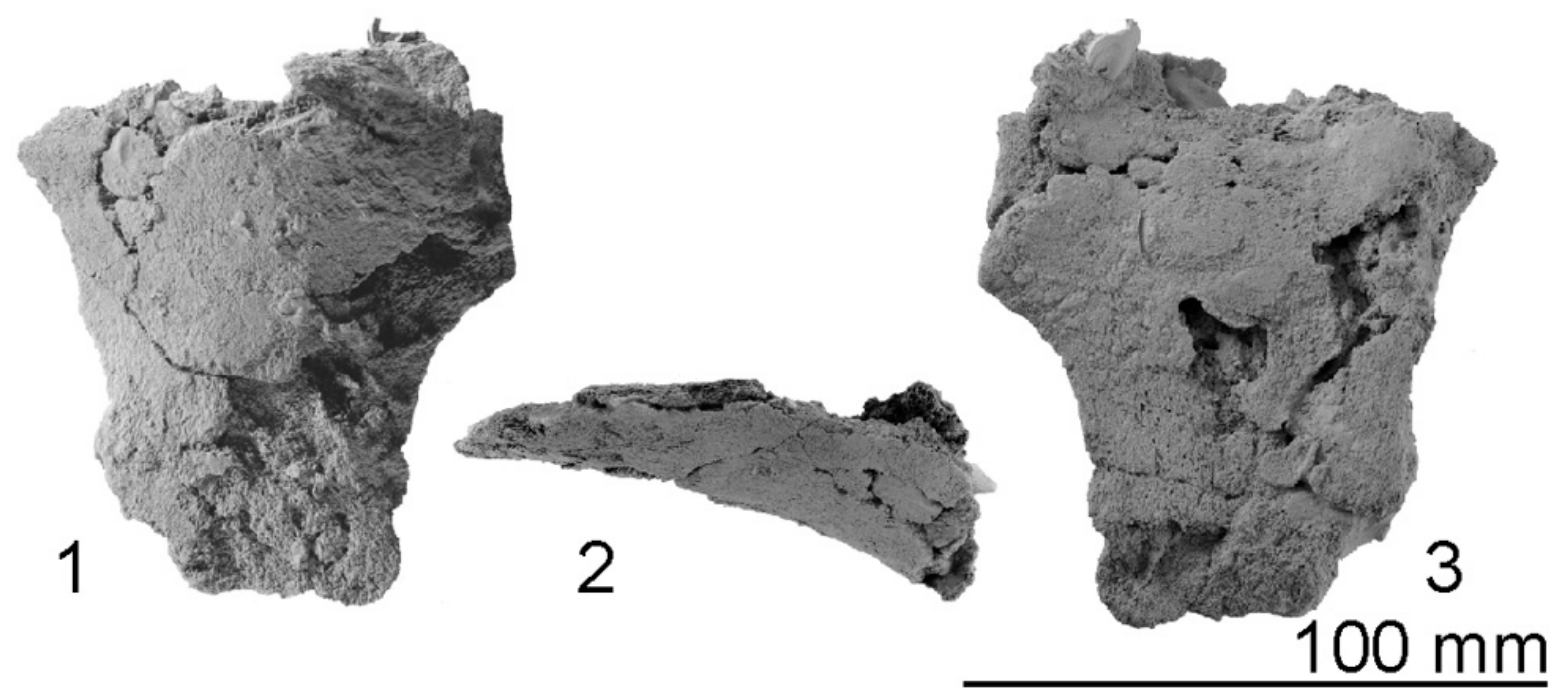

FIGURE 18. The type sternum. OU 22306, Otekaikea huata. 1, ventral. 2, left lateral. 3, dorsal.

anterior view, the nasal is medially very thick but laterally thin, resulting in a triangular profile.

Ethmoid. The ethmoid is used in the sense of Mead and Fordyce (2009), but note that Ichishima (2011) suggested that the mesethmoid might be absent in odontocetes. Morphological terms of the ethmoid follow Godfrey (2013).

The profile of the ethmoid is uncertain but in the mesethmoid ridge (area for attachment of the mesorostral cartilage) of the vomer, there is a spongy bone with a foramen at the center (Figure 4). The large void dorsal to the foramen may be for the missing or undeveloped area of the cribriform plate of the mesethmoid. On the posterodorsal part, the cribriform plate has a pair of large and strongly curved crescentic foramina. Between the foramina, there is a tubercle, which is assumed to be the mesethmoid.

Vomer. The robust rostral part of the vomer is broken and isolated from the cranium (Figure 7). The mesorostral groove is anteriorly shallow and $U$ shaped, and posteriorly deep and more V-shaped. Its lateral wall is unexpectedly thick, thinning ventrally; the greatest bilateral width is $75.4 \mathrm{~mm}$, with one side attaining a thickness of $27.6 \mathrm{~mm}$, and the depth is around $30 \mathrm{~mm}$. From the widest point, the vomer narrows rapidly, both anteriorly and posteriorly. Both ventrally and laterally, the vomer is covered by the maxilla cemented by matrix; the sutures are not fused. In ventral view (Figures 7 and 8), the vomer carries two flat areas, which might be sutures for the maxilla (this feature occurs in an unfused young individual of Cephalorhynchus hectori and in Otekaikea marplesi). Vomer is present below the olfactory region, as shown in broken section in anterior view. Posteriorly, the vomer covers the basisphenoid.

Lacrimojugal. The right lacrimal and jugal are fused without evident suture. There is no obvious lacrimal foramen or groove. A transversely long $(36.3+\mathrm{mm})$, thin $(6.8 \mathrm{~mm})$, and bar-like anterior margin of lacrimojugal contributes to the right antorbital notch (Figure 3.2), and is separated from the rest of the bone by a lacrimojugal cleft. There is no evident base for the styloid process of the jugal. Medially, the anterior margin enlarges to become subspherical, sutured with the maxilla in a fossa (seen ventrally on the left maxilla) close to a prominent anterior infraorbital foramen. The lacrimojugal does not, however, reach the larger more-posterior infraorbital foramen. More posteriorly, the lacrimojugal is plate-like, as also implied by the slightly ridged planar suture for the missing lacrimojugal under the left antorbital process of the frontal.

Frontal. Each frontal contributes a large surface to the orbit and a small exposure at the vertex (Figure 2 ). At the vertex, the frontals are bounded by the nasals, maxillae, and supraoccipital; there is a clear but irregular median interfrontal suture, not to be confused with a mollusc shell imprint (limpet homing mark?) on the right nasal. Each frontal is trapezoidal and has a long finger-like medial projection which forms a narial process. The frontals are asymmetrical: wider on the left and longer on the right. Each frontal contacts the parietal laterally. On the face, the left ascending process of the maxilla is lost and shows the profile of the postorbital process; the right process, which is almost covered by maxilla, appears not to project as far as the left, 


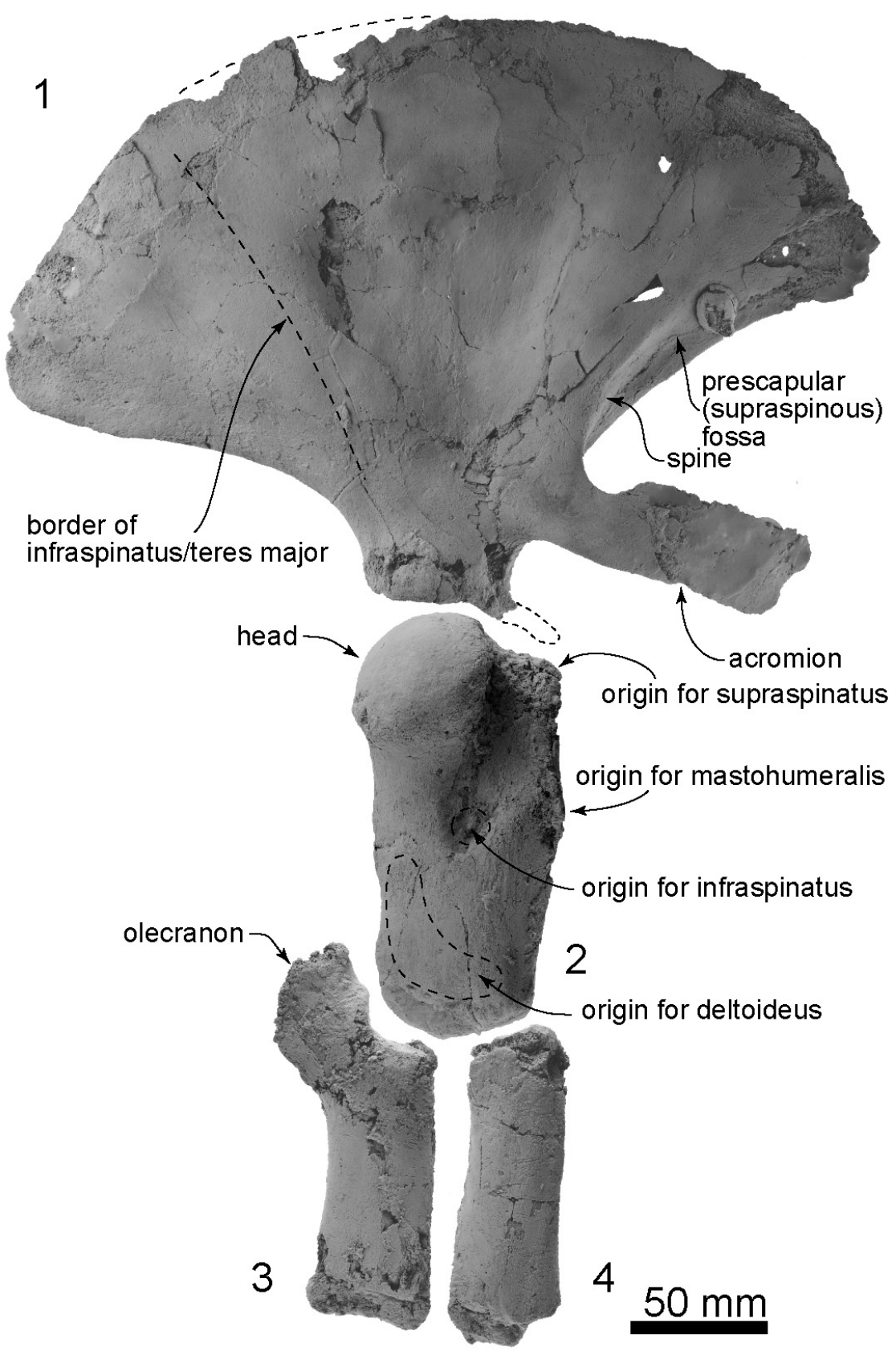

FIGURE 19. The type right forelimb bones in lateral view, OU 22306, Otekaikea huata. 1, right scapula. 2, humerus. 3 , ulna. 4 , radius.

judging from the profile of the bar-like jugal (above).

Ventrally, the frontal forms the anterodorsal wall of the braincase and most of the shallow and long orbit (Figure 3). A weak preorbital ridge (Fordyce, 1994) is indistinct at the antorbital process laterally, but becomes elevated and narrow toward the posterior margin of the narial passage. The frontal contributes the posterior and lateral margins of the infraorbital foramen. Medially, an oval presumed optic foramen (3.0 $\mathrm{mm}$ diameter) opens anterolaterally. The strongly posteriorly-concave postorbital ridge is sharp, high, and meets the postorbital process, which is a blunt, ventrally-projecting triangular shape as seen in lateral view. Between these ridges, the triangular roof of the orbit is anteroposteriorly long and dorsoventrally shallow. Foramina for the diploic vein are absent.

Orbitosphenoid. The orbitosphenoid (Figure 3 ) is identified by the presumed ethmoid foramen, which 


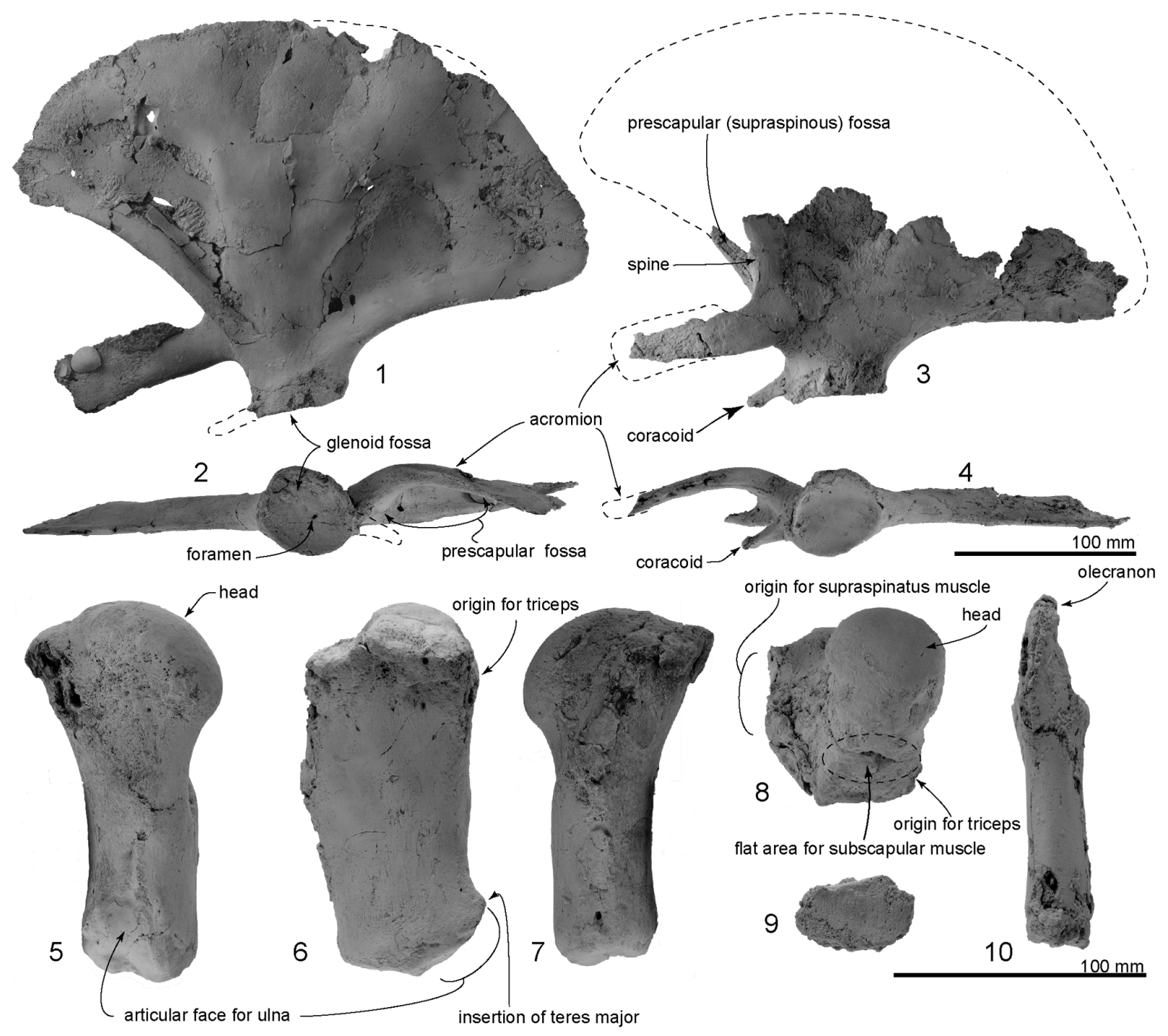

FIGURE 20. The type forelimb bones, OU 22306, Otekaikea huata. 1, right scapula in medial view. 2, right scapula in distal view. 3, left scapula in lateral view. 4, left scapula in distal view. 5-8, right humerus. 5, posterior view. 6, medial view. 7, anterior view. 8, proximal view. 9, carpus. 10, ulna in posterior view.

opens 61-62 $\mathrm{mm}$ medial to the orbital margin, lateral and anterior relative to the region of the optic foramen. The foramen is surrounded by a smooth bone surface, presumed orbitosphenoid, in the roof of the orbit toward the optic foramen. No sutures are evident.

Parietal. The parietal forms the lateral wall of the braincase (Figure 6) at the temporal fossa, which is strongly excavated medially and anteroposteriorly shorter than in Archaeoceti and stem Odontoceti, which have dorsally more open temporal fossa. Anteriorly, the parietal has a roughly rectangular thin supratemporal flange [new term], directed obliquely forward to encroach the frontal in the roof of the right temporal fossa. (The flange is lost on the left, but an exposed suture is apparent.) Such a flange is also clear in the undescribed specimen OU 22540 and is uncertainly present (the bone surface is damaged) in Otekaikea marplesi. Within the temporal fossa, the parietosquamosal suture is not clear in $O$. huata, and there is no obvious postparietal foramen. Parietal forms a ventral exposure between the basioccipital and squamosal, separating the foramen ovale from the cranial hiatus as in Waipatia maerewhenua and O. marplesi. The parietal-alisphenoid suture is clear on the left, between the foramen ovale and the base of the falciform process. "Foramen 1" sensu Fordyce (1994) is seen in $O$. huata further suggesting the position of parietal (see ventral details of the squamosal, 
TABLE 2. Measurements in mm of holotype, OU 22306, Otekaikea huata: periotic and tympanic bulla. Dimensions follow Fordyce et al. (2002), Perrin (1975), and Kasuya (1973). Measurements are rounded to the nearest $0.5 \mathrm{~mm}$.

$\begin{array}{lr}\text { Periotic } & 44.0 \\ \text { maximum anteroposterior length, from anterior apex of anterior process to apex of posterior process } & 43.0 \\ \text { maximum anteroposterior length parallel to dorsal margin } & 15.0 \\ \text { maximum dorsoventral depth anterior process, perpendicular to axis of periotic } & 22.5 \\ \text { length of anterior process, from anterior apex to level of posterior of mallear fossa } & 14.5 \\ \text { length of anterior process, from anterior apex of anterior process to level of anterior of pars cochlearis } & 1.5 \\ \text { in notch immediately lateral to fine ridge } & 17.5 \\ \text { dorsoventral depth at fovea epitubaria } & 2.0 \\ \text { length facet on posterior process point to point } & 11.5 \\ \text { facial canal anteroposterior diameter } & 18.0 \\ \text { maximum width of anterior process at base } & 10.5 \\ \text { approximate anteroposterior length of pars cochlearis } & 22.0 \\ \text { approximate transverse width of pars cochlearis, from internal edge to fenestra ovalis } & 18.5 \\ \text { transverse width of periotic, internal face of pars cochlearis to apex of lateral tuberosity } & 18.0 \\ \text { length of posterior process of periotic } & 14.0 \\ \text { length of posterior process parallel to posterior profile/ steeply acute to long axis of body } & 8.5 \\ \text { Tympanic bulla } & \\ \text { width of sigmoid process } & 1.5 \\ \text { height of sigmoid process } & 1\end{array}$

below). The clear parietal-alisphenoid suture has foramen 1 on its junction with the squamosal, but otherwise the relationships of the foramen and sutures are obscure. The parietal contacts "foramen 2" sensu Fordyce (1994) posteriorly and the cranial hiatus medially.

Squamosal. Description is based mainly on the right. In dorsal view (Figure 2), a wide (34.2 $\mathrm{mm}$ at the subtemporal crest) and long zygomatic process $(90.1 \mathrm{~mm})$ projects slightly laterally, posterior to the orbit. The anterior end is blunt and narrower than the posterior, and reaches to the level of the posterior end of the nasals, still distant from the postorbital process $(14.6 \mathrm{~mm}$ gap between the processes, possibly widened by postmortem distortion). The temporal fossa is exposed widely in lateral view, is not obvious in dorsal view, and is widely open to posterior view. The temporal fossa has an unclear squamosal-parietal suture on its lateral wall on the right (Figure 6). In lateral view, the anterior end of the squamosal is squared. On the lateral surface, a triangular, depressed neck muscle fossa (34.0 mm long) occupies midpoint of the zygomatic. This depression has been termed sternomastoid fossa in recent literature on fossil Cetacea, but the muscle insertions in extant species are quite variable (Schulte, 1916; Howell, 1927, 1930; Cotten et al., 2008), and the more-general term neck muscle fossa (Fordyce, 1981, p. 1035) makes fewer assumptions about homologies.

Ventrally (Figures 3 and 9), the zygomatic process has a wide and shallow mandibular fossa without an obvious anterior border, a slightly swollen lateral portion, and a strongly curved internal face. The postglenoid process is not thickened anteroposteriorly, nor markedly expanded laterally, and slopes obliquely posteroventrally. The large, prominent tympanosquamosal recess separates the zygomatic process from the falciform process, occupying the squamosal from the subtemporal crest to the anterior meatal crest and spiny process. Posteriorly, the recess descends down the medial margin of the postglenoid process, while posteromedially the recess deepens toward the spiny process. The periotic apposes the falciform process dorsally and anteriorly, separated by a small gap. In the articulated periotic, the position of the lateral tuberosity lies more ventrally than the margin of the falciform process (Figure 11). The apex of the spiny process points forward toward the lateral tuberosity of the periotic, to bridge (pass ventrally to) the path of the middle sinus. An irregu- 
TABLE 3. Measurements in mm of holotype, OU 22306, Otekaikea huata: postcranial elements. Dimensions follow Fordyce et al. (2002) and Perrin (1975). Measurements are rounded to the nearest $0.5 \mathrm{~mm}$. + means measurements of preserved distances of broken part.

\begin{tabular}{|c|c|}
\hline \multicolumn{2}{|l|}{ Atlas } \\
\hline maximum preserved length & 63.0 \\
\hline maximum preserved height & $70.5+$ \\
\hline maximum preserved width & $101.0+$ \\
\hline length of body & 60.0 \\
\hline height of anterior articular surface & 48.5 \\
\hline width of anterior articular surface & 90.0 \\
\hline height of posterior articular surface & 47.5 \\
\hline width of posterior articular surface & 87.5 \\
\hline \multicolumn{2}{|l|}{ Axis } \\
\hline maximum preserved height & 76.0 \\
\hline maximum preserved width & 129.0 \\
\hline length of body & 55.5 \\
\hline length of dens & 23.0 \\
\hline height of anterior articular surface & 36.0 \\
\hline width of anterior articular surface & 88.5 \\
\hline height of posterior articular surface & 49.0 \\
\hline width of posterior articular surface & 54.5 \\
\hline \multicolumn{2}{|l|}{ 4th cervical vertebra } \\
\hline maximum preserved length & 39.5 \\
\hline maximum preserved height & $88.0+$ \\
\hline maximum preserved width & $80.5+$ \\
\hline length of neural spine & $79.0+$ \\
\hline height of neural spine & $11.0+$ \\
\hline length of body & 28.0 \\
\hline height of anterior articular surface & 47.0 \\
\hline width of anterior articular surface & 45.5 \\
\hline height of posterior articular surface & 40.5 \\
\hline width of posterior articular surface & 46.5 \\
\hline \multicolumn{2}{|l|}{ 5th cervical vertebra } \\
\hline maximum preserved length & $28.5+$ \\
\hline maximum preserved height & $71.5+$ \\
\hline maximum preserved width & $98.0+$ \\
\hline length of body & 27.0 \\
\hline height of anterior articular surface & 51.5 \\
\hline width of anterior articular surface & 51.5 \\
\hline height of posterior articular surface & 49.0 \\
\hline width of posterior articular surface & 51.0 \\
\hline \multicolumn{2}{|l|}{ 6th cervical vertebra } \\
\hline maximum preserved height & $74.0+$ \\
\hline maximum preserved width & $85.5+$ \\
\hline
\end{tabular}


TABLE 3 (continued).

length of body $\quad 26.5$

height of anterior articular surface $\quad 44.0+$

width of anterior articular surface $\quad 47.0$

height of posterior articular surface $\quad 47.0+$

width of posterior articular surface $\quad 46.5+$

Thoracic vertebra 1 in Fig. 14

maximum preserved height

$66.0+$

maximum preserved width

$107.0+$

length of body

32.0

Thoracic vertebra 2 in Fig. 14

maximum preserved length $\quad 49.0+$

maximum preserved height $\quad 120.0+$

maximum preserved width $\quad 89.0+$

length of neural spine $\quad 23.0+$

height of neural spine $49.5+$

$\begin{array}{ll}\text { length of body } & 44.0\end{array}$

Thoracic vertebra 3 in Fig. 14

maximum preserved length $\quad 83.5^{+}$

maximum preserved height $128.0+$

maximum preserved width $\quad 83.5+$

length of neural spine $\quad 56.5+$

height of neural spine $\quad 49.0+$

$\begin{array}{lr}\text { length of body } & 58.0\end{array}$

Thoracic vertebra 4 and 5 in Figure 14

maximum preserved length $\quad 73.5+$

maximum preserved height $\quad 95.5+$

maximum preserved width $\quad 81.5+$

length of neural spine $\quad 52.0+$

height of neural spine $\quad 16.0+$

$\begin{array}{ll}\text { length of body } & 63.0\end{array}$

Thoracic vertebra 6 in Figure 14

maximum preserved height $\quad 60.5+$

$\begin{array}{ll}\text { maximum preserved width } & 244.0+\end{array}$

$\begin{array}{ll}\text { length of body } & 74.5\end{array}$

Scapula left

right

maximum preserved length

$284.0+\quad 328.0$

maximum preserved height

$118.0+\quad 224.0$

length of acromion process

$79.0+\quad 95.5+$

length of glenoid fossa

$52.5 \quad 50.5$

width of glenoid fossa

$47.5 \quad 48.5$

depth of glenoid fossa

$10.0 \quad 9.0$


TABLE 3 (continued).

\author{
Humerus \\ Length \\ narrowest length of shaft \\ width of shaft at the narrowest point \\ Ulna \\ Length \\ length without olecranon process \\ narrowest length of shaft \\ width of shaft at the narrowest point \\ Radius \\ Length \\ narrowest length of shaft \\ width of shaft at the narrowest point \\ Sternum \\ preserved length \\ preserved widest width \\ preserved narrowest width
}

\begin{tabular}{cc} 
left & right \\
153.0 & 151.0 \\
55.0 & 56.0 \\
39.5 & 41.5 \\
left & right \\
- & 146.0 \\
- & 103.0 \\
- & 40.0 \\
- & 21.0 \\
left & right \\
115.0 & 120.0 \\
34.0 & 37.0 \\
26.5 & 27.5 \\
\hline $97.0+$ & \\
$86.5+$ & \\
$58.0+$ &
\end{tabular}

lar transverse depression lies lateral to the spiny process, immediately in front of the anterior meatal crest and behind a small anterior transverse ridge sensu Fordyce (2002, p. 203); this may include the sigmoid fossa sensu Geisler et al. (2005, p. 16). The long base of the well-developed falciform process arises near the squamosal-alisphenoid suture at the subtemporal crest, and extends to the spiny process. There is no evidence that a lateral lamina was directed forward from the falciform process to bound the pterygoid sinus fossa. The falciform process is skewed medially to underlie the alisphenoid; its ventral tip has a small oblique facet probably for the outer lip of the bulla, while further dorsally the concave posterior face closely parallels the anterior process of the periotic. Laterally, the margin of the falciform process closely matches the anterior process and lateral tuberosity of the periotic; the spiny process fills the hiatus epitympanicus but with the periotic articulated it is apparent that a few $\mathrm{mm}$ of the spiny process is missing (there is incomplete contact posteriorly at the hiatus epitympanicus). The walls of the external auditory meatus form a narrow triangle medially, widening a little laterally, where the meatus undercuts the postglenoid process and passes into a groove that rises forward onto the lateral face of the squamosal ventral to the neck muscle fossa.
Associated with the latter groove is a small notch at the lateral end of the meatus. The anterior meatal crest is damaged; the posterior crest is arched transversely, with a facet on the posterior face at the suture for the posterior process of the bulla.

The anteroposteriorly long periotic fossa is hidden when the periotic is in situ; it includes anterior and posterior portions that are transversely wide and divided by a strong ridge. In the middle of the anterior portion, the foramen spinosum has two openings, anterior and posterior, which are separated by an elliptical tubercle, as also seen in Otekaikea marplesi. The anterior foramen spinosum is associated with a deep groove (the parietalsquamosal and parietal-alisphenoid sutures), which runs to the foramen ovale. The posterior portion of the periotic fossa is transversely wide (15.9 $\mathrm{mm}$ ) and deep, and contains the suprameatal pit. When in situ, the periotic sits firmly in a single position in the periotic fossa, with the apex of the posterior process in close contact with the squamosal, medial to the post-tympanic process, but separated a few $\mathrm{mm}$ from the exoccipital. A conical space, which opens medially between the periotic and exoccipital, could be for part of the peribullary sinus. The squamosal is fissured, with several foramina, directly above the posterior process of the periotic. The ventrolateral apex of the post-tym- 
panic process lacks obvious grooved sutures for the tip of the posterior process of the tympanic bulla, in contrast to the structure in Waipatia.

Basioccipital. Ventrally (Figure 3), the basioccipital is a trapezoid. Anteriorly, the basisphenoidbasioccipital synchondrosis is fused. Each basioccipital crest gradually widens posteriorly, forms a gently curved ventral profile, and has an indistinct muscular tubercle on the medial surface of the crest. Between the crests, the basioccipital basin is trapezoidal and flat. The lateral border of the basioccipital, which is slightly excavated behind the carotid foramen, contributes to the anterior and medial margins of the cranial hiatus. It is not clear whether the exoccipital contributes to the posterodorsal part of the basioccipital crest medial to the jugular notch.

Supraoccipital and exoccipital. Posteriorly, the supraoccipital is rugose and roughly squared, and constricted by the temporal fossa. The nuchal crest is weakly developed. The dorsal condyloid fossa is deep and wide $(60.9 \mathrm{~mm})$ and curves over the condyle. Each occipital condyle has a smooth and small surface, is semicircular in lateral view, is less obviously curved horizontally (dorsal view), is somewhat elliptical in posterior view, and has a very short but distinct pedicle that is slightly narrower than the condyle. The right pedicle has a small foramen (2.7 $\mathrm{mm}$ diameter), on the ventral surface. The foramen magnum is a dorsally wider trapezoid, widely open, wider than high $(37.9 \mathrm{~mm}$ wide and $29.0 \mathrm{~mm}$ height), and slightly arched dorsally; the profile may result from dorsoventral crushing. The intercondyloid notch is U-shaped. Laterally, the exoccipital is a thin rectangular plate. There is no distinct posterior sinus fossa here.

In ventral view, the exoccipital extends laterally almost as far as the adjacent post-tympanic process of the squamosal. The ventral surface is a smooth, transversely elongate, narrow, tabular to slightly depressed, tongue-shaped paroccipital process for stylohyal articulation. The rounded tip of the process extends medially to within about $5 \mathrm{~mm}$ of the basioccipital crest, and partly underlies the oblique narrow jugular notch $(2.9 \mathrm{~mm}$ wide, 10.1 $\mathrm{mm}$ deep) that opens posterolaterally above the paroccipital process. The small hypoglossal foramen opens in the medial end of the jugular notch.

Alisphenoid. The large alisphenoid forms the posteromedial margin of the subtemporal crest. On the basicranium (Figures 3 and 9), the alisphenoid is posterior to the frontal, anterior to the squamosal and basisphenoid, and lateral to the pharyngeal crest; there are clear sutures with the squamosal and parietal, but the contact with the frontal is broken. A blunt projection of alisphenoid extends back to the base of the falciform process, but does not form a posterolaterally-prolonged wedge. There is no distinct suture with the basisphenoid medially; the latter is indicated by the carotid foramen, but its lateral extent beyond the foramen is uncertain.

Anteriorly, the pterygoid sinus fossa comprises 3 small shallow depressions between the subtemporal crest, the large medially-placed foramen for the optic nerve, foramen rotundum and orbital fissure, and the foramen ovale. The foramen for the optic infundibulum is anteroposteriorly long and elliptical (31.4 $\mathrm{mm}$ long and $25.6 \mathrm{~mm}$ wide); it is bordered by alisphenoid posteriorly, basisphenoid medially, and frontal (and orbitosphenoid?) anteriorly. Just slightly posterior to the pterygoid sinus, a weak transverse ridge on the alisphenoid marks the groove for the mandibular nerve and associated vessels between the small foramen ovale $(8.8 \mathrm{~mm}$ wide and $7.6 \mathrm{~mm}$ long) and the anterior end of the falciform process. The foramen ovale is complete, formed entirely by alisphenoid, which is apparently sutured with itself posteriorly. The alisphenoid is separated from the cranial hiatus by $25-26 \mathrm{~mm}$ of parietal and possibly by basisphenoid. A prominent rod-like projection of alisphenoid underlies the anterior border of the foramen ovale, prolonged toward the basisphenoid.

Basisphenoid. Anteriorly, the basisphenoidalvomer suture has two foramina, which open posteriorly into anteroposteriorly long shallow grooves (Figure 3). The basisphenoid-basioccipital synchondrosis is fused. Laterally, a large and rounded carotid foramen (5.3 $\mathrm{mm}$ diameter) opens, just posteromedial to the foramen ovale. The basisphenoid apparently does not contribute to the margin of the foramen ovale or, anteriorly, to the border of the foramen for the optic infundibulum (the combined openings for the foramen rotundum and infra- and superior orbital fissures).

Periotic. The periotic is a structurally complex and phylogenetically informative bone, and deserves detailed description. Figure 11 shows the orientation of the periotic in its original position on the skull. When the periotic is in situ, the ventral foramen of the facial canal can be seen in ventral view, but the fenestra ovalis is partially obscured by the pars cochlearis.

The right periotic (Figures 12 and 13) has a slender anterior process, slightly smaller posterior process, and a dorsoventrally weakly inflated pars cochlearis between these processes. Both the 
anterior and posterior processes make a wide angle with the anteroposterior axis when the periotic is placed into original position on the skull.

The anterior process is prolonged anteriorly, with a blunt apex. The anterior process is deep and somewhat laterally widened, as seen in Waipatia maerewhenua. Dorsally, a very weak anteroexternal sulcus runs from just anterior to the lateral tuberosity to the anterior end of the dorsal crest. The parabullary sulcus (Tanaka and Fordyce, 2014) is deep and strongly curved (C-shaped). The anteroventral angle, as seen anteriorly, is a small bump just medial to the anterior bullar facet. There is no obvious anterior keel or anterodorsal angle, and this region of the anterior process is smoothly rounded. A small tubercle on the medial surface of the anterior process has a tiny foramen or vertical canal as seen in $W$. maerewhenua. On the weak tubercle, a straight groove runs from the anterior incisure. The anterior bullar facet is a shallow groove, about $8.5 \mathrm{~mm}$ long, with raised parallelsided margins ( $3.7 \mathrm{~mm}$ width). The fovea epitubaria is occupied by a slightly damaged and moderate sized accessory ossicle, which is preserved between the anterior bullar facet and the mallear fossa. The ossicle has a thin subrectangular flange on its medial side. The flange has a shallow groove on its margin (see Figures 12 and 13.2) and is also widely grooved anteroposteriorly on its dorsal face, possibly forming a sulcus for the tensor tympani muscle. Just posteromedial to the accessory ossicle, there is a tiny foramen. The dorsal surface of the periotic has a prominent dorsal crest, medial to which is a deep anteroposterior groove $(9.1 \mathrm{~mm})$, as seen in Otekaikea marplesi but longer and shallower. The anterior incisure is less distinctly grooved than seen in Waipatia maerewhenua and Otekaikea marplesi.

The pars cochlearis is hemispherical ventrally, transversely compressed, and long relative to width. The smooth anteromedial corner passes back into a straight medial margin then an obtuse posteromedial angle. The internal auditory meatus opens on the center medially. A tiny slit-like foramen for the hiatus Fallopii opens on the anterior incisure. The internal auditory meatus is open, posteriorly wider, and rounded tear-shape (maximum length, $8.8 \mathrm{~mm}$ ). The meatus contains four foramina or groups of foramina: the proximal opening of the facial canal, the foramen singulare, the spiral cribriform tract, and the area cribrosa media. A very low transverse ridge separates the small, narrow proximal opening for the facial canal $(2.6 \mathrm{~mm})$ from the foramen singulare, which is also small and narrow. Between the foramen singulare and the spiral cribriform tract, there is a higher crest that bounds a large (anteroposterior length; $5.6 \mathrm{~mm}$ ), deep and rounded area, which is shared by a cluster of foramina forming the spiral cribriform tract, and a pit for the area cribrosa media. As with some other odontocetes (Mead and Fordyce, 2009), the area cribrosa media is not clearly perforate. The spiral cribriform tract has a rounded opening and screw structure.

The fenestra rotunda is an anteroposteriorly short compressed reniform opening (transverse diameter $3.3 \mathrm{~mm}$ ). The aperture for the cochlear aqueduct is subcircular and small $(1.3 \mathrm{~mm}$ diameter). The small aperture for the vestibular aqueduct is a transversely long ellipse $(2.6 \mathrm{~mm})$. Just ventral to the medial margin of the internal auditory meatus, there is a weak groove that might be the median promontorial groove (see Mead and Fordyce, 2009, p. 122).

The posterior extremity of the pars cochlearis is lying lateral to the fenestra rotunda and medial to the fossa for the stapedial muscle, with a small tubercle of the dorsoventrally slightly thin caudal tympanic process, which projects posteroventrally.

On the body of the periotic, ventrally, the mallear fossa is deep, wide, and slightly reniform in shape; the rim of the fossa connects with the accessory ossicle anteriorly. The lateral tuberosity is weakly developed. A short grooved facial crest arises at the base of the mallear fossa and descends posteriorly to the apex of the posterior process. An indistinct depression lateral to the crest at the posterior part of the mallear fossa is probably the fossa incudis. Further posteriorly and lateral to the facial crest, the large hiatus epitympanicus comprises a smooth anterior depression and a rugose grooved posterior part just anterior to and parallel with the face of the posterior process. The narrow groove between the facial crest and the facial sulcus is possibly the tympanohyal sulcus, as seen in Otekaikea marplesi. The fenestra ovalis is rounded, small $(2.1 \mathrm{~mm})$, and filled by the footplate of the stapes (the head is missing). The ventral foramen of the facial canal is small, round, and posteriorly directed, located about level with the anterior of the fenestra ovalis; the foramen is slightly covered by the facial crest. The facial sulcus runs along the posteromedial face of the posterior process, close to the posterior bullar facet, becoming indistinct about $3 \mathrm{~mm}$ behind the level of the caudal tympanic process (13-14 $\mathrm{mm}$ anterior to the tip of the posterior process). The stapedial muscle fossa runs back along the face of the pos- 
terior process to within about $10 \mathrm{~mm}$ of the tip of the posterior process, separated from the facial sulcus by a faint ridge. Most of the stapedial muscle fossa lies immediately behind the fenestra ovale; the fossa is deep and slightly longer than wide, and forms a subcylindrical depression on the face of the caudal tympanic process.

The posterior process is rectangular and slender (17.6 $\mathrm{mm}$ long and $7.8 \mathrm{~mm}$ wide). The posterior bullar facet has three sections separated by faint ridges: small anterior and posterior sections, and a larger medial section. The dorsal margin of the tip of the process was originally sutured with the squamosal; the periotic was freed by removing matrix with dilute acetic acid and was found to be unfused with the squamosal.

Posterior to the lateral tuberosity, the distinctive articular rim projects laterally. Medial to the articular rim, there are at least three large presumed posteroexternal foramina. A deep groove runs from anteromedial to posterolateral, at the lateral end of the posterior process, so that the anterolateral part of the posterior process is a thin flange. Posterior to the groove, there are many weak striae on the posterolateral end of the posterior process.

Stapes. The stapes has a wide footplate, in situ in the right periotic. The crura are broken at the dorsal level of the stapedial foramen. The footplate is anteroposteriorly long and sub-elliptical, with slightly perpendicular anterior and medial margins, and slightly rounded posterior and lateral margins. A fine crest spans between the two broken crura; whether the stapedial foramen was open is uncertain. Ventrally, the head provides a small articulation for the incus. Just dorsal to the head, posteromedially, there is a large rounded muscular process. This preservation, broken in the midheight, is very similar with the stapes of Prosqualodon davidis (Flynn, 1948, figure 7), perhaps reflecting weakness caused by a large stapedial foramen. Conversely, some more-crownward platanistoids (Platanista gangetica and Notocetus vanbenedeni AMNH 29026) reportedly lack the stapedial foramen (Anderson, 1878; de Muizon, 1987). In Tursiops, the foramen is vestigial and non-patent (Mead and Fordyce, 2009).

Bulla. Only the rounded left sigmoid process (Figures 12 and 13) is preserved. The dorsal surface lacks the slightly flattened facet that, in some other odontocetes, matches the sigmoid fossa on the squamosal. Anterior to the sigmoid process, on the ventral surface, there is a depressed area with a few weak grooves. In ventral view, the margins of the sigmoid process are thickened. Inside the sigmoid process, the tympanic sulcus runs from the posteromedial end to anterolateral part of the sigmoid process. A broken fossa for malleus is on the medial base of the sigmoid process.

Mandibles. The fused mandibles preserve the symphysis and the alveoli but lack the anterior and posterior ends. The incomplete mandible is $520+$ $\mathrm{mm}$ long; judging from premaxillary length, at least $170 \mathrm{~mm}$ is missing from the anterior.

The anterior part of the mandible is flat ventrally, with at least five mental foramina directed anteriorly on the ventral surface (Figure 14.7). The most anterior preserved foramen is notably long $(131 \mathrm{~mm})$ and deep. The anteroposteriorly long and shallow (20.5 mm height) mandibular symphysis has three foramina on its suture on the dorsal surface (Figure 14.4). The damaged part of the symphysis shows internal openings of the mental foramina. Some of the internal areas are filled by cemented matrix, suggesting that the mandible contains canals for the nerves, vessels, and especially the intra-mandibular fat body. Mental foramina are preserved on the ventral surface of the mandible (Figure 14.8). The ventral surface of the mandibular symphysis has a triangular depression between the prominent ventral margins. The dorsal surface is tabular.

Around $28 \mathrm{~mm}$ lateral from the posterior end of the mandibular symphysis, the long bilateral alveolar groove opens dorsolaterally, widening posteriorly. Width ranges from 4.5-7.5 mm. Posteriorly, there are slightly elongate alveoli (around 17 $\mathrm{mm}$ long and $6 \mathrm{~mm}$ width). Here, the body of each mandible swells laterally; the dorsal border rises gradually. The most dorsal part of the coronoid process is broken but the base of the process shows a strong coronoid crest. Medially, each mandibular fossa is long and high. Only the dorsal border is preserved near the coronoid process, indicating a maximum depth of about $95 \mathrm{~mm}$. The profile of the inflated lateral margin suggests that the fossa could have been $150+\mathrm{mm}$ long.

Teeth. Otekaikea huata is near-homodont and polydont (Figure 10). Fifty-one single-rooted teeth are preserved isolated; in at least one cheek-tooth, the roots are vestigially double but almost completely fused. Tooth positions are identified with reference to other archaic odontocetes, especially Waipatia maerewhenua. The term dimension is used in preference to "length" for overall size, as length is an anteroposterior or mesiodistal measurement, akin to diameter in most of the teeth described below. 
An extremely long-rooted tusk (Figure 10.1-2) with a worn crown, presumably an incisor, is thick at the crown and the upper part of the root, tapering and becoming slightly flattened toward the root apex. The rough-surfaced root is long $(197+\mathrm{mm})$ and becomes thickest $(16.1 \mathrm{~mm}$ widest diameter) slightly below the crown; this root is around 2.5 times longer and 1.6 times the diameter than the largest tooth in Otekaikea marplesi. The crown is naturally worn, leaving the crown base $(11.9 \mathrm{~mm}$ maximum diameter at the enamelo-dentin junction) with exposed dentin and a pulp cavity infilled by matrix. Of note, the wear pattern around the crown is asymmetric and elliptical; one side is worn more than the other, retaining a small area of enamel. From another view, the worn end is slightly curved like a shovel (Figure 10.2).

Two more tusks (Figure 10.3-4, 93.5 and 93.1 $\mathrm{mm}$, respectively) are shorter than the former tooth. Both are also worn, with exposed dentin. Their diameters are $7.7 \mathrm{~mm}$ and $9.6 \mathrm{~mm}$, respectively, narrowing toward the root tip. They have a stronger curve than the large tusk, viewed from the worn surface and are presumed to be posterior incisors (i.e., second or third incisors).

Four conical medium-sized teeth (Figure 10.56) are $48-57 \mathrm{~mm}$ in total dimension and $7-8 \mathrm{~mm}$ in diameter. In the figured tooth, the crown, which is slightly laterally compressed, comprises $40 \%$ of the total dimension; it is slightly worn on the apex. A small enamel slit may indicate the posterior face, judging from the single-rooted teeth of Waipatia maerewhenua (Tanaka and Fordyce, 2014). The outer surface (probably labial, rather than buccal) of the conical crown is weakly convex. A little below the crown, the root swells on one face and forms the thickest part on the tooth. Apically (away from the crown), the root becomes thinner and slightly laterally compressed, with a shallow long groove on the presumed labial face.

Thirty-six smaller moderately curved teeth (Figure 10.7-9) are from 31 to $26 \mathrm{~mm}$ in total dimension and 5.7-6.7 mm diameter. The crown is about $30 \%$ of the total dimension. Loch et al. (2015) examined one tooth from this specimen, and reported the enamel as thin (75-85 microns), with an inner layer of radial enamel and an outer layer of prismless enamel. Some teeth are worn markedly; most show slight wear. They also have a small enamel slit posteriorly.

Eleven buccolingually flattened teeth (Figure 10.10-12) are 21-23 mm total dimension and 6.4$6.7 \mathrm{~mm}$ diameter. Around $30 \%$ of the total dimension comprises the crown. There are elongate grooves on the buccal and lingual surfaces of the root.

One tooth, with a large main denticle and two small posterior accessory denticles (Figure 10.1314 ), is the only tooth indicating some vestigial heterodonty, in contrast with the homodont teeth of most extant odontocetes (single rooted teeth with a conical crown and no accessory denticles). Dimensions are $23.2 \mathrm{~mm}$ from tip of crown to tip of root, $7.0 \mathrm{~mm}$ anteroposteriorly and $5.7 \mathrm{~mm}$ buccolingually. The crown comprises $30 \%$ of the total dimension. Its anterior keel is worn along a narrow (1.0 $\mathrm{mm}$ wide) band. The accessory denticles barely project from the posterior keel; the moreapical (more-anterior) denticle is slightly larger and more prominent than the more basal denticle. Both faces on the crown have subvertical long enamel ridges that are more-regularly subparallel buccally. Lingually, a weak entocingulum is developed. The single root has marked grooves on both buccolingual surfaces, as if marking the junction of two confluent roots. Just below the crown base, the root swells markedly posteriorly.

Atlas. The atlas (Figure 15.1, 15.6 and 15.11) is anteroposteriorly thick and not fused to the axis. The epiphyses are fused with the body. Only basal parts of the neural arch are preserved, including part of the margin of the transverse foramen (for the first spinal nerve and vertebral artery; see Flower, 1885b, figure 15). The neural canal and confluent odontoid fovea have a dorsally wide open V-shape. The maximum dorsal width is 41.9 $\mathrm{mm}$, and height (between a line of both sides of the fragmentary neural arch and the ventral border of the neural canal) is $37.5 \mathrm{~mm}$. The upper transverse process is small $(25.0+\mathrm{mm}$ projection beyond the body) and directed strongly dorsolaterally. The lower process is smaller but more robust than the upper transverse process, is wide (9.2 $\mathrm{mm}$ long) and low (10.9 mm in thickness), and projects posterolaterally. The condyloid facets (articular surfaces) for the occipital condyles are deep and distinctly separated ventrally with clear ridges. In lateral view, the condyloid facets face down at about 20 degrees to the plane of the tabular articular facets for the axis. The latter facets are separated by the deep fovea for the odontoid process of the axis. On each articular facet, oblique strong tubercles descend forward to delimit the odontoid region; the transverse ligament (see Struthers, 1872) probably arose from the ridge. From the posteroventral margin of the ventral arch, a long robust hypapophysis (ventral tubercle) projects posteroventrally from an elongate base. The process 
extends $12.9 \mathrm{~mm}$ below and $15.7 \mathrm{~mm}$ behind the body. Its cross-section is elliptical.

Axis. The axis (Figure 15.2, 15.7, and 15.12) is anteroposteriorly thinner than the atlas and not fused with the adjacent vertebrae. The epiphyses are fused with the body. The neural spine is broken but the transversely robust neural arch curves and rises dorsally. In anterior and posterior view, the neural canal appears ventrally wide and subtriangular, with a prominent median crest that separates bilateral depressions at the base of each pedicle. Each transverse process is thick, high, and strongly projected laterally, with bifurcated extremities. There is no vertebrarterial canal, but the weak depression on the posterior surface of the transverse process is probably the homologous feature.

The wide and flat articulations for the atlas anteriorly merge at the smooth surface under the strongly projecting odontoid process. The elliptical (wide) posterior epiphysis is depressed at the center, has a vertical crease, has an indistinct notochordal pit, and has indistinct circumferential striations for the annular ligament. The ventral margin projects, passing into a weak crest on the ventral surface of the body to the odontoid process.

Cervical vertebrae. Three cervical vertebrae (Figure 15.3-5, 15.7, and 15.10), probably the fourth to sixth, are preserved; all the vertebral epiphyses are ankylosed. Each vertebra has a tiny neural spine, thin neural arches, a wide rounded-pentagonal neural canal, and strongly ventrolaterally projecting and wide transverse processes, each inferred to have formed a vertebrarterial canal. The anteroposteriorly flattened body has a slightly convex anterior face, and has a sagittal ventral keel and a low dorsal sagittal crest separating bilateral dorsal depressions. On the lateral surface of the body, there is a deep and large depression, dorsal to the transverse process. The bodies of the posterior cervical vertebrae are anteroposteriorly thicker than the most anterior one.

Thoracic vertebrae. Twelve thoracic vertebrae are preserved (Figure 16; not all are figured), all with the anterior epiphyses ankylosed. Each thoracic vertebra has: a high, long, and flat neural spine; a small fovea (synovial articulation) for the rib on the robust transverse process, and a larger fovea on the body; a weakly depressed anterior surface of the body; an anteroposteriorly long body (lengthens progressively posteriorly in the series); and no distinctive ridge on ventral surface of the body. On the dorsal surface of the body, there are paired anteroposteriorly long oval dorsal foramina.
Thoracic vertebra 1 on Figure 16 is assumed to be an anterior thoracic vertebra because the transverse process arises in a lower position. It has a wide and low neural canal, short body and anteroposteriorly shortest neural arch. Two to four thoracic vertebrae are more posterior and have an anteroposteriorly long neural spine, high pentagonal shaped neural canal, and a longer body. The transverse process arises from a high point dorsally on the neural arch. Vertebra 4 shows a short and blunt transverse process from the dorsal part of the body. It has a deep and tear-shaped fossa on the anterior base of the transverse process.

Two lumbar vertebrae (Figure 16.6) have the anterior epiphyses ankylosed. Each lumbar vertebra has a very long wing-like transverse process; flat anterior and posterior surfaces of the body; and an anteroposteriorly long body. Vertebra F on Figure 16 is $139.3+\mathrm{mm}$ wide across the transverse processes and $54.4+\mathrm{mm}$ long, while another lumbar vertebra (not pictured) is $52.5 \mathrm{~mm}$ wide and $43.1 \mathrm{~mm}$ long.

Ribs. In total, 12 ribs (Figure 17); two right and two left, and six others with only the mid-part of the shaft (their sides are uncertain) are preserved. Two right and left anterior double-headed ribs, damaged ventrally, are $180+$ and $176+\mathrm{mm}$ chord length, respectively, anteroposteriorly flat and wide. There is a diffuse triangular and shallow cavity on the posterior surface. On the shaft, anterior and posterior surfaces are weakly swollen and flat, respectively. The rib portion converges distally.

Four presumed mid-series of ribs show a conical shaft with slightly anteroposterior flattening, and with medial and lateral blunt margins. The longest preserved rib is $402+\mathrm{mm}$ chord length, around $13 \mathrm{~mm}$ length and $20 \mathrm{~mm}$ width around at the mid-shaft. The anterior and posterior surfaces are weakly swollen and flat, respectively. A left rib has the strong tubercle at around $70 \mathrm{~mm}$ distal to the capitulum on the lateral edge. Two right ribs show that both dorsal and ventral ends are widened dramatically, twice as wide as the mid-shaft. The dorsal end is short (or anteroposteriorly flat). The ventral end is thick and shows transversely long elliptical surface for the cartilaginous sternal ribs.

Sternum. The symmetrical flat manubrium (or presternum) (Figure 18) has incomplete outlines. Dimensions are $96.9+\mathrm{mm}$ long, $85.6+\mathrm{mm}$ wide, and $17.4 \mathrm{~mm}$ thick. The presumed ventral side is ventrally warped. The presumed anterior is wider, perhaps providing an area for the cartilaginous sternal ribs. 
Scapula. The right scapula is better preserved (Figures 19, 20), but the left scapula (Figure 20) retains the coracoid process, which is broken on the right. For this description, the orientation of the scapula has the glenoid fossa ventral, and the suprascapular border dorsal as figured (Figure 19). The fan-shaped scapula is transversely thin and longer than high and has two projections (the acromion and coracoid) anteriorly.

The scapular blade is anteroposteriorly long (wide in lateral view), with the angle of the lines from the anterior and posterior borders is $106^{\circ}$. Anteriorly, the narrow prescapular (supraspinous) fossa and the large postscapular (infraspinous) fossa are separated by a rounded ridge. Both fossae have a smooth undulating surface; there is strong depression at the center of the scapula. The posterior convexity for the border between the infraspinatus and the teres major lies slightly posterior to the center of the scapula. On the medial surface, two ridges may be origins for tendons of the subscapularis muscle.

The acromion projects slightly ventrally when the glenoid cavity of the scapula is sitting on a flat plane, and curves gently laterally at the base and stops anteromedially. It provides a huge space for the supraspinatus muscle. The long $(94 \mathrm{~mm})$ acromion is parallel-sided anteriorly. A relatively small rod-like coracoid is long relative to diameter $(25.3$ $\mathrm{mm}$ long, versus diameters of $8.3 \mathrm{~mm}$ and $7.8 \mathrm{~mm}$ at mid-length), and robust at the base $(13.7 \mathrm{~mm}$ width, $14.2 \mathrm{~mm}$ height). The neck of the scapula is strongly constricted. The scapula has a deep rounded glenoid cavity ventrally with a small foramen in the center.

Humerus. The right and left humeri are well preserved (Figures 19.2 and 20.5-8). The humerus is long, cylindrical (153 mm), and transversely slightly flattened $(40 \mathrm{~mm}$ width and $65.4 \mathrm{~mm}$ length at the mid-shaft). For identifications of the muscle attachments, our direct examination of Globicephala melas and previous studies on the Odontoceti are used (Schulte and Smith, 1918; Howell, 1930; Smith et al., 1976; Strickler, 1978).

Proximally, a rounded, transversely long, elliptical, and smooth head is exposed laterally, occupying around $30 \%$ of the total length of the humerus. Medial to the head, there is a wide flat area for the subscapularis muscle. Below the head, there are weak anterior and posterior constrictions (proximal view). The small tuberosity lies posterior to the head and provides a small corner probably for the triceps muscle. Between the tuberosities, the bicipital groove appears to be absent. Anterior to the angle for the coracobrachialis, there is a large steep step for the supraspinatus muscle, formed by the proximal part of the humeral anterior margin. Anterior to the head, distal to the steep step for the supraspinatus, is a large proximodistally long depression for the infraspinatus muscle, beyond which is a large nutrient foramen at the level of the mid-shaft. The anterior margin of the humerus is thin and sigmoidal. Just slightly proximal to the fossa for the infraspinatus, there is a rough surface for the mastohumeralis muscle on the anterior edge. At the same level with the fossa for the infraspinatus, there is a small tubercle, probably for the serratus muscle on the posterior margin of the humerus. Just proximal to the distal end of the humerus is a weak crescent depression for the deltoid muscle. On the medial surface, muscle origins are uncertain (i.e., the teres major and minor). Distally, the joints for the ulna and radius are smooth with weak depressions on their centers. These joints are separated by a ridge. The posterior angle carries the joint for the ulna and has a small tubercle anteriorly and a strongly projected tubercle (an attachment for the triceps muscle) posteriorly. The anterior half of the distal end of the humerus is the joint for the radius.

Ulna. The right ulna is robust proximally and transversely thin distally (Figures 19.3 and 20.10). The olecranon projects posteriorly and is slightly curved laterally from proximal and distal view. The base of the olecranon and the proximal articular face for the humerus are thick (or wide). The trochlear notch is strongly curved (angle around $90^{\circ}$ ). The interosseous and the outer borders are straight, and gradually and weakly widened distally. On the distal end, the epiphysis is not fused. The distal end is an anteroposteriorly long ellipse (length $47.9+\mathrm{mm}$ and width $22.8+\mathrm{mm}$ ).

Radius. The right and left radii (Figure 19.4) are preserved. The right radius shows an exact fit with the humerus. The shaft is weakly curved anteriorly and slightly thinner than the ulna. Both proximal and distal epiphyses are not fused. The proximal end is triangular with a small projection at the anterior end of the posteriorly-tilted articular face for the humerus. The anterior margin is thin, and the posterior margin shows a flattened area. The shaft widens gradually to the distal end.

Carpus. A single carpus (Figure 20.9) is $40+\mathrm{mm}$ long, $26 \mathrm{~mm}$ wide, and $18.3 \mathrm{~mm}$ thick. It may be a proximal carpus because it is very wide and is almost the same width as the ulna and radius. 


\section{PHYLOGENETIC ANALYSIS}

The phylogenetic position of Otekaikea huata was analyzed using the matrix of Tanaka and Fordyce (2014) with 16 additional characters from previous studies (de Muizon, 1987; Fordyce, 1994; Bianucci et al., 2013; Gutstein et al., 2014) (see Appendices 1-6). Originally, the matrix was modified from that of Murakami et al. (2012b), which was designed to focus on Odontoceti phylogeny, particularly Delphinoidea. The matrix of Tanaka and Fordyce (2014) included 76 extant and extinct taxa, all named and described, and 278 characters (with 31 soft tissue characters) cited and/or modified from previous studies (Barnes, 1985a, 1985b; Heyning, 1989; Barnes, 1990; Fordyce, 1994; Arnold and Heinsohn, 1996; Heyning, 1997; Messenger and McGuire, 1998; Geisler and Sanders, 2003; Lambert, 2005; Lambert and Post, 2005; Lambert et al., 2008; Aguirre-Fernández et al., 2009; Geisler et al., 2011; Murakami et al., 2012a, 2012b; Murakami et al., 2014).

The matrix of Tanaka and Fordyce (2014) was modified in minor ways (see Appendix 5). Five taxa were added: Otekaikea huata of this study, the archaic Odontoceti Simocetus rayi (based on study of the holotype USNM 256517, on a cast at OU, and on Fordyce, 2002), Phocageneus venustus (based on study of referred specimen USNM 21039, and on Kellogg, 1957), Microcetus hectori (based on study of the holotype MoNZ Ma 653), $M$. ambiguus (based on the type teeth photos), $M$. sharkovi (a cast of the type held at OU), and an undescribed species (based on study of OU 22125). An archaeocete, Georgiacetus vogtlensis, was the outgroup taxon. (The new genus Huaridelphis Lambert et al. (2014) appeared in print when this article was in review, too late for formal inclusion in the cladistic analysis, although we offer some comments elsewhere in the text.) Percentages of missing data were: for Otekaikea huata $43 \%$ (includes soft tissue characters) and 36\% (excludes soft tissue), Simocetus rayi $48 \%$ (includes soft tissue characters) and $41 \%$ (excludes soft tissue), Phocageneus venustus $89 \%$ (includes soft tissue characters) and $88 \%$ (excludes soft tissue), Microcetus hectori $86 \%$ (includes soft tissue characters) and $85 \%$ (excludes soft tissue), M. ambiguus $97.6 \%$ (includes soft tissue characters) and $97.3 \%$ (excludes soft tissue), M. sharkovi 90\% (includes soft tissue characters) and $97.3 \%$ (excludes soft tissue), OU $2212573 \%$ (includes soft tissue char- acters), and $70 \%$ (excludes soft tissue). In summary, the present matrix has 83 taxa and 292 characters.

Character data and tree data were managed using Mesquite 2.75 (Maddison and Maddison, 2011). The matrix files are in Appendices 1 (nexus format), 2 (tnt format), and 3 (text). Two sorts of cladistic analyses were performed with TNT, 1.1 (Goloboff et al., 2008). All characters were treated as unweighted and unordered (analysis 1), or implied weights with $\mathrm{K}=3$ without ordering (analysis 2). Both analyses used New Technology Search with the setting: recover minimum length trees = 1000 times. To measure node stability, we used the decay index method (Bremer, 1994) for the strict consensus trees. After the analyses, as above, species in the more-diverse families crown-ward of Papahu (particularly Physeteroidea, Ziphiidae, Phocoenidae and Delphinidae) were merged for ease of illustrating. The full cladograms which show positions for all OTUs are provided as tree tif files in Appendices 7 and 8.

\section{Phylogenetic Relationships}

Analysis 1; unweighted and unordered. The phylogenetic analysis shows 1266 of the shortest trees of 1858 steps each. The strict consensus tree (Figure 21) shows almost the same topology as the Tanaka and Fordyce (2014) unweighted and unordered strict consensus tree, except that Papahu taitapu now appears immediately crownward to the clade Platanistoidea, thus clustering with laterdiverging Odontoceti.

Analysis 2; implied weighting. The phylogenetic analysis recovers 18 trees with a score of 138.02 (Figure 21). The strict consensus tree also shows almost the same topology as the Tanaka and Fordyce (2014) single tree, except that Papahu taitapu is again crownward to the Platanistoidea.

In both analyses, Otekaikea belongs in a clade with the Platanistidae and Waipatiidae. In analysis 2 , the clade with Otekaikea is broadly the same as the Platanistoidea proposed by de Muizon (1987). Otekaikea huata forms a clade with O. marplesi, separate from Waipatia. The genus Otekaikea is supported by three synapomorphies: the ventromedial edge of the internal opening of infraorbital foramen is formed by the both maxilla and palatine (Character 44); there is a fused accessory ossicle on the periotic (Character 199); and an intra-premaxillary foramen is present bilaterally, bounded by the premaxilla and maxilla. 


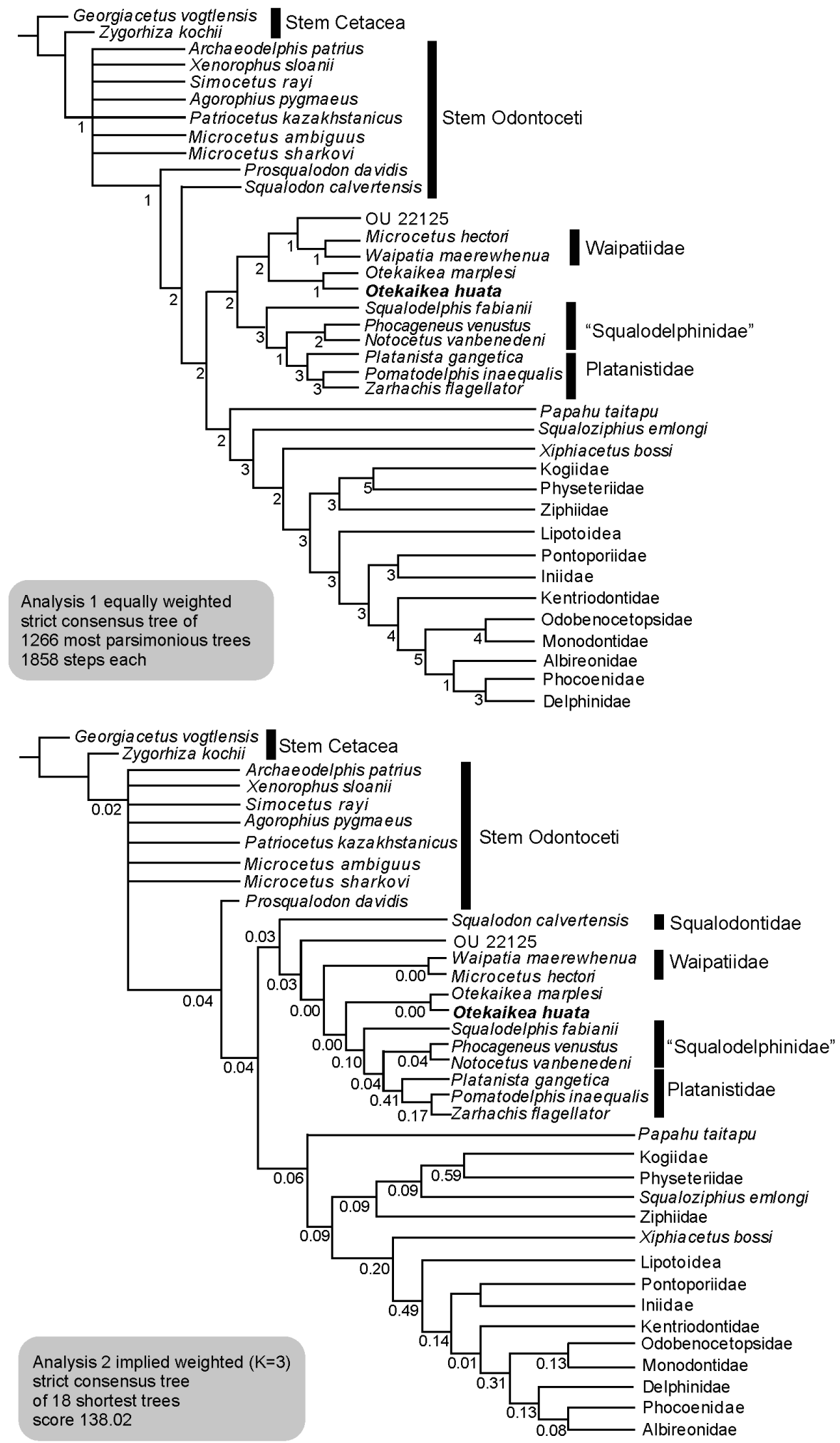

FIGURE 21. Phylogenetic analysis of Otekaikea huata and the Odontoceti. Top, strict consensus tree of equally weighted analysis 1 with decay index values shown. This figure shows simplified cladograms, with species in the more-diverse families crown-ward of Papahu merged for ease of illustrating. Complete trees are provided in Appendices 7 and 8 . Bottom, strict consensus tree of implied weighted analysis 2 with decay index labeled. Synapomorphies for some nodes are: Platanistoidea (sensu lato), Characters 59, 169, 186, 195, 196, 212; Platanistoidea (sensu stricto), Characters 166, 167, 175, 288, 291. 

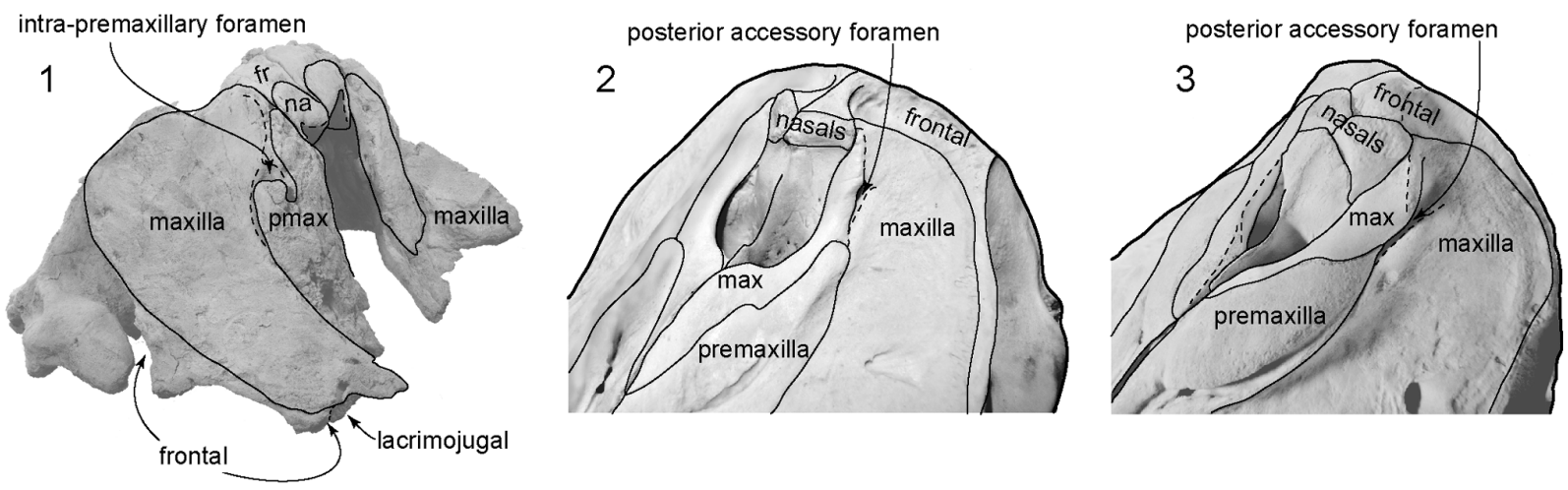

FIGURE 22. Close-up photo of the intra-premaxillary foramen of 1, Otekaikea huata and the posterior accessory foramen of 2, Monodon monoceros and 3, Delphinapterus leucas. Figures are not to scale. Fr, frontal. Ma, maxilla. $\mathrm{Na}$, nasal. Pmax, premaxilla.

\section{DISCUSSION}

\section{Function - Face}

The excavated and voluminous facial fossa would have held enlarged nasofacial muscles, inserting around the nasal diverticula, implying a well-developed echolocation apparatus, but there are no features that clearly show particular muscle origins or imply particular acoustic specializations. The premaxillary sac fossa has a transversely convex surface, rather than the concave surface seen in Waipatia; implications for shape and function of the premaxillary sac are uncertain. The antorbital notch appears to have been shallow, judging from the remnant preserved on the right, but the size of the antorbital process, if any, is uncertain.

The newly named intra-premaxillary foramen is one of many dorsal foramina of the facial fossa that are part of the infraorbital canal-foramen complex (Figure 22). Previously, Tanaka and Fordyce (2014) reported the foramen in Otekaikea marplesi as lying between the posterior extremities of the maxilla and premaxilla, and used the name posterior accessory foramen, earlier proposed by VélezJuarbe and Pyenson (2012) for a comparable foramen in the Monodontidae. Closer study shows that the foramina in the Monodontidae and in Otekaikea have different bone relationships, below, suggesting independent origins. Thus, the foramen in Otekaikea is here named the intra-premaxillary foramen. Both species of Otekaikea have the foramen associated with the maxilla and the bifurcated premaxilla (the posterolateral plate and posteromedial splint). The posterolateral plate passes back toward the nearly-vertical medial part of the maxilla, which is elevated to form a vertex crest. The intra-premaxillary foramen opens in the premaxilla in the fold between the maxillary vertex crest and posterolateral plate, partly covered by the premaxilla. Conversely, in Monodon and Delphinapterus, the posterior accessory foramen is formed mainly by the maxilla, because of shortening of the premaxilla, more-lateral to the nares, and well below the vertex. The premaxilla may contribute to the anterior part of the posterior accessory foramen, but does not cover most of the foramen; further, the homologies in terms of posterolateral plate and posteromedial splint are uncertain. Thus, the foramen is exposed as a long groove on the maxilla, posterior to the ascending process of the premaxilla. The intra-premaxillary foramen should not be confused with the premaxillary foramen, which supplies vessels to the anterior part of the premaxillary sac fossa.

The phylogenetic patterns for the intra-premaxillary foramen are not well documented. The foramen is absent in the basal platanistoid Waipatia. In some Squalodontidae and putative Dalpiazinidae, the fold between the posteromedial splint and posterolateral plate is fissured, possibly for a vessel. In squalodontid OU 21798, a large dorsal infraorbital foramen opens close to the fold, but slightly laterally. Similarly, some platanistoids, extant $P$. gangetica, Zarhachis flagellator USNM 10911, reported by Kellogg (1926) and Huaridelphis raimondii Lambert et al. (2014) show a foramen on the medial part of the maxilla, just posterolateral to the end of the premaxilla. Could such a foramen arise by the migration, medially, of an existing dorsal infraorbital foramen, or might it be a neomorphic structure? To consider the origin and significance of foramina on the face, all the taxa in the phylogenetic analysis have one dorsal infraorbital foramen (Agorophius pygmaeus, 
Otekaikea marplesi, and Papahu taitapu), or sometimes two as an adjacent pair (Simocetus rayi, Waipatia maerewhenua, Zarhachis flagellator, and Notocetus vanbenedeni). None has a set of three, which if one foramen were to migrate medially, might otherwise be a precursor situation for the structure in Otekaikea huata.

\section{Function - Basicranium}

Ventrally, Otekaikea lacks the enlarged orbital fossae for the basicranial pterygoid sinuses that, in Platanista (Fraser and Purves, 1960), Notocetus and Huaridelphis (Bianucci et al., 2014; Lambert et al., 2014), are linked to development of maxillary thickenings or crests on the face. The presence of a subtemporal crest in $O$. huata further suggests that lobes of the pterygoid sinus did not invade the orbit. Shallow fossae on the alisphenoid for parts of the pterygoid sinus are comparable in development to those of Waipatia. There is no evidence that the pterygoid sinus fossa had a bony lateral lamina running forward from the falciform process. The tympanosquamosal recess, which forms the fossa for the middle sinus, is prominent, with a distinct posteromedial sulcus marking the probable origin of the sinus from the middle ear via the epitympanic hiatus. The periotic sits snugly in the skull without evidence, however, of bony fusion with the squamosal. Cavities between the periotic and periotic fossa indicate a marked volume of soft tissues, but whether vascular or pneumatic sinus is uncertain. Whether these are truly parts of the foramen spinosum must be established by dissection of modern material. The significance is uncertain for the elongate, tongue-like paroccipital process; there are no obvious modern equivalents. Its transversely elongate structure could have been a laterally extensive base for a widened stylohyal, or alternatively may have allowed the base of the stylohyal to move in a transverse plane during feeding (for the role of the stylohyal in feeding, see Reidenberg and Laitman, 1994).

\section{Systematics - Family Waipatiidae}

The family Waipatiidae was established for the single species Waipatia maerewhenua Fordyce, 1994. Recently, Tanaka and Fordyce (2014) used cladistic analysis to identify Otekaikea marplesi as a second species in the family. The cladistic analysis here allows revision of the Waipatiidae to include only two species (W. maerewhenua and Microcetus hectori), with the clade characterized by having a squared postglenoid process in lateral view (character 115). Analyses 1 and 2 (Figure 21) now show two different relationships for $W$. maerewhenua. Analysis 1 (equally weighted characters) shows a clade with five species: Waipatia maerewhenua and Microcetus hectori as sister-species in Waipatiidae and, more basally, the unnamed OU 22125, and the two Otekaikea sister-species. Analysis 2 (implied weights) also recovers Waipatia maerewhenua and Microcetus hectori as sister-species in Waipatiidae, with the unnamed OU 22125 immediately basal, but the two Otekaikea species now lie immediately crown-ward. The clade Waipatiidae + Otekaikea and OU 22125 of equal-weights analysis 1 is supported by six characters, three of which have mosaic state distributions in different lineages. These homoplasous characters are downweighted in the implied-weights analysis 2 . Two of six synapomorphies in analysis 1 are reversals (or show the same states as the outgroup). Only one character is a synapomorphy for the clade Waipatiidae + Otekaikea and OU 22125 (poorly defined ventromedial keel of the tympanic bulla: character 212). One taxonomically important and enigmatic species included here, Microcetus hectori, is known from a single incomplete specimen for which $86 \%$ of skeletal characters could not be coded. It is axiomatic that relationships will probably change as new material becomes available to study. Such fossils include five more recently-identified small odontocetes, with skulls, from the upper Otekaike Limestone of Hakataramea Valley.

\section{Systematics - Content of the Platanistoidea}

Another difference between analyses 1 and 2 is the position of the genus Squalodon. In analysis 1, Squalodon appears as a stem Odontoceti, but in analysis 2, Squalodon appears within the Platanistoidea sensu lato. Prosqualodon does not form a clade with Squalodon in this study. The Platanistoidea sensu stricto (namely, with Squalodon excluded) is supported by six synapomorphies: presence of the posterior dorsal infraorbital foramina of the maxilla (character 59); C-shaped or weakly curved parabullary sulcus (character 169); presence of the articular rim (character 186); presence of the anterior spine of the tympanic bulla (character 195); presence of the anterolateral convexity of the tympanic bulla with anterolateral notch (character 196); and presence of the ventral groove (median furrow) of bulla anteriorly (character 212). Derived states for one of six characters (character 59) are seen in other linages, not only for the Platanistoidea sensu lato. Other synapomorphies of the Platanistoidea sensu lato were 
mentioned in previous studies (de Muizon, 1987, 1991; Fordyce, 1994; Lambert et al., 2014; Tanaka and Fordyce, 2014). Monophyly of the Platanistoidea is supported by relatively low decay indices, because this taxon contains only one extant species, plus related fossils. It is axiomatic that future analyses with new fossils will probably change topology and clade content.

\section{Paleoecology}

Otekaikea marplesi and O. huata are similar in geological age, and the uncertainties about exact ages make it possible that the species could have been coeval. In addition, their skull sizes are similar. To what extent, then, might these species have had similar ecologies? Otekaikea huata can be distinguished clearly from $O$. marplesi by characters given in the diagnosis. To consider some possibly functional differences, the dentition of $O$. huata is near-homodont, while $O$. marplesi is probably heterodont (based on the presence of at least one denticulate double-rooted tooth). Other platanistoids from New Zealand (here, Otekaikea, Waipatia maerewhenua, Microcetus hectori and OU 22125) show better-developed double rooted posterior teeth. In addition, uniquely $O$. huata has an extremely large tusk $(197+\mathrm{mm}$, admittedly not in place, and worn) and smaller long tusks (see description and Figure 10) with a long root. The largest tusk originally had a crown estimated at 280 $\mathrm{mm}$ long, based on the proportions of the procumbent incisors of Waipatia maerewhenua, and of OU 22397. Otekaikea marplesi and W. maerewhenua also have tusks (Fordyce, 1994; Tanaka and Fordyce, 2014), but smaller than in O. huata. Large tusks in odontocetes have been reported from other lineages (at least the Kentriodontidae, Monodontidae, Odobenocetopsidae, Dalpiazinidae, and Ziphiidae) (de Muizon and Domning, 2002; Nweeia et al., 2012). Tusk function is problematic (de Muizon et al., 2002; Fordyce et al., 2013). Erupted mandibular tusks are sexually dimorphic in living Ziphiidae, occurring in adult males, and perhaps in some fossil ziphiids (Lambert et al., 2010). Other structural differences imply differences in function and thus ecology: $O$. huata has a relatively deeper facial fossa, more asymmetrical nasals, and a tongue-like paroccipital process. The latter implies a stylohyal articulation, and presumably mode of action, without a comparable modern equivalent.

\section{Taphonomy}

At the locality, the Otekaike Limestone is subhorizontal and diffusely bedded, suggesting depo- sition below storm wave base and in conditions with limited traction currents. The matrix of Otekaikea huata contains well-preserved macroinvertebrates, consistent with quiet waters. The ostracod Bisulcocythere (Cytheroidea; Ostracoda) implies a paleodepth of roughly mid-shelf (50-100 m) (Ayress and Swanson, 1992; Ayress, 1993). Molluscan studies suggest that the Otekaike Limestone represents a sheltered, warm water, middle shelf setting (Fordyce, 2009; Fordyce and Maxwell, 2003).

Otekaikea huata was preserved right side down. Figure 23 shows the specimen, which is exposed with the lower side visible and the lower part of the field plaster jacket partly removed. The upper figure is based on the original distribution of bones, as traced on plastic sheets by Andrew Grebneff during preparation in 1996. The skeleton (from the skull to lumbar vertebrae) is not articulated, but most of the elements (include both scapulae and mandible, and a digit close to the scapula) are near to original positions in the $2 \mathrm{~m}$ long limestone field block. Such semi-articulated specimens are not reported commonly (Kellogg, 1925; Lancaster, 1986; Fordyce and de Muizon, 2001). In contrast to the inferred preservation of $O$. huata, Schäfer and Craig (1972) noted that marine mammal carcasses may "drift for weeks on the surface of the sea," with parts such as the mandibles and skull lost (dropped) from the trunk early on. Such preservation has been noted in previous studies (Bianucci et al., 2010; Boessenecker, 2013).

The carcass sank to the sea floor with little loss of bones, presumably shortly after death. The lack of bedding in the limestone suggests that traction currents were weak, but water movement may have sufficed to move a carcass made almost buoyant by decomposition gas. Immediately postmortem, the rostrum and mandible were broken off, filled by matrix, and scattered along with small bone fragments. A rib and left forelimb elements lay close to the skull. Bioturbators probably were invertebrates, such as burrowing crustaceans, with additional movement from scavengers such as bony fish and chondrichthyans. Most damage probably occurred before full burial, but some bioerosion could have been infaunal. The braincase was also filled by matrix with well-preserved shells. Molluscan scars include inferred homing marks from limpets such as Crepidula and Sigapatella. Figure 22 shows some of the large shells around the dolphin carcass. Traces of bioactivity on bone surface include some bite marks, albeit not abun- 

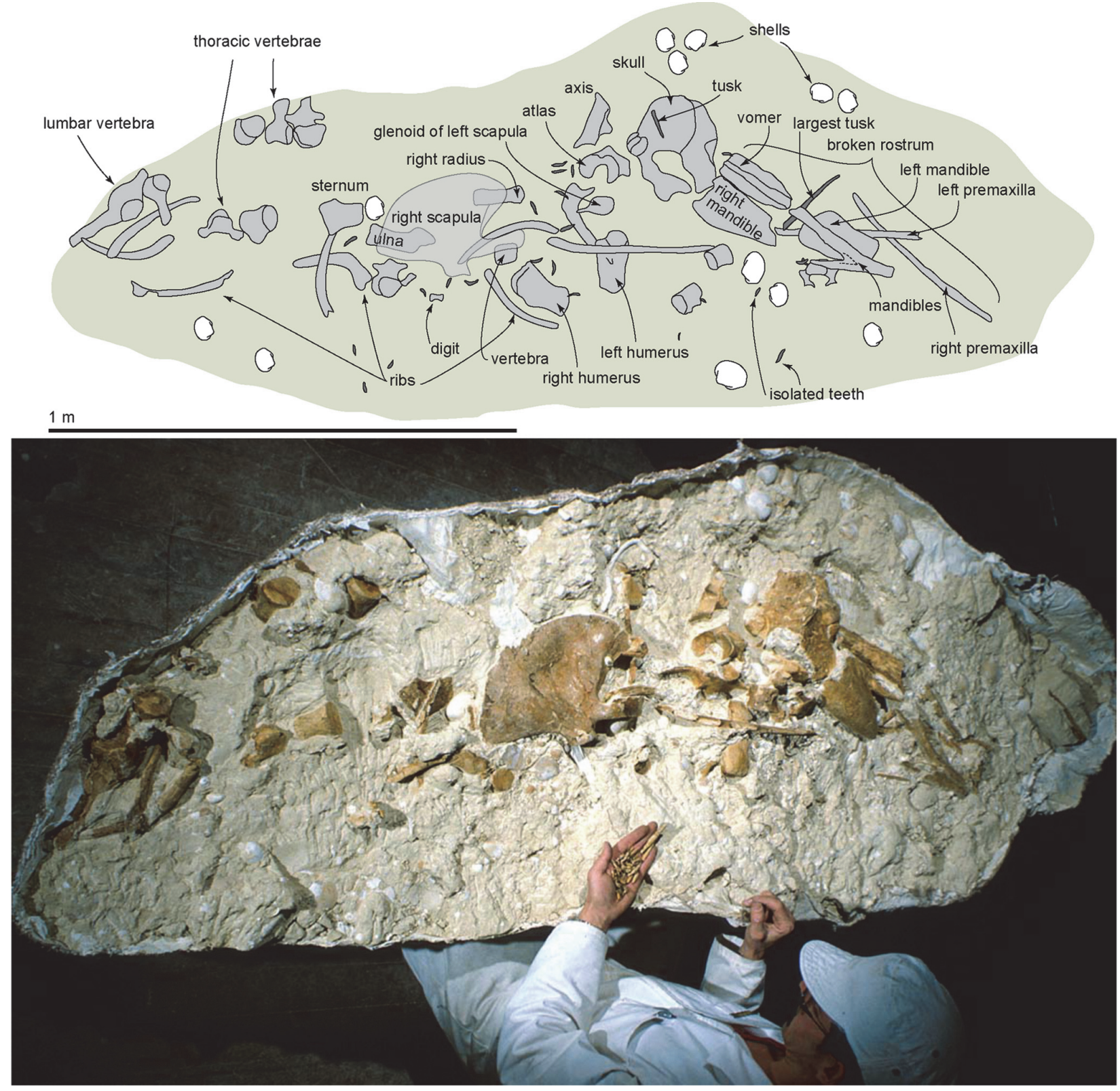

FIGURE 23. The original distribution of type elements, OU 22306, Otekaikea huata. Top, line art based on tracing of bone outlines as uncovered during preparation. Bottom, partly prepared field jacket with bones partly exposed. Andrew Grebneff is holding loose teeth. Photo @ R. Ewan Fordyce.

dant (Figure 14.4). There is no sign of death from predation. The skeleton was slightly scattered by bioturbation and scavenging before burial.

\section{CONCLUSION}

The archaic dolphin Otekaikea huata (Otekaike Limestone, Oligo/Miocene boundary), from Hakataramea Valley, South Canterbury, New Zealand, is described as a new species of Otekaikea. The single known specimen adds to odontocete structural and taxonomic diversity during the Waitakian Stage, latest Oligocene to earliest Miocene (22.28 to $24.61 \mathrm{Ma}$ ) in the Southwest Pacific Ocean. Otekaikea huata and other dolphins from the Oligocene of New Zealand ( $O$. marplesi and Waipatia maerewhenua) were at least $2.6 \mathrm{~m}$ long. The type specimen of Otekaikea huata preserves at least one large tusk and an elevated face for the nasofacial muscles implicated in production of echolocation sounds. New terms for skull features are: the anterolateral process of the nasal and the intra-premaxillary foramen. The phy- 
logenetic analyses based on morphological features place Otekaikea huata as a near-basal member of the clade Platanistoidea. The new species implies wider diversity of the superfamily Platanistoidea in latest Oligocene time.

\section{ACKNOWLEDGEMENTS}

We thank many who helped in diverse ways. The late A. Grebneff (University of Otago) prepared the type specimen, with later preparation by S.E. White, R.E. Fordyce, and Y. Tanaka. In the field, A. Grebneff, B.V.N. Black, and O. Sarll (all University of Otago) helped R.E. Fordyce recover the specimen. The management of Foveran Station and Waitaki Transport (the then-owners and operators, respectively, of Hakataramea Quarry) granted access and permission to collect. D.A. Teagle (University of Southampton) graciously provided the strontium date. M. Murakami (Waseda University), G. Aguirre-Fernandez (University of Otago) and F.G. Marx (National Museum of Nature and Science) discussed phylogenetics. S.E. White (University of Otago) discussed possible Maori names for the fossil. We particularly thank the two journal peer-reviewers, J. H. Geisler and O. Lambert, for their constructive comments that helped improve the manuscript. J. Galkin (American Museum of Natural History), M.A. Reguero (Museo de La Plata), T.K. Yamada (National Museum of Nature and Science), and D.J. Bohaska and N.D. Pyenson (National Museum of Natural History) provided access to comparative specimens. Field and lab work was supported with research funds from the National Geographic Society (grants 4024-88 and 4341-90 to R.E. Fordyce) and the Department of Geology, University of Otago.

\section{REFERENCES}

Abel, O. 1905. Les odontocètes du Boldérien (Miocène supérieur) d'Anvers. Mémoires du Musée royal d'Histoire Naturelle de Belgique, 3:1-155.

Abel, O. 1914. Die Vorfahren der Bartenwale. Denkschriften der Akademie der Wissenschaften, Wien, Mathematisch-naturwissenschaftliche Klasse, 90:155-224.

Aguirre-Fernández, G. and Fordyce, R.E. 2014. Papahu taitapu, gen. et sp. nov., an early Miocene stem odontocete (Cetacea) from New Zealand. Journal of Vertebrate Paleontology, 34(1):195-210.
Aguirre-Fernández, G., Barnes, L.G., Aranda-Manteca, F.J., and Fernández-Rivera, J.R. 2009. Protoglobicephala mexicana, a new genus and species of Pliocene fossil dolphin (Cetacea; Odontoceti; Delphinidae) from the Gulf of California, Mexico. Boletin de la Sociedad Geologica Mexicana, 61(2):245-265.

Allen, G.M. 1921. A new fossil cetacean. Bulletin of the Museum of Comparative Zoology, Harvard, 65(1):114.

Allen, G.M. 1923. The black finless porpoise, Meomeris. Bulletin of the Museum of Comparative Zoology, 65(7):233-256.

Anderson, J. 1878. Anatomical and zoological researches: Comprising an account of the zoological results of the two expeditions to Western Yunnan in 1868 and 1875; and a monograph on the two cetacean genera, Platanista and Orcella. 2 vols. B. Quaritch, London.

Arnold, P.W. and Heinsohn, G.E. 1996. Phylogenetic status of the Irrawaddy dolphin Orcaella brevirostris (Owen in Gray): a cladistic analysis. Memoirs of the Queensland Museum, 39(2):141-204.

Ayress, M.A. 1993. Ostracod biostratigraphy and paleoecology of the Kokoamu Greensand and Otekaike Limestone (late Oligocene to early Miocene), North Otago and South Canterbury, New Zealand. Alcheringa, 17(1-2):125-151.

Ayress, M. and Swanson, K. 1992. New genera and species of Ostracoda (Crustacea) from the Cenozoic of South Island, New Zealand. New Zealand Natural Sciences, 18:1-18.

Barnes, L.G. 1984a. Fossil odontocetes (Mammalia: Cetacea) from the Almejas Formation, Isla Cedros, Mexico. Paleobios, 42:1-46.

Barnes, L.G. 1984b. Whales, dolphins and porpoises; origin and evolution of the Cetacea. In Gingerich, P.D. and Badgle, C.E. (eds.), Mammals. Notes for a short course, University of Tennessee, Department of Geological Science.

Barnes, L.G. 1985a. Evolution, taxonomy and antitropical distributions of the porpoises (Phocoenidae, Mammalia). Marine Mammal Science, 1(2):149-165.

Barnes, L.G. 1985b. Fossil pontoporiid dolphins (Mammalia: Cetacea) from the Pacific coast of North America. Contributions to Science, Natural History Museum of Los Angeles County, 363:1-34.

Barnes, L.G. 1990. The fossil record and evolutionary relationships of the genus Tursiops, p. 3-26. In Leatherwood, S. and Reeves, R.R. (eds.), The Bottlenose Dolphin. Academic Press Inc, San Diego, New York.

Barnes, L.G. 2008. Miocene and Pliocene Albireonidae (Cetacea, Odontoceti), rare and unusual fossil dolphins from the eastern North Pacific Ocean. Geology and Vertebrate Paleontology of Western and Southern North America, Contributions in Honor of David P. Whistler. Natural History Museum of Los Angeles County Science Series, 41:99-152. 
Bianucci, G. 2005. Arimidelphis sorbinii a new small killer whale-like dolphin from the Pliocene of Marecchia River (Central eastern Italy) and a phylogenetic analysis of the Orcininae (Cetacea: Odontoceti). Rivista Italiana di Paleontologia e Stratigrafia, 111(2):329344.

Bianucci, G., Lambert, O., and Post, K. 2010. High concentration of long-snouted beaked whales (genus Messapicetus) from the Miocene of Peru. Palaeontology, 53(5):1077-1098.

Bianucci, G., Urbina, M., and Lambert, O. 2014. A new record of Notocetus vanbenedeni (Squalodelphinidae, Odontoceti, Cetacea) from the Early Miocene of Peru. Comptes Rendus Palevol, 14(1):5-13.

Bianucci, G., Lambert, O., Salas-Gismondi, R., Tejada, J., Pujos, F., Urbina, M., and Antoine, P.-O. 2013. A Miocene relative of the Ganges River dolphin (Odontoceti, Platanistidae) from the Amazonian Basin. Journal of Vertebrate Paleontology, 33(3):741-745.

Boessenecker, R.W. 2013. A new marine vertebrate assemblage from the Late Neogene Purisima Formation in Central California, part II: Pinnipeds and Cetaceans. Geodiversitas, 35(4):815-940.

Bremer, K. 1994. Branch support and tree stability. Cladistics, 10(3):295-304.

Brisson, A. 1762. Regnum Animale in Classes IX distributum sive synopsis methodica. Edito altero auctior, Theodorum Haak, Leiden.

Brownell, R.L., Findley, L.T., Vidal, O., Robles, A., and Silvia Manzanilla, N. 1987. External morphology and pigmentation of the vaquita, Phocoena sinus (Cetacea: Mammalia). Marine Mammal Science, 3(1):2230.

Cotten, P.B., Piscitelli, M.A., McLellan, W.A., Rommel, S.A., Dearolf, J.L., and Pabst, D. 2008. The gross morphology and histochemistry of respiratory muscles in bottlenose dolphins, Tursiops truncatus. Journal of Morphology, 269(12):1520-1538.

Cranford, T.W., Amundin, M., and Norris, K.S. 1996. Functional morphology and homology in the odontocete nasal complex: implications for sound generation. Journal of Morphology, 228(3):223-285.

Curry, B.E. 1992. Facial anatomy and potential function of facial structures for sound production in the harbor porpoise (Phocoena phocoena) and Dall's porpoise (Phocoenoides dalli). Canadian Journal of Zoology, 70(11):2103-2114.

de Muizon, C. 1983. Pliopontos littoralis un nouveau Platanistidae (Cetacea) du Pliocène de la côte péruvienne. Comptes Rendus de l'Académie des Sciences Paris, 296:625-628.

de Muizon, C. 1984. Les vertébrés fossiles de la Formation Pisco (Pérou). deuxiéme partie: les Odontocétes (Cetacea, Mammalia) du Pliocéne inférieur de SudSacaco. Travaux de l'Institut Français d'Études Andines, 27:1-188 de Muizon, C. 1985. Nouvelles données sur le diphylétisme des Dauphins de rivière (Odontoceti, Cetacea, Mammalia). Comptes rendus l'Academie des Sciences series 2, 301:359-362.

de Muizon, C. 1987. The affinities of Notocetus vanbenedeni, an Early Miocene platanistoid (Cetacea, Mammalia) from Patagonia, southern Argentina. American Museum novitates, 2904:1-27.

de Muizon, C. 1988. Les relations phylogenetiques des Delphinida (Cetacea, mammalia). Annales de paléontologie, 74(4):159-227.

de Muizon, C. 1991. A new Ziphiidae (Cetacea) from the Early Miocene of Washington State (USA) and phylogenetic analysis of the major groups of odontocetes. Bulletin du Muséum National d'Histoire Naturelle, 12(3-4):279-326.

de Muizon, C. 1994. Are the squalodonts related to the platanistoids? Proceedings of the San Diego Society of Natural History, 29:135-146.

de Muizon, C. and Domning, D.P. 2002. The anatomy of Odobenocetops (Delphinoidea, Mammalia), the walrus-like dolphin from the Pliocene of Peru and its palaeobiological implications. Zoological Journal of the Linnean Society, 134(4):423-452.

de Muizon, C., Domning, D.P., and Ketten, D.R. 2002. Odobenocetops peruvianus, the walrus-convergent delphinoid (Mammalia: Cetacea) from the Early Pliocene of Peru. Smithsonian Contributions to Paleobiology, 93:223-261.

de Smet, W.M.A. 1977. The regions of the cetacean vertebral column volume 3, p. 59-80. In Harrison, R.J. (ed.), Functional Anatomy of Marine Mammals. Academic Press, London.

Dickson, M.R. 1964. The skull and other remains of Prosqualodon marplesi, a new species of fossil whale. New Zealand Journal of Geology and Geophysics, 7(3):626-635.

Doran, A.H. 1878. Morphology of the mammalian ossicula auditus. Transactions of the Linnaean Society, Series 2, Zoology, 1(18):371-497.

Dubrovo, I.A. and Sanders, A.E. 2000. A new species of Patriocetus (Mammalia, Cetacea) from the late Oligocene of Kazakhstan. Journal of Vertebrate Paleontology, 20:577-590.

Dubrovo, I. and Sharkov, A. 1971. Kit iz verkhnego Oligotsena Mangyshlaka [A whale from the Upper Oligocene of Mangyshlak]. Doklady Akademia Nauk SSSR, 194(6):1403-1406.

Evans, H.E. and de Lahunta, A. 2013. Miller's anatomy of the dog. Elsevier, St. Louis, Missouri.

Fajardo-Mellor, L., Berta, A., Brownell, R.L., Boy, C.C., and Goodall, N.P. 2006. The phylogenetic relationships and biogeography of true porpoises (Mammalia: Phocoenidae) based on morphological data. Marine Mammal Science, 22(4):910-932. 
Flower, W.H. 1867. Description of the skeleton of Inia geoffrensis and the skull of Pontoporia blainvillii, with remarks on the systematic position of these animals in the Order Cetacea. Transactions of the Zoological Society of London, 6(3):87-116.

Flower, W.H. 1868. On the osteology of the cachalot or sperm-whale (Physeter macrocephalus). Transactions of the Zoological Society of London, 6(6):309372.

Flower, W.H. 1872. On the recent ziphioid whales, with a description of the skeleton of Berardius arnouxi. Transactions of the Zoological Society of London, 8(3):203-234.

Flower, W.H. 1884. On the characters and divisions of the Family Delphinidae. Proceedings of the Zoological Society of London, 1883:466-513.

Flower, W.H. 1885a. An introduction to the osteology of the Mammalia. Macmillan and Co., London.

Flower, W.H. 1885b. List of the specimens of Cetacea in the Zoological Department of the British Museum. British Museum, London.

Flynn, T.T. 1948. Description of Prosqualodon davidi Flynn, a fossil cetacean from Tasmania. Transactions of the Zoological Society of London, 26(2):153-197.

Fordyce, R.E. 1981. Systematics of the odontocete whale Agorophius pygmaeus and the Family Agorophiidae (Mammalia, Cetacea). Journal of Paleontology, 55(5):1028-1045.

Fordyce, R.E. 1994. Waipatia maerewhenua, new genus and new species (Waipatiidae, new family), an archaic Late Oligocene dolphin (Cetacea: Odontoceti: Platanistoidea) from New Zealand. Proceedings of the San Diego Society of Natural History, 29:147176.

Fordyce, R.E. 2002. Simocetus rayi (Odontoceti: Simocetidae, new family): A bizarre new archaic Oligocene dolphin from the eastern North Pacific. Smithsonian Contributions to Paleobiology, 93:185222.

Fordyce, R.E. 2003. New Oligocene dalpiazinids from the Waitaki region: increasing the diversity of platanistoid dolphins. Geological Society of New Zealand miscellaneous publication, 116a:53.

Fordyce, R.E. 2009. Fossil sites, p. 459-466. In Perrin, W.F., Thewissen, J.G.M., and Würsig, B. (eds.), Encyclopedia of Marine Mammals. Elsevier, San Diego.

Fordyce, R.E. 2014. A southern view of Oligocene marine tetrapods: Kokamu Greensand and Otekaike Limestone, Hakataramea Valley, New Zealand. Abstracts, Secondary Adaptations of Tetrapods to Life in the Water 7th triennial meeting, George Mason University, Virginia, June 2014:http:// events2.gmu.edu/secad2014/category/abstracts/.

Fordyce, R.E., Aguirre-Fernandez, G., Loch, C., and Tanaka, Y. 2013. Tusks in extinct Oligocene dolphins: feeding, display, agonism, or sensory? Abstracts, 20th Biennial Conference on the Biology of Marine Mammals 2013 (Society for Marine Mammalogy):71.
Fordyce, R.E., and de Muizon, C. 2001. Evolutionary history of whales: a review, p. 169-234. In Mazin, J.-M. and de Buffrenil, V. (eds.), Secondary Adaptation of Tetrapods to Life in Water. Pfeil, München, Germany.

Fordyce, R.E. and Jones, C.M. 1990. The history of penguins, and new fossil penguin material from New Zealand, p. 419-446. In Davis, L.S. and Darby, J.D. (eds.), Penguin Biology. Academic Press, San Diego.

Fordyce, R.E. and Maxwell, P.A. 2003. Canterbury Basin paleontology and stratigraphy (Field trip 8, Annual Conference, Geological Society of New Zealand). Geological Society of New Zealand miscellaneous publication, $116 \mathrm{~b}(4): 1-18$.

Fordyce, R.E., Quilty, P.G., and Daniels, J. 2002. Australodelphis mirus, a bizarre new toothless ziphild-like fossil dolphin (Cetacea : Delphinidae) from the Pliocene of Vestfold Hills, East Antarctica. Antarctic Science, 14(1):37-54.

Fraser, F.C. and Purves, P.E. 1960. Hearing in cetaceans: evolution of the accessory air sacs and the structure of the outer and middle ear in recent cetaceans. Bulletin of the British Museum of Natural History (Zoology) 7:1-140.

Gage, M. 1957. The geology of Waitaki subdivision. New Zealand Geological Survey Bulletin, 55:1-135.

Geisler, J.H., Colbert, M.W., and Carew, J.L. 2014. A new fossil species supports an early origin for toothed whale echolocation. Nature, 508(7496):383386.

Geisler, J.H., Godfrey, S.J., and Lambert, O. 2012. A new genus and species of late Miocene inioid (Cetacea, Odontoceti) from the Meherrin River, North Carolina, USA. Journal of Vertebrate Paleontology, 32(1):198-211.

Geisler, J.H. and Luo, Z. 1996. The petrosal and inner ear of Herpetocetus sp.(Mammalia: Cetacea) and their implications for the phylogeny and hearing of archaic mysticetes. Journal of Paleontology 70:10451066.

Geisler, J.H., McGowen, M.R., Yang, G., and Gatesy, J. 2011. A supermatrix analysis of genomic, morphological, and paleontological data from crown Cetacea. BMC Evolutionary Biology, 11:1-33.

Geisler, J.H. and Sanders, A.E. 2003. Morphological evidence for the phylogeny of Cetacea. Journal of Mammalian Evolution, 10(1/2):23-129.

Geisler, J.H., Sanders, A.E., and Luo, Z.-X. 2005. A new protocetid whale (Cetacea: Archaeoceti) from the late middle Eocene of South Carolina. American Museum Novitates, 3480:1-68.

Godfrey, S.J. 2013. On the olfactory apparatus in the Miocene odontocete Squalodon sp. (Squalodontidae). Comptes Rendus Palevol, 12(7):519-530.

Goloboff, P.A., Farris, J.S., and Nixon, K.C. 2008. TNT, a free program for phylogenetic analysis. Cladistics, 24(5):774-786. 
Gottfried, M.D., Fordyce, R.E., and Rust, S. 2012. A new billfish (Perciformes, Xiphioidei) from the late Oligocene of New Zealand. Journal of Vertebrate Paleontology, 32(1):27-34.

Graham, I.J., Morgans, H.E.G., Waghorn, D.B., Trotter, J.A., and Whitford, D.J. 2000. Strontium isotope stratigraphy of the Oligocene-Miocene Otekaike Limestone (Trig $Z$ section) in southern New Zealand: age of the Duntroonian/Waitakian Stage boundary. New Zealand Journal of Geology and Geophysics, 43(3):335-347.

Gray, J.E. 1863. On the arrangement of the cetaceans. Proceedings of the Scientific Meetings of the Zoological Society of London, 3:197-202.

Gutstein, C.S., Figueroa-Bravo, C.P., Pyenson, N.D., Yury-Yañez, R.E., Cozzuol, M.A., and Canals, M. 2014. High frequency echolocation, ear morphology, and the marine-freshwater transition: A comparative study of extant and extinct toothed whales. Palaeogeography, Palaeoclimatology, Palaeoecology, 400:62-74.

Heyning, J.E. 1989. Comparative facial anatomy of beaked whales (Ziphiidae) and a systematic revision among the families of extant Odontoceti. Contributions in Science, Natural History Museum of Los Angeles County, 405:1-64.

Heyning, J.E. 1997. Sperm whale phylogeny revisited: analysis of the morphological evidence. Marine Mammal Science, 13(4):596-613.

Howell, A.B. 1927. Contribution to the anatomy of the Chinese finless porpoise Neomeris phocaenoides. Proceedings of The United States National Museum, 70(13):1-43.

Howell, A.B. 1930. Myology of the narwhal (Monodon monoceros). American Journal of Anatomy, 46(2):187-215.

Hulbert Jr., R.C., Petkewich, R.M., Bishop, G.A., Bukry, D., and Aleshire, D.P. 1998. A new middle Eocene protocetid whale (Mammalia: Cetacea: Archaeoceti) and associated biota from Georgia. Journal of Paleontology, 72(5):907-927.

Ichishima, H. 2011. Do cetaceans have the mesethmoid? Memoir of the Fukui Prefectural Dinosaur Museum, 10:63-75.

Ichishima, H. and Kimura, M. 2005. Haborophocoena toyoshimai, a new Early Pliocene porpoise (Cetacea; Phocoenidae) from Hokkaido, Japan. Journal of Vertebrate Paleontology, 25(3):655-664.

International Commission of Zoological Nomenclature 1999. International code of zoological nomenclature. International Trust for Zoological Nomenclature London, UK.

Jefferson, T.A. and Newcomer, M.W. 1993. Lissodelphis borealis. Mammalian Species, 425:1-6.

Jefferson, T.A., Webber, M.A., and Pitman, R.L. 2008. Marine Mammals of the World: A Comprehensive Guide to Their Identification. Academic Press, Oxford, UK.
Jenkins, D.G. 1965. Planktonic foraminiferal zones and new taxa from the Danian to Lower Miocene of New Zealand. New Zealand Journal of Geology and Geophysics, 8(6):1088-1126.

Kasuya, T. 1973. Systematic consideration of recent toothed whales based on the morphology of tympano-periotic bone. Scientific Reports of the Whales Research Institute, Tokyo, 25:1-103.

Kellogg, R. 1923. Description of an apparently new toothed cetacean from South Carolina. Smithsonian Miscellaneous Collections, 76:1-7.

Kellogg, R. 1925. Additions to the Tertiary history of the pelagic mammals on the Pacific coast of North America. Proceedings of the U.S. National Museum, 66(26):1-40.

Kellogg, A.R. 1926. Supplementary observations on the skull of the fossil porpoise Zarhachis flagellator. Proceedings of the U.S. National Museum, 67(28):1-18.

Kellogg, R. 1927. Kentriodon pernix, a Miocene porpoise from Maryland. Proceedings of the United States National Museum, 69(19):1-14.

Kellogg, R. 1936. A review of the Archaeoceti. Carnegie Institution of Washington publication, 482:1-366.

Kellogg, R. 1957. Two additional Miocene porpoises from the Calvert Cliffs, Maryland. Proceedings of the U.S. National Museum, 107(3387):279-337.

Klima, M., Oelschlaeger, H.A., and Wünsch, D. 1980. Morphology of the pectoral girdle in the Amazon dolphin Inia geoffrensis with special reference to the shoulder joint and the movements of the flippers. Zeitschrift Saugertierkunde, 45:288-309.

Kuzmin, A.A. 1976. Embryogenesis of the osseous skull of the sperm whale (Physeter macrocephalus Linnaeus, 1758). Investigations on Cetacea, 7:187-202.

Lambert, O. 2005. Phylogenetic affinities of the longsnouted dolphin Eurhinodelphis (Cetacea, Odontoceti) from the Miocene of Antwerp, Belgium. Palaeontology, 48(3):653-679.

Lambert, O. 2008. A new porpoise (Cetacea, Odontoceti, Phocoenidae) from the Pliocene of the North Sea. Journal of Vertebrate Paleontology, 28(3):863-872.

Lambert, O., Bianucci, G., and de Muizon, C. 2008. A new stem-sperm whale (Cetacea, Odontoceti, Physeteroidea) from the latest Miocene of Peru. Comptes Rendus Palevol, 7(6):361-369.

Lambert, O., Bianucci, G., and Post, K. 2010. Tusk-bearing beaked whales from the Miocene of Peru: sexual dimorphism in fossil ziphiids? Journal of Mammalogy, 91(1):19-26.

Lambert, O., Bianucci, G., and Urbina, M. 2014. Huaridelphis raimondii, a new early Miocene Squalodelphinidae (Cetacea, Odontoceti) from the Chilcatay Formation, Peru. Journal of Vertebrate Paleontology, 34(5):987-1004.

Lambert, O. and Post, K. 2005. First European pontoporiid dolphins (Mammalia: Cetacea, Odontoceti) from the Miocene of Belgium and The Netherlands. Deinsea, 11:7-20. 
Lancaster, W. 1986. The taphonomy of an archaeocete skeleton and its associated fauna. Gulf Coast Association of Geological Societies publication, 119:119131.

Leatherwood, S., Reeves, R.R., and Foster, L. 1983. Sierra Club handbook of whales and dolphins. Sierra Club Books, San Francisco.

Loch, C., Kieser, J.A., and Fordyce, R.E. 2015. Enamel Ultrastructure in Fossil Cetaceans (Cetacea: Archaeoceti and Odontoceti). PLoS ONE, 10(1):e0116557.

Luo, Z. and Marsh, K. 1996. Petrosal (periotic) and inner ear of a Pliocene kogiine whale (Kogiinae, Odontoceti): implications on relationships and hearing evolution of toothed whales. Journal of Vertebrate Paleontology, 16(2):328-348.

Maddison, W.P. and Maddison, D.R. 2011. Mesquite: a modular system for evolutionary analysis. Available at http://mesquiteproject.org.

Marsh, H., Lloze, R., Heinsohn, G.E., and Kasuya, T. 1989. Irrawaddy dolphin - Orcaella brevirostris, (Gray, 1866), p. 101-118. In Ridgway, S.H., and Harrison, S. (eds.), Handbook of marine mammals. Volume 4: river dolphins and the larger toothed whales. Academic Press, London.

McArthur, J.M., Howarth, R.J., and Shields, G.A. 2012. Chapter 7 - Strontium isotope stratigraphy, p. 127144. In Gradstein, F.M., Ogg, J.G., Schmitz, M., and Ogg, G. (eds.), The Geologic Time Scale. Elsevier, Boston.

Mead, J.G. 1975. Anatomy of the external nasal passages and facial complex in the Delphinidae (Mammalia, Cetacea). Smithsonian Contributions to Zoology, 207:1-72.

Mead, J. 1989. Shepherd's beaked whale Tasmacetus shepherdi Oliver, 1937. In Ridgway, S.H., and Harrison, S. (eds.), Handbook of marine mammals. Volume 4: river dolphins and the larger toothed whales. Academic Press, London.

Mead, J.G., and Fordyce, R.E. 2009. The therian skull: a lexicon with emphasis on the odontocetes. Smithsonian Contributions to Zoology, 627:1-248.

Mellor, L., Cooper, L.N., Torre, J., and Brownell, R.L., Jr. 2009. Paedomorphic ossification in porpoises with an emphasis on the Vaquita (Phocoena sinus). Aquatic Mammals, 35(2):193-202.

Messenger, S. 1994. Phylogenetic relationships of platanistoid river dolphins (Odontoceti, Cetacea): assessing the significance of fossil taxa. Contributions in Marine Mammal Paleontology Honoring Frank Whitmore Jr.Proceedings of the San Diego Society of Natural History:125-133.

Messenger, S.L. and McGuire, J.A. 1998. Morphology, molecules, and the phylogenetics of cetaceans. Systematic Biology, 47(1):90-124.

Miller, G.S. 1918. A new river-dolphin from China. Smithsonian Miscellaneous Collections, 68(9):1-12.

Miller, G.S. 1923. The telescoping of the cetacean skull. Smithsonian Miscellaneous Collections, 76(5):1-70.
Moore, J.C. 1968. Relationships among the living genera of beaked whales with classifications, diagnoses and keys. Fieldiana: Zoology, 53(4):509-598.

Murakami, M., Shimada, C., Hikida, Y., and Hirano, H. 2012a. A new basal porpoise, Pterophocaena nishinoi (Cetacea, Odontoceti, Delphinoidea), from the upper Miocene of Japan and its phylogenetic relationships. Journal of Vertebrate Paleontology, 32(5):1157-1171.

Murakami, M., Shimada, C., Hikida, Y., and Hirano, H. 2012b. Two new extinct basal phocoenids (Cetacea, Odontoceti, Delphinoidea), from the upper Miocene Koetoi Formation of Japan and their phylogenetic significance. Journal of Vertebrate Paleontology, 32(5):1172-1185.

Murakami, M., Shimada, C., Hikida, Y., Soeda, Y., and Hirano, H. 2014. Eodelphis kabatensis, a new name for the oldest true dolphin Stenella kabatensis Horikawa, 1977 (Cetacea, Odontoceti, Delphinidae), from the upper Miocene of Japan, and the phylogeny and paleobiogeography of Delphinoidea. Journal of Vertebrate Paleontology, 34(3):491-511.

Noble, B. and Fraser, F. 1971. Description of a skeleton and supplementary notes on the skull of a rare porpoise Phocoena sinus Norris \& McFarland 1958. Journal of Natural History, 5(4):447-464.

Norris, K.S. 1964. Some problems of echolocation in cetaceans, p. 317-336. In Tavolga, W.N. (ed.), Marine bio-acoustics. MacMillan, New York.

Norris, K.S. and Harvey, G.W. 1972. A theory for the function of the spermaceti organ of the sperm whale (Physeter catodon L). NASA Special Publication, 262:397.

Nweeia, M.T., Eichmiller, F.C., Hauschka, P.V., Tyler, E., Mead, J.G., Potter, C.W., Angnatsiak, D.P., Richard, P.R., Orr, J.R., and Black, S.R. 2012. Vestigial tooth anatomy and tusk nomenclature for Monodon monoceros. The Anatomical Record, 295(6):10061016.

Perrin, W.F. 1975. Variation of spotted and spinner porpoise (Genus, Stenella) in the eastern Pacific and Hawaii. Bulletin of the Scripps Institution of Oceanography, 21:1-206.

Pyenson, N.D. and Sponberg, S.N. 2011. Reconstructing body size in extinct crown Cetacea (Neoceti) using allometry, phylogenetic methods and tests from the fossil record. Journal of Mammalian Evolution, 18(4):269-288.

Reeves, R., Stewart, B., Clapham, P., and Powell, J. 2002. Marine mammals of the world. Chanticleer Press, Inc, New York.

Reidenberg, J.S. and Laitman, J.T. 1994. Anatomy of the hyoid apparatus in Odontoceti (toothed whales): Specializations of their skeleton and musculature compared with those of terrestrial mammals. The Anatomical Record, 240(4):598-624.

Rice, D.W. and Wolman, A.A. 1990. The stomach of Kogia breviceps. Journal of Mammalogy, 71:237242. 
Rommel, S. 1990. Osteology of the bottlenose dolphin, p. 29-49. In Leatherwood, S. and Reeves, R.R. (eds.), The Bottlenose Dolphin. Academic Press Inc, San Diego, New York.

Sanders, A.E. and Barnes, L.G. 2002. Paleontology of the late Oligocene Ashley and Chandler Bridge formations of South Carolina, 2: Micromysticetus rothauseni, a primitive cetotheriid mysticete (Mammalia: Cetacea). Smithsonian Contributions to Paleobiology, 93:271-293.

Schäfer, W. and Craig, G.Y. 1972. Ecology and palaeoecology of marine environments. Oliver and Boyd, Edinburgh.

Schenkkan, E. 1971. The occurrence and position of the "connecting sac" in the nasal tract complex of small odontocetes (Mammalia, Cetacea). Beaufortia, 19(246):37-43.

Schulte, W. 1916. Anatomy of a foetus of Balaenoptera borealis. Memoirs of the American Museum of Natural History, 1(6):389-502.

Schulte, H.v.W. 1917. The skull of Kogia breviceps Blainv. Bulletin of the American Museum of Natural History, 37:361-404.

Schulte, H.v.W. and Smith, M.D.F. 1918. The external characters, skeletal muscles, and peripheral nerves of Kogia breviceps (Blainville). Bulletin American Museum of Natural History, 38:7-72.

Simpson, G.G. 1945. The principles of classification and a classification of mammals. Bulletin of the American Museum of Natural History, 85:1-350.

Smith, G., Browne, K., and Gaskin, D. 1976. Functional myology of the harbour porpoise, Phocoena phocoena (L.). Canadian Journal of Zoology, 54(5):716729.

Steeman, M.E., Hebsgaard, M.B., Fordyce, R.E., Ho, S.Y.W., Rabosky, D.L., Nielsen, R., Rahbek, C., Glenner, H., Sørensen, M.V., and Willerslev, E. 2009. Radiation of extant cetaceans driven by restructuring of the oceans. Systematic Biology, 58(6):573-585.

Strickler, T.L. 1978. Myology of the shoulder of Pontoporia blainvillei, including a review of the literature on shoulder morphology in the Cetacea. American Journal of Anatomy, 152(3):419-431.

Struthers, J. 1872. On the cervical vertebrae and their articulations in Fin-whales. Journal of Anatomy and Physiology, 7:1-55.

Tanaka, Y. and Fordyce, R.E. 2014. Fossil dolphin Otekaikea marplesi (latest Oligocene, New Zealand) expands the morphological and taxonomic diversity of Oligocene cetaceans. PLoS ONE, 9(9):e107972.
True, F.W. 1904. The whalebone whales of the western North Atlantic compared with those occurring in European waters with some observations on the species of the North Pacific. Smithson Contribution to Knowledge, 33:1-332.

True, F.W. 1912. Description of a New Fossil Porpoise of the Genus Delphinodon from the Miocene Formation of Maryland. Journal of the Academy of Natural Sciences of Philadelphia, 2:165-194.

Uhen, M.D. 2008. A new Xenorophus - like odontocete cetacean from the Oligocene of North Carolina and a discussion of the basal odontocete radiation. Journal of Systematic Palaeontology, 6(4):433-452.

Van Valen, L. 1968. Monophyly or diphyly in the origin of whales. Evolution, 22:37-41.

Vandenberghe, N., Hilgen, F.J., Speijer, R.P., Ogg, J.G., Gradstein, F.M., Hammer, O., Hollis, C.J., and Hooker, J.J. 2012. Chapter 28 - The Paleogene Period, p. 855-921. In Gradstein, F.M., Ogg, J.G., Schmitz, M., and Ogg, G. (eds.), The Geologic Time Scale. Elsevier, Boston.

Vélez-Juarbe, J. and Pyenson, N.D. 2012. Bohaskaia monodontoides, a new monodontid (Cetacea, Odontoceti, Delphinoidea) from the Pliocene of the western North Atlantic Ocean. Journal of Vertebrate Paleontology, 32(2):476-484.

Whitmore, F.C. and Sanders, A.E. 1977. Review of the Oligocene Cetacea. Systematic Zoology, 25(4):304320.

Wilson, L.E. 1973. A delphinid (Mammalia, Cetacea) from the Miocene of Palos Verdes Hills, California. University of California, Publications in Geological Sciences, 103:1-34.

Yablokov, A. 1964. Convergence or parallelism in the evolution of cetaceans. International Geology Review, 7(8):1461-1468.

Yamada, M. 1953. Contribution to the anatomy of the organ of hearing of whales. Scientific Reports of the Whales Research Institute Tokyo, 8:1-79.

Zhou, K. 1982. Classification and phylogeny of the superfamily Platanistoidea, with notes on evidence of the monophyly of the Cetacea. Scientific Reports of the Whales Research Institute Tokyo, 34: 93-108.

Zhou, K., Qian, W., and Li, Y. 1979. Recent advances in the study of the baiji, Lipotes vexillifer. J. Nanjing Normal College (Natural Science), 1:8-13. 


\section{APPENDIX 1, 2 AND 3.}

1. Cladistic matrix in nexus format.

2. Cladistic matrix in TNT format.

3.Cladistic matrix in TXT format.

Files for Appendixes 1-3 are available in one zipped file online at palaeo-electronica.org/content/2015/ 1161-fossil-platanistoid-dolphin. 


\section{APPENDIX 4.}

Morphological characters used in the phylogenetic analysis.

Terminology generally follows that of the cladistic papers cited, which in a few cases does not agree with the recommended uses of Mead and Fordyce (2009). For each character, references are given for the main past uses, with the relevant published character number given with a hatch \# thus: Murakami et al. (2012a) \#1.

\section{Rostrum, Dental, and Mandibular}

(1) Length of rostrum as percent skull length: moderately long, $50-55 \%$ (0); long, $55-60 \%$ (1); very long, $>60 \%$ (2); medium, $50-40 \%$ (3); very short, $40-35 \%$ (4). (Murakami et al. (2012a, 2012b) \#1; modified from Arnold and Heinsohn (1996) \#8; Bianucci (2005) \#1; Lambert (2008) \#1).

(2) Premaxillae transverse proportion: transversely inflated almost entire length of rostrum (0); flat almost entire length of the rostrum (1). (Murakami et al. (2012a, 2012b) \#2).

(3) Premaxillae mediolateral proportion: not compressed mediolaterally (0); compressed mediolaterally at anterior of rostrum (1). (Murakami et al. (2012a, 2012b) \#3).

(4) Premaxillae at apex of rostrum: with lateral margins parallel or diverging (0); narrowing (1). (Murakami et al. (2012a, 2012b) \#4; modified from Bianucci (2005) \#2).

(5) Maxilla length as percent rostrum length: short, $<85 \%$, tips of maxillae not reaching tip of rostrum, (0); long, $>89 \%$, tips of maxillae to within $10 \%$ of rostrum tip (1); same as state 1 except lack of alveoli (2). (Murakami et al. (2012a, 2012b) \#5; modified from Lambert (2005) \#1).

(6) Mesorostral groove: V-shaped or U-shaped opening (0); partially or completely filled in with vomer, becoming a solid rod of bone (1); absent (2). (Messenger and McGuire (1998) \#1429; Geisler and Sanders (2003) \#5; Geisler et al. (2011, 2012) \#5; Murakami et al. (2012a, 2012b) \#6; derived from Moore (1968)).

(7) Mesorostral groove constricted posteriorly, anterior to the nares and behind the level of the antorbital notch, then rapidly diverging anteriorly: absent (0); present (1). (modified from Murakami et al. (2012b) \#279).
(8) Lateral margin of rostrum anterior to maxillary flange: concave (0); straight (1); convex (2); absent (3) (Murakami et al. (2012a, 2012b) \#7; modified from Bianucci (2005) \#3).

(9) Rostral constriction: absent (0); constriction anterior to antorbital notch (1); constriction anterior to maxillary flange (2). (Murakami et al. (2012a, 2012b) \#8; modified from de Muizon (1984); Barnes (1985b); Messenger and McGuire (1998) \#1424; Geisler and Sanders (2003) \#6; Geisler et al. (2011, 2012) \#6).

(10) Antorbital notch: absent or weakly developed (0); well developed (1). (Messenger and McGuire (1998) \#1426; Fajardo-Mellor et al. (2006) \#6; Murakami et al. (2012a, 2012b) \#9).

(11) Width of premaxillae at mid-rostrum as percent greatest width of maxillae at level of postorbital processes: wide, $>25 \%(0)$; medium, 25-15\% (1); narrow, <15\% (2). (Murakami et al. (2012a, 2012b) \#10; modified from Aguirre-Fernández et al. (2009) \#4) If the supraorbital process of the maxilla does not reach above the postorbital process, then the width is measured as a percent of the frontal width, excluding the postorbital process at the postorbital line.

(12) Width of rostrum at mid-length as percent greatest width of maxillae at level of postorbital processes: wide, $>35 \%(0)$; medium, 35-30\% (1); narrow, $<30 \%$ (2). (Murakami et al. (2012a, 2012b) \#11; modified from Aguirre- Fernández et al. (2009) \#6).

(13) Width of rostrum at antorbital notch as percent greatest width of maxillae at level of postorbital processes: wide, $>68 \%(0)$; medium, 68-45\% (1); narrow, <45\% (2). (Murakami et al. (2012a, 2012b) \#12; modified from Geisler and Sanders (2003) \#7; Geisler et al. (2011, 2012) \#7).

(14) Premaxillae in dorsal view: contacting along midline for less than half length of rostrum (0); widely separated by mesorostral groove in rostrum (1); narrowly separated by mesorostral groove in rostrum (2); contacting along midline for approximately half the entire length or more than of rostrum 
but not fused (3); contacting along midline for approximately half the entire length or more than of rostrum and partially fused (4); converging (either contacting and separating) in mid-rostrum (5). (modified from Murakami et al. (2012a, 2012b) \#13; modified from de Muizon (1988); Fordyce (1994) \#52; Messenger and McGuire (1998) \#1405; Geisler and Sanders (2003) (9); Geisler et al. $(2011,2012)$ \#9).

(15) Suture between maxilla and premaxilla on rostrum: unfused except distal tip of rostrum (0); fused partly or along most of rostrum (1). (Murakami et al. (2012a, 2012b) \#14; modified from Fordyce (1994) \#36; Messenger and McGuire (1998) \#1418; Geisler and Sanders (2003) \#10; Lambert (2005) \#2; Geisler et al. (2011, 2012) \#10).

(16) Posterior wall of antorbital notch: maxilla (0); lacrimal and jugal, or maxilla appeared in small area posterior to antorbital notch parallel with lacrimal and jugal (1); no notch but horizontal groove inferred to be for the facial nerve in the maxilla laterally on the face well above the margin of the rostrum (2). (Murakami et al. (2012a, 2012b) \#15; modified from Geisler and Sanders (2003) (15); Geisler et al. (2011, 2012) \#15).

(17) Vomer anterior to maxilla-palatine suture in ventral view: not exposed (0); width of vomer $<10 \%$ length of vomer, (1); vomer width ratio $>10 \%$ vomer length (2). (Messenger and McGuire (1998) \#1428; Murakami et al. (2012a, 2012b) \#16; derived from Zhou (1982).

(18) Anterior sinus fossa: absent (0); between anterior extremity of pterygoid sinus and posterior extremity of upper tooth row (1); between posterior extremity of upper tooth row and midpoint of rostrum (2); beyond midpoint of rostrum (3). (Murakami et al. (2012a, 2012b) \#17; modified from de Muizon (1988); Barnes (1990); Bianucci (2005) \#13; Arnold and Heinsohn (1996) \#21; Geisler and Sanders (2003) \#157; Aguirre-Fernández et al. (2009) \#18; Geisler et al. (2011, 2012) \#157; derived from Fraser and Purves (1960)).

\section{Teeth}

(19) Number of double-rooted teeth in maxilla: 6-8 (0); 0 (1). (modified from Geisler and
Sanders (2003) \#23; Geisler et al. (2011, 2012) \#23; Murakami et al. (2012a, 2012b) \#18).

(20) Tooth enamel: reticulating striae (0); smooth (1); nodular (2); absent (3). (Murakami et al. (2012a, 2012b) \#20; modified from Messenger and McGuire (1998) \#1469; Geisler and Sanders (2003) \#26; Geisler et al. $(2011,2012)$ \#26; derived from Zhou (1982)).

(21) Teeth: heterodont and some teeth with denticle (0); conical, with or without accessory cusp (1); spatulate (2); laterally compressed (3). (Murakami et al. (2012a, 2012b) \#21; modified from Heyning (1989) \#40; Heyning (1997) \#72; Arnold and Heinsohn (1996) \#25; Messenger and McGuire (1998) \#1470; Geisler and Sanders (2003) \#27; Geisler et al. (2011, 2012) \#27; Lambert (2008) \#16; derived from Barnes (1984a)).

(22) Upper anterior "teeth": about same size as upper posterior teeth (0); greatly enlarged (1); clearly smaller than upper posterior teeth or absent (2). (modified from Murakami et al. (2012a, 2012b) \#22).

(23) Cheek teeth ectocingulum: present (0); absent (1). (Murakami et al. (2012a, 2012b) \#23; modified from Geisler and Sanders (2003) \#31; Geisler et al. (2011, 2012) \#31).

(24) Cheek teeth entocingulum: present (0); absent (1). (Geisler and Sanders (2003) \#32; Geisler et al. (2011, 2012) \#32; Murakami et al. (2012a, 2012b) \#24).

(25) Greatest diameter of largest functional tooth as percent of greatest width of maxillae at the level of the postorbital processes: large, >5\% (0); medium, 5-3\% (1); small, $<3 \%$ (2). (Murakami et al. (2012a, 2012b) \#25; modified from Aguirre-Fernández et al. (2009) \#15).

\section{Mandible}

(26) Anterior mandibular teeth: deeply rooted, root $>50 \%$ of tooth (0); not deeply rooted, root $<50 \%$ of tooth (1). (Messenger and McGuire (1998) \#1471; Geisler and Sanders (2003) \#28; Geisler et al. (2011, 2012) \#28; Murakami et al. (2012a, 2012b) \#26; derived from Flower (1872); Moore (1968)).

(27) Anterior-most mandibular "tooth": about same size as posterior teeth (0); smaller than 
posterior teeth (1); greatly enlarged (2); forming a tusk (3). (Murakami et al. (2012a, 2012b) \#27; modified from de Muizon (1991); Geisler and Sanders (2003) \#36; Messenger and McGuire (1998) \#1477; Geisler et al. $(2011,2012)$ \#36; derived from Flower (1872)).

(28) Number of teeth in mandible: 16-11 (0); 9-8 (1); 2 (2); 1 (3); 17-23 (4); 24-27 (5); 2839 (6); >40 (7). (Murakami et al. (2012a) \#28; modified from Messenger and McGuire (1998) \#1468; Geisler and Sanders (2003) \#37; Geisler et al. $(2011,2012)$ \#37).

(29) Length of mandibular symphysis as percent of mandible length: long, $>20 \%$ (0); short, $<20 \%$ (1). (Murakami et al. (2012a, 2012b) \#29; modified from Messenger and McGuire (1998) \#1465; Arnold and Heinsohn (1996) \#7; Bianucci (2005) \#26).

(30) Mandibular symphysis: sutured but unfused (0); fused (1). (Fordyce (1994) \#5; Messenger and McGuire (1998) \#1466; Geisler and Sanders (2003) \#40; Geisler et al. $(2011,2012)$ \#40; Murakami et al. (2012a, 2012b) \#30; derived from Flower (1885b)).

(31) Longitudinal groove on underside of mandibles: absent (0); present (1). (Geisler and Sanders (2003) \#41; Geisler et al. (2011, 2012) \#41; Murakami et al. (2012a, 2012b) \#31; derived from Miller (1923)).

(32) Mandible: bowed medially (0); straight (1); slightly bowed laterally (2). (Sanders and Barnes (2002); Geisler and Sanders (2003) \#42; Geisler et al. (2011, 2012) \#42; Murakami et al. (2012a, 2012b) \#32; derived from Miller (1923)).

(33) Elevation of coronoid process: very high (0); moderate (1); low (2). (Murakami et al. (2012a, 2012b) \#33; modified from Geisler and Sanders (2003) \#44; Bianucci (2005) \#27; Geisler et al $(2011,2012)$ \#44).

\section{Orbit}

(34) Antorbital process of maxilla in from dorsal view: triangular (0); robust and globose or rectilinear (1); absent (2). (Bianucci (2005) \#4; Murakami et al. (2012a, 2012b) \#34).

(35) Angle of anterior edge of supraorbital process and the median line: oriented slightly anterolaterally, at an angle $<30^{\circ}( \pm)$ with sagittal plane $(0)$ oriented anteromedially (1). (Murakami et al. (2012a, 2012b) \#35; modified from Geisler and Sanders (2003) \#49; Geisler et al. (2011, 2012) \#49).

(36) Ratio of length of antorbital process of lacrimal to length of the orbit: $<0.6(0)$; $\geq 0.6$ (1). (Murakami et al. (2012a, 2012b) \#36).

(37) Lacrimal: wrapping around anterior edge of supraorbital process of frontal and slightly overlying its anterior end (0); appearing dorsally and forming most of antorbital process (1); appearing dorsally but not prominently in antorbital process (2); restricted to below the supraorbital process of maxilla (3). (Murakami et al. (2012a, 2012b) \#37; modified from Geisler and Sanders (2003) \#51; Geisler et al. (2011, 2012) \#51; derived from Kellogg (1923); Miller (1923)).

(38) Lacrimal foramen or groove: present (0); absent (1). (Geisler and Sanders (2003) \#52; Geisler et al. $(2011,2012)$ \#52; Murakami et al. (2012a, 2012b) \#38).

(39) Lacrimal and jugal: separated (0); fused (1). (Heyning (1989) \#7; Heyning (1997) \#39; Geisler and Sanders (2003) \#53; Geisler et al. $(2011,2012)$ \#53; Murakami et al. (2012a, 2012b) \#39; derived from Flower (1868); Schulte (1917); Miller (1923)).

(40) Lacrimal and jugal: contacting each other externally (0); lacrimal excluded from edge of skull, jugal directly contacting anterior edge of frontal (1). (Geisler and Sanders (2003) \#54; Geisler et al. (2011, 2012) \#54; Murakami et al. (2012a, 2012b) \#40; derived from Miller (1923)).

(41) Jugal: thick and sturdy (0); thin, splint, or absent (1). (Geisler and Sanders (2003) \#56; Lambert (2005) \#21; Geisler et al. (2011, 2012) \#56; Murakami et al. (2012a, 2012b) \#41; derived from Miller (1923); Barnes (1990)).

(42) Combined anteroposterior length of the lacrimal and jugal exposure that is posterior to antorbital notch: With skull in ventral view, exposure is small and combined length forms $<50 \%$ of anteroposterior distance from antorbital notch to postorbital ridge (0); intermediate, forms between 50 and $62 \%$ of that distance (1); large, forms between 62 and $69 \%$ that distance (2); very large, forms $>69 \%$ of that distance (3). (Murakami et al. (2012a, 2012b) \#42; modified from Geisler and Sanders (2003) \#55; Geisler et al. (2011, 2012) \#55). 
(43) Dorsolateral edge of internal opening of infraorbital foramen: formed by maxilla (0); formed by maxilla and lacrimal and/or jugal (I); formed by lacrimal and/or jugal (2); formed by frontal (3). (Geisler and Sanders (2003) \#57; Geisler et al. $(2011,2012)$ \#57; Murakami et al. (2012a, 2012b) \#43; derived from Miller (1923)).

(44) Ventromedial edge of internal opening of infraorbital foramen: formed by maxilla (0); formed by maxilla and palatine and/or pterygoid (1); formed by palatine and/or pterygoid (2). (Geisler and Sanders (2003) \#58; Geisler et al. (2011, 2012) \#58; Murakami et al. (2012a, 2012b) \#44; derived from Miller (1923)).

(45) Maxillary tuberosity: present (0); absent (1). (Geisler and Sanders (2003) \#59; Geisler et al. (2011) \#59; Geisler et al. (2012) \#59; modified from Murakami et al. (2012a) \#45; derived from Miller (1923)).

(46) Direction of apex of postorbital process of frontal: projected posterolaterally and slightly ventrally (0); directed ventrally (1); not clear because of extremely reduced process (2). (modified from Murakami et al. (2012a, 2012b) \#46; Geisler and Sanders (2003) \#61; Geisler et al. (2011, 2012) \#61).

(47) Shape of postorbital process of frontal: robust, blunt descending posteriorly (0); pointed, attenuated, or acute triangular (1); triangular, trapezoidal, or an anteroposteriorly widened falciform (2); dorsoventrally long falciform (3). (modified from Murakami et al. (2012a, 2012b) \#47).

(48) Frontal-maxilla suture angled posterodorsally at an angle of $50-70^{\circ}( \pm)$ from axis of rostrum, with lateral exposure of frontal thickening posteriorly: absent (0); present (1). (Geisler and Sanders (2003) \#48; Geisler et al. $(2011,2012)$ \#48; Murakami et al. (2012a, 2012b) \#48; derived from Miller (1923)).

\section{Facial Region}

(49) Anterior dorsal infraorbital foramina: one (0); two (1); three or more (2). (Murakami et al. (2012a, 2012b) \#49; modified from Barnes (1984b); Geisler and Sanders (2003) \#64; Geisler et al. (2011, 2012) \#64).

(50) Rostral basin: absent or poorly defined (0); present, situated medial to antorbital notch and anterior to supraorbital process of frontal (1). (Geisler and Sanders (2003) \#65; Geisler et al. (2011, 2012) \#50; Murakami et al. (2012a, 2012b) \#50).

(51) Width of premaxillae at antorbital notches as percent width of rostrum at antorbital notch: narrow, $<49 \%(0)$; moderate, 50 $64 \%$ (1); wide, $>65 \%$ (2); antorbital notch absent (3). (Geisler and Sanders (2003) \#66; Geisler et al. $(2011,2012)$ \#66; modified from Murakami et al. (2012a, 2012b) \#51).

(52) Premaxillary foramina: absent (0); one on right side (1); two on right side (2); three on right side (3). (Geisler and Sanders (2003) \#69; Geisler et al. (2011, 2012) \#69; Murakami et al. (2012a, 2012b) \#52; derived from Barnes (1990)).

(53) Size of premaxillary foramen: right and left subequal (0); right much larger than left (1); premaxillary foramen absent (2). (Messenger and McGuire (1998) \#1415; Murakami et al. (2012a, 2012b) \#53; modified from Geisler and Sanders (2003) \#70; Geisler et al. (2011, 2012) \#70).

(54) Position of premaxillary foramen: anterior of antorbital notch and anterior edge of supraorbital process (0); approximately medial to or posterior to antorbital notch region (1); premaxillary foramen absent (2). (Geisler and Sanders (2003) \#71; Geisler et al. (2011, 2012) \#71; Murakami et al. (2012a, 2012b) \#54).

(55) Premaxillary foramen locating: medial (0); midpoint to lateral (1) absent (2). (modified from Murakami et al. (2012b) \#280).

(56) Lateral margin of the right premaxilla posterior to premaxillary foramen: widen posteriorly (0); straight (1). (Murakami et al. (2012b) \#281).

(57) Posterolateral sulcus: deep (0); shallow or absent (1); presence of additional posterolateral sulcus (longitudinal striation) (2). (Murakami et al. (2012a, 2012b) \#55; modified from de Muizon (1984, 1988); Lambert (2008) \#6; Geisler and Sanders (2003) \#72; Geisler et al. $(2011,2012)$ \#72).

(58) Posterior projections of premaxillae: both premaxillae extending posterior to anterior tip of nasals (0); both premaxillae extending posterior to nasals (1); only right premaxil- 
lae extended posterior to nasal (2); neither premaxillae extending posterior to external nares, and narrow posterior end of premaxillae adjacent to external nares (3); neither premaxillae extending beyond external nares, and premaxillae displaced laterally by medial projection of maxilla (4); only right premaxilla extending beyond or in line with anterior-most portion of nasals (5). (Murakami et al. (2012a, 2012b) \#76; modified from de Muizon (1984); Barnes (1985a); Heyning (1989) \#39, 42; Heyning (1997) \#63, 71, 74; Arnold and Heinsohn (1996) \#35; Messenger and McGuire (1998) \#1407, 1408; Fajardo-Mellor et al. (2006) \#3; Lambert (2008) \#5; Fordyce (1994) \#27).

(59) Posterior dorsal infraorbital foramina of maxilla: absent (0); one (1); two or more (2); (Murakami et al. (2012a, 2012b) \#57; modified from Barnes (1990); Geisler and Sanders (2003) \#75; Geisler et al. $(2011,2012)$ \#75).

(60) A posterior dorsal infraorbital foramen placed posteromedially, near posterior extremity of premaxilla: absent (0); present (1). (Fordyce (1994) \#62; Lambert (2005) \#13; Murakami et al. (2012a, 2012b) \#58).

(61) Premaxillary sac fossae: absent (0); present (1). (Messenger and McGuire (1998) \#1411; Lambert (2005) \#4; Murakami et al. (2012a, 2012b) \#59).

(62) Maxilla on dorsal surface of skull: does not contact supraoccipital posteriorly, maxilla separated by frontal and/or parietal (0); contact present (1). (Geisler and Sanders (2003) \#129; Geisler et al. (2011, 2012) \#129, modified from de Muizon (1991, 1994); Murakami et al. (2012a, 2012b) \#60).

(63) Maxillae at anterior edge of supraorbital processes: abutting anterior edge of supraorbital processes of frontals (0); covering partially or almost completely surface of supraorbital processes (1). (Murakami et al. (2012a, 2012b) \#61; modified from Fordyce (1994) \#3; Messenger and McGuire (1998) \#1419; Geisler and Sanders (2003) \#76; Geisler et al. $(2011,2012)$ \#76; derived from Miller (1923)).

(64) Anterolateral corner of maxilla overlying supraorbital process of frontal: thin and equal in thickness to parts posteromedial
(0); thickened with thinner maxilla in posteromedial direction (1). (Geisler and Sanders (2003) \#78; Geisler et al. (2011, 2012) \#78; Murakami et al. (2012a, 2012b) \#62).

(65) Pneumatic maxillary crest overhanging medially: absent (0); present (1). (Zhou (1982); Heyning (1989) \#26; Heyning (1997) \#58; Fordyce (1994) \#66; Arnold and Heinsohn (1996) \#14; Messenger and McGuire (1998) \#1421; Murakami et al. (2012a, 2012b) \#63).

(66) Maxillary crest on supraorbital process of maxilla: longitudinal ridges absent except at lateral edge of antorbital process (0); presence of longitudinal ridge except at lateral edge of antorbital process (1); longitudinal ridge present and joined with maxillary flange (2); presence of transversely compressed high crest, except at lateral edge of antorbital process (3); absent (4). (Murakami et al. (2012a, 2012b) \#64; modified from de Muizon (1984, 1987); Barnes (1985b); Messenger and McGuire (1998) \#1420; Geisler and Sanders (2003) \#79; Geisler et al. (2011, 2012) \#79; derived from Miller (1923)).

(67) Anterior edge of nasals: anterior to, or in line with, anterior edges of supraorbital processes of frontals (0); posterior to anterior edges of supraorbital processes of frontals (1). (Murakami et al. (2012a, 2012b) \#65; modified from Geisler and Sanders (2003) \#80; Geisler et al. (2011, 2012) \#80).

(68) Premaxillae in dorsal view: separated anterior to bony nares, exposing mesethmoid (0); joined premaxillae (or maxillae) closing at least posterior part of mesorostral groove (1). (Lambert (2005) \#3; Murakami et al. (2012a, 2012b) \#66).

(69) Anterior edge of bony nares: inverted Vshaped, premaxillae gradually converging anteriorly to midline (0); inverted $\mathrm{U}$ shaped, premaxillae abruptly converging anteriorly to midline (1). (de Muizon (1988); Geisler and Sanders (2003) \#81; Geisler et al. (2011, 2012) \#81; Murakami et al. (2012a, 2012b) \#67).

(70) Fossa for inferior vestibule on maxilla lateral to external nares or lateral to premaxilla: absent (0); present (1). (de Muizon (1988); Murakami et al. (2012a, 2012b) \#68; derived from Curry (1992)). 
(71) Maxillary intrusion, anterior to external nares and encroaching the posteromedial or medial face of each premaxilla: absent (0); maxilla visible within opened mesorostral canal as small exposure medially (1); exposure of maxilla reaches dorsally to level of premaxilla and forms a square, rectangular to triangular plate (2); exposure of maxilla reaches dorsally and forms a small subcircular to polygonal ossicle (3). (de Muizon (1984, 1988); Arnold and Heinsohn (1996) \#24; Messenger and McGuire (1998) \#1422; Murakami et al. (2012a, 2012b) \#69).

(72) Premaxillary crest or posterior maxillary crest adjacent to nasal: absent (0); present (1). (transverse premaxillary crest, sensu Lambert (2005) \#6; Murakami et al. (2012a, 2012b) \#70).

(73) Premaxilla: not overhanging itself or maxilla laterally (0); overhanging itself or maxilla laterally, from anterior to midpoint of external nares (1). (Murakami et al. (2012a, 2012b) \#71).

(74) Premaxillary sac fossa: smooth (0); rugose (1). (Messenger and McGuire (1998) \#1551; Murakami et al. (2012a, 2012b) \#72).

(75) Ratio of width of right premaxilla to width of left premaxilla in line with midpoint of external nares: $0.90-1.19(0) ; 1.20-1.50(1) ; 1.50>$ (2). (Murakami et al. (2012a, 2012b) \#73).

(76) Ratio of greatest width of premaxillae to greatest width of maxillae at level of postorbital processes: $\geq 0.50(0) ; 0.49-0.38(1) ;<0.38$ (2). (Murakami et al. (2012a, 2012b) \#74).

(77) Premaxillary eminence: absent (0); present but low (1); present and high (2). (Lambert (2008) \#4; Murakami et al. (2012a, 2012b) \#75; modified from de Muizon (1984); Barnes (1985a); Heyning (1989) \#36; Heyning (1997) \#68; Arnold and Heinsohn (1996) \#12; Messenger and McGuire (1998) \#1410; Geisler and Sanders (2003); \#68; Fajardo-Mellor et al. (2006) \#2; Geisler et al. (2011) \#68; Geisler et al. (2012) \#69; derived from Flower (1867); Noble and Fraser (1971)).

(78) Right premaxilla: portion anterior to nasal opening wider than portion posterior to opening, with nasal septum angled anteriorly and to left (0); portion posterior to nasal opening wider than portion anterior to opening, with nasal septum angled anteriorly and to right (1). (modified from Geisler and Sanders (2003); \#86; Geisler et al. $(2011,2012)$ \#86; Murakami et al. (2012a, 2012b) \#77).

(79) Left bony naris: same size or slightly larger than right bony naris (0); at least twice the size of right bony naris (1). (Barnes (1990); Geisler and Sanders (2003) \#87; Geisler et al. $(2011,2012)$ \#87; Murakami et al. (2012a, 2012b) \#78).

(80) Supracranial basin: absent (0); present (1). (Heyning (1989) \#8; Heyning (1997) \#40; Fordyce (1994) \#18; Messenger and McGuire (1998) \#1400; Geisler and Sanders (2003) \#88; Lambert (2005) \#10; Geisler et al. (2011, 2012) \#88; Murakami et al. (2012a, 2012b) \#79).

(81) Proximal ethmoid region: not visible in dorsal view, roofed over by nasals (0); exposed dorsally (1). (Messenger and McGuire (1998) \#1455; Geisler and Sanders (2003) \#92; Geisler et al. (2011, 2012) \#92; Murakami et al. (2012a, 2012b) \#80; derived from Miller (1923)).

(82) Mesethmoid: not expanded posterodorsally (0); extended posterodorsally but narrow (1); expanded posterodorsally and visible in lateral view (2). (Murakami et al. (2012a, 2012b) \#81; modified from de Muizon (1984, 1988); Messenger and McGuire (1998) \#1454; Bianucci (2005) \#9).

\section{Vertex and Area Adjacent to the Nares}

(83) Inflections of ascending processes of premaxillae: gradual (0); vertical (1). (Geisler and Sanders (2003) \#107; Geisler et al. (2011, 2012) \#107; modified from Murakami et al. (2012a, 2012b) \#82; derived from Fordyce (1994)).

(84) Inflections of premaxillae just anterior to, or in line with, anterior edge of supraorbital processes of frontals: absent (0); present (1) (Murakami et al. (2012a, 2012b) \#83; modified from Geisler and Sanders (2003) \#108; Geisler et al. $(2011,2012)$ \#108).

(85) Premaxillary cleft: absent (0); present, posterior part of ascending processes of premaxillae bearing a distinct cleft, originating at posterior edge of premaxillae and continuing anteriorly, dividing each premaxilla into two (1); present, with shallow cleft (2). (Geisler and Sanders (2003) \#109; Geisler 
et al. (2011, 2012) \#109; Murakami et al. (2012a, 2012b) \#84).

(86) Nasal bones: two (0); one or zero (1). (Heyning (1989) \#9; Heyning (1997) \#41; Murakami et al. (2012a, 2012b) \#85; modified from Messenger and McGuire, (1998) \#1431; Geisler and Sanders (2003) \#113; Geisler et al. (2011, 2012) \#113; derived from Kuzmin (1976)).

(87) Nasals: lower than frontals (0); nearly same height as frontals (1); clearly higher than frontals (2). (de Muizon (1988); Messenger and McGuire (1998) \#1434; Geisler and Sanders (2003); \#124; Geisler et al. (2011, 2012) \#124; Murakami et al. (2012a) \#86).

(88) Nasal protuberance: absent (0); present (1). (de Muizon (1988); Messenger and McGuire (1998) \#1433; Fajardo-Mellor et al. (2006) \#7; Lambert (2008) \#8; Murakami et al. (2012a, 2012b) \#87).

(89) Both nasals: straight anterior edges in one transverse plane (0); with point on midline and gap on each side between premaxilla and nasal (1); concave posteriorly on midline and gap on each side between premaxilla and nasal (2); concave posteriorly on midline (3). (Murakami et al. (2012a, 2012b) \#88; modified from Geisler and Sanders (2003) \#116; Geisler et al. (2011, 2012) \#116; derived from Moore (1968)).

(90) Nasals: fossae on nasals absent (0); smoothsurfaced fossa on anterior to anterolateral surface (1). (Messenger and McGuire (1998) \#1437; Murakami et al. (2012a, 2012b) \#89).

(91) Transverse width of either of nasals as percent maximum length of nasals: very narrow, $<20 \%$ (0); narrow, 21-69\% (1); wide, $>70 \%$ (2). (Murakami et al. (2012a) \#90; modified from de Muizon (1988); Messenger and McGuire (1998) \#1432; Geisler and Sanders (2003); \#119; Geisler et al. (2011, 2012) \#119).

(92) Nasals: medial portions roughly in same horizontal plane as, or higher than, lateral portions (0); medial portions depressed, forming a median trough immediately posterior to nasal openings (1). (de Muizon (1988, 1991); Geisler and Sanders (2003); \#118; Geisler et al. (2011, 2012) \#118; Murakami et al. (2012a, 2012b) \#91).
(93) Lateral edges of nasals: not overhanging or covering maxillae or premaxillae (0); overhanging or partly covering maxillae or premaxillae (1). (Murakami et al. (2012a, 2012b) \#92).

(94) Nasal-frontal suture: approximately straight transversely (0); anterior wedge (narial process) between frontal posterior ends of nasals (1); $W$ or reversed $U$ suture line (2). (Murakami et al. (2012a, 2012b) \#93; modified from de Muizon (1988); Geisler and Sanders (2003) \#121; Geisler et al. (2011, 2012) \#121).

(95) Frontals posterior to nasals and between premaxillae: wider than maximum transverse width across nasals (0); same as transverse width of nasals (1); narrower than transverse width of nasals, maxillae expanded medially posterior to nasals (2). (Geisler and Sanders (2003) \#125; Geisler et al. $(2011,2012) \# 125$; Murakami et al. (2012a, 2012b) \#94; modified from Messenger and McGuire (1998) \#1457).

(96) Frontal boss on vertex: absent (0); present (1). (de Muizon (1984, 1988); Messenger and McGuire (1998) \#1461; Fajardo-Mellor et al. (2006) \#12; Murakami et al. (2012a, 2012b) \#95; modified from Lambert (2008) \#9).

(97) Vertex: absent (0); present (1); highly developed (2). (Murakami et al. (2012a) \#96; de Muizon (1991); Messenger and McGuire (1998) \#1404; Lambert (2005) \#7).

(98) Cranial vertex skewed asymmetrically to left side: absent (0); present (1). (Barnes (1990); Bianucci (2005) \#7; AguirreFernández et al. (2009) \#18; Murakami et al. (2012a, 2012b) \#97).

(99) Anterodorsal wall of braincase: formed by frontals (0); mostly formed by maxillae (1). (Geisler and Sanders (2003) \#127; Geisler et al. $(2011,2012) \# 127$; Murakami et al. (2012a, 2012b) \#98; derived from Schulte (1917); Miller (1923)).

(100) Nuchal crest: higher than frontals and/or nasals (0); at same level as frontals and/or nasals (1); below frontals and/or nasals (2). (Murakami et al. (2012a, 2012b) \#99; modified from Geisler and Sanders (2003) \#128; derived from Moore (1968)). 


\section{Temporal Fossae, Zygomatic Arch, and} Occipitals

(101) Temporal fossa: not roofed over by lateral expansion of maxillae (0); roofed over by lateral expansion of maxillae (1). (de Muizon (1988); Heyning (1989) \#22; Heyning (1997) \#54; Arnold and Heinsohn (1996) \#39; Messenger and McGuire (1998) $\# 1453$; Murakami et al. (2012a, 2012b) \#100).

(102) Roof of temporal fossa formed by: frontals (0); frontals, but with large opening through maxillae and/or premaxillae exposing margins of window formed by a frontal ring (1). (Geisler and Sanders (2003) \#132; Geisler et al. $(2011,2012) \# 132$; Murakami et al. (2012a, 2012b) \#101).

(103) Position and orientation of origin for temporal muscle on supraorbital process of frontal: origin laying on posterior face of supraorbital process and directed roughly posteriorly (0); origin lying on posteroventral face of supraorbital process and directed roughly ventrally (1). (Fordyce (1994) \#8; Lambert (2005) \#23; Murakami et al. (2012a, 2012b) \#102).

(104) Parietal dorsally: not fused to frontal or supraoccipital (0); completely fused to, and indistinguishable from, frontal or supraoccipital (1). (Murakami et al. (2012a, 2012b) \#103).

(105) Parietals in dorsal view: contacting each other on the midline or separated by interparietal (0); in skull roof but visible only as small triangular areas at edges of intertemporal constriction, with supraoccipital overlapping and obscuring median portions (1); completely absent in skull roof (2); visible only as triangular areas, dorsolateral to supraoccipital, with non-overlapping supraoccipital separated from and contacting parietals along irregular suture (3). (Geisler and Sanders (2003) \#134; Geisler et al. (2011, 2012) \#134; Murakami et al. (2012a, 2012b) \#104; derived from Whitmore and Sanders (1977); Barnes (1990); modified from Lambert (2005) \#15).

(106) Interparietal: present (0); absent or fused and therefore not distinguishable from parietals and frontals (1). (Geisler and Sanders (2003) \#135; Geisler et al. (2011, 2012) \#135; Murakami et al. (2012a) \#105).
(107) Sagittal crest for temporal muscle: present (0); absent (1). (Murakami et al. (2012a, 2012b) \#106; modified from Geisler and Sanders (2003) \#136; Geisler et al. (2011, 2012) \#136).

(108) Alisphenoid: broadly exposed laterally in temporal fossa (0); lateral surface broadly overlapped by parietal, with a narrow strip visible or invisible on ventral edge of temporal fossa in lateral view (1). (Geisler and Sanders (2003) \#141; Geisler et al. (2011, 2012) \#141; Murakami et al. (2012a) $\# 107)$.

(109) Zygomatic process of squamosal: directed anterolaterally (0); directed anteriorly (1). (Sanders and Barnes (2002); Geisler and Sanders (2003) \#142; Geisler et al. (2011, 2012) \#142; Murakami et al. (2012a, 2012b) \#108).

(110) Zygomatic process of squamosal in lateral view: part of dorsal face visible (0); entire dorsal surface of squamosal visible (1). (Murakami et al. (2012a, 2012b) \#109).

(111) Emargination of posterior edge of zygomatic process by neck muscle fossa, skull in lateral view: absent, posterior edge forming nearly right angle with dorsal edge of zygomatic process of squamosal (0); shallow emargination (1); deep emargination (2). (Geisler and Sanders (2003) \#144; Geisler et al. $(2011,2012) \# 144$; Murakami et al. (2012a, 2012b) \#110).

(112) Width of squamosal lateral to exoccipital as percent greatest width of exoccipitals, skull in posterior view: exposed portion of squamosal narrow, $<15 \%(0)$; moderate, $16-$ $35 \%$ (1). (modified from Geisler and Sanders (2003) \#145; Geisler et al. $(2011,2012)$ \#145; Murakami et al. (2012a, 2012b) \#111).

(113) Ventral edge of zygomatic process of squamosal in lateral view: concave (0); almost straight (1); convex (2). (Geisler and Sanders (2003); \#150; Geisler et al. (2011, 2012) \#150; Murakami et al. (2012a, 2012b) \#112).

(114) Postglenoid process of squamosal: not reduced (0); greatly reduced (1). (Murakami et al. (2012a, 2012b) \#113).

(115) Postglenoid process in lateral view: tapering ventrally (0); squared off ventrally (1); same as state 1 except very wide antero- 
posterior diameter of process (2). (Geisler and Sanders (2003) \#151; Lambert (2005) \#24; Geisler et al. $(2011,2012)$ \#151; Murakami et al. (2012a, 2012b) \#114; derived from de Muizon (1991)).

(116) Relative ventral projections of postglenoid and post-tympanic processes of squamosal: postglenoid process more ventral or at same level as post-tympanic process (0); apex of postglenoid process dorsally higher than post-tympanic process (1). (Lambert (2005) \#25; Murakami et al. (2012a). b \#115).

(117) Nuchal crest in dorsoposterior view: semicircular, pointed anteriorly (0); rectangular or weakly convex anteriorly or posteriorly (1); convex posteriorly and/or midpoint convex triangular and pointed anteriorly (2); prominently convex anteriorly (3); strongly convex posteriorly (4). (Murakami et al. (2012a, 2012b) \#116; modified from Geisler and Sanders (2003) \#152; Geisler et al. $(2011,2012)$ \#152; derived from Barnes (1985b)).

(118) Occipital shield: smoothly convex or concave (0); bearing distinct sagittal crest (1). (Sanders and Barnes (2002); Geisler and Sanders (2003) \#155; Geisler et al. (2011, 2012) \#155; Murakami et al. (2012a, 2012b) \#117).

(119) Dorsal condyloid fossa: absent (0); present, situated anterodorsal to dorsal edge of condyle (1); present and forming deep pit (2). (Geisler and Sanders (2003) \#156; Geisler et al. (2011, 2012) \#156; Murakami et al. (2012a, 2012b) \#118; derived from Sanders and Barnes (2002)).

\section{Anterior Basicranium}

(120) Palatine in nasal passage: thin, forming posterior part of nasal passage (0); thick, forming part of anterior wall of nasal cavities (1); palatine does not join anterior wall of nasal passage (2). (Murakami et al. (2012a, 2012b) \#119; modified from Geisler and Sanders (2003) \#158; Geisler et al. (2011, 2012) \#158; derived from Miller (1923)).

(121) Palatine exposure: exposed ventrally (0); partially covered by pterygoid, which divides it into medial and lateral exposures (1); ventral surfaces completely covered by pterygoids (2). (de Muizon (1987);
Arnold and Heinsohn (1996) \#15; Messenger and McGuire (1998) \#1440; Geisler and Sanders (2003) \#159; Lambert (2005) \#27; Geisler et al. $(2011,2012)$ \#159; Murakami et al. (2012a, 2012b) \#120; derived from Miller (1923)).

(122) Lateral lamina of palatine: absent (0); present (1). (de Muizon (1984, 1988, 1991); Arnold and Heinsohn (1996) \#16; Messenger and McGuire (1998) \#1443; Murakami et al. (2012a, 2012b) \#121).

(123) Lateral lamina of palatine: free from or sutured to maxilla (0); fused to maxilla (1). (de Muizon (1988); Messenger and McGuire (1998) \#1439; Geisler and Sanders (2003) \#161; Geisler et al. $(2011,2012)$ \#161; Murakami et al. (2012a, 2012b) \#122).

(124) Lateral lamina of palatine: does not form bony bridge "over" (= ventral to) orbit (0); does form bony bridge "over" (= ventral to) orbit (1). (de Muizon (1984); Messenger and McGuire (1998) \#1444; Murakami et al. (2012a, 2012b) \#123).

(125) Pterygoids in anteroventral view: separated from each other by posteroventrally elongated palatines and/or vomer (0); contacting entire length of hamular process (1); contacting each other partially (2). (Murakami et al. (2012a, 2012b) \#124; modified from Arnold and Heinsohn (1996) \#5; Messenger and McGuire (1998) \#1445; Fajardo-Mellor et al. (2006) \#9; derived from Flower (1884); Barnes (1985a); Marsh et al. (1989)).

(126) Medial pterygoid-palatine suture in ventral view: angled anteromedially (0); nearly transverse (1); angled anterolaterally (2); angled anteroposteriorly (3). (Murakami et al. (2012a, 2012b) \#125; modified from Geisler and Sanders (2003) \#162; Geisler et al. $(2011,2012) \# 162)$.

(127) Lateral lamina of pterygoid: absent (0); present and articulated with alisphenoid (1); partial, restricted to region lateral to hamular process (2). (Murakami et al. (2012a) \#126; modified from Arnold and Heinsohn (1996) \#121; Messenger and McGuire (1998) \#1446; Geisler and Sanders (2003) \#164; Lambert (2005) \#32; Geisler et al. (2011, 2012) \#164; derived from Miller (1923); Kellogg (1936); Fraser and Purves (1960)). 
(128) Subtemporal crest: present (0); present but reduced, or absent (1). (modified from Geisler and Sanders (2003) \#165; Geisler et al. $(2011,2012) \# 165$; Murakami et al. (2012a, 2012b) \#127).

(129) Superior lamina of pterygoid: absent from sphenoidal region but present in orbital region (0); present and covers most of ventral exposure of alisphenoid (1); partially absent from orbital region (2); completely absent from orbital region (3). (Murakami et al. (2012a, 2012b) \#128; modified from Arnold and Heinsohn (1996) \#16; Geisler and Sanders (2003) \#167; Geisler et al. (2011, 2012) \#167; derived from Miller (1923); Fraser and Purves (1960)).

(130) Pterygoids excavated anterior to choanae by the pterygoid sinuses, with distinct anterior fossa clearly limited forwards by rounded wall: absent (0); present (1). (Lambert (2005) \#28; Murakami et al. (2012a, 2012b) \#129).

(131) Depth of pterygoid sinus fossa in basicranium: shallow or partially excavated (0); deep, excavated dorsally to level of cranial foramen oval (1); deep, and extended dorsally into orbit (2). (modified from Fordyce (1994) \#6; Lambert (2005) \#30; Murakami et al. (2012a, 2012b) \#130).

(132) Anterior level of pterygoid sinus fossa: interrupted posterior to, or the level of, antorbital notch (0); extending beyond the level of the antorbital notch (1). (Lambert (2005) \#29; Murakami et al. (2012a, 2012b) $\# 131)$.

(133) Preorbital and postorbital fossae of pterygoid sinuses: widened apices of preorbital and postorbital fossae of pterygoid sinuses present but fossae not merged or fused (0); widened apices of preorbital and postorbital fossae of pterygoid sinuses merged or fused dorsal to path of optic nerve (1). (Murakami et al. (2012a, 2012b) \#132; modified from de Muizon (1988); Arnold and Heinsohn (1996) \#19; Bianucci (2005) \#10; Aguirre-Fernández et al. (2009) \#19).

(134) Fossa for preorbital lobe of pterygoid sinus in orbit: absent (0); present (1). (Fraser and Purves (1960); Arnold and Heinsohn (1996) \#18; Murakami et al. (2012a, 2012b) \#133).
(135) Dorsal development of fossa for preorbital lobe of pterygoid sinus toward the frontalmaxilla suture: absent (0); present (1). (de Muizon (1984, 1988); Heyning (1989) \#37; Heyning (1997) \#69; Messenger and McGuire (1998) \#1460; Arnold and Heinsohn (1996) \#20; Lambert (2008) \#13; Murakami et al. (2012a, 2012b) \#134; modified from Fajardo-Mellor et al. (2006) \#13; derived from Fraser and Purves (1960)).

(136) Postorbital lobe of pterygoid sinus fossa: absent (0); present (1). (Arnold and Heinsohn (1996) \#18; Geisler and Sanders (2003) \#170; Geisler et al. (2011, 2012) \#170; Murakami et al. (2012a, 2012b) $\# 135$; derived from Fraser and Purves (1960)).

(137) Anteroposteriorly elongated pterygoid sinus fossa, at level of orbit, bordered by mediolaterally compressed subtemporal crest of frontal: absent (0); present (1). (Murakami et al. (2012a, 2012b) \#136).

(138) Orbitosphenoid: not contacting lacrimal or lacrimojugal (0); contacting lacrimal or lacrimojugal (1). (Murakami et al. (2012a, 2012b) \#137).

(139) Ratio of length of hamular process of pterygoid to cranium length: $<0.30(0) ; 0.30-$ 0.44 (1); $0.45-0.59$ (2); >0.60 (3). The length of the hamular process of the pterygoid is measured from anterior edge of the pterygoid to posterior edge of the hamular process. The cranium length is measured from anterior edge of the antorbital process to posterior edge of occipital condyles. (Murakami et al. (2012a, 2012b) \#138; modified from Heyning (1989) \#18; Heyning (1997) \#50; de Muizon (1991); Messenger and McGuire (1998) \#1447; Lambert (2005) \#31).

(140) Keel affecting ventral surfaces of hamular processes: absent (0); present (1). (de Muizon (1988); Messenger and McGuire (1998) \#1449; Bianucci (2005) \#14; Murakami et al. (2012a, 2012b) \#139; modified from Fajardo-Mellor et al. (2006) \#10).

(141) Exposure of medial lamina of pterygoid hamuli in lateral view: complete or broad exposure due to extreme reduction of lateral lamina of pterygoid hamuli (0); no exposure due to a posterior extension of lateral 
lamina extending posterior to medial lamina (1); medial lamina of pterygoid hamuli exposing lateral lamina through ovoid window in lateral view (2). (de Muizon (1988); Fajardo-Mellor et al. (2006) \#11; Murakami et al. (2012a, 2012b) \#140; derived from Noble and Fraser (1971)).

\section{Posterior Basicranium}

(142) Falciform process of squamosal: plate-like with anteroposteriorly wide base (0); rodlike with narrow base (1); poorly developed or absent (2). (Geisler and Sanders (2003) \#176; Geisler et al. $(2011,2012)$ \#176; Murakami et al. (2012a, 2012b) \#141; modified from Lambert (2005) \#36).

(143) Falciform process of squamosal: medial surface not sutured to lateral lamina of pterygoid (0); medial surface sutured to lateral lamina of pterygoid (1). (Murakami et al. (2012a, 2012b) \#142; modified from Geisler and Sanders (2003) \#177; Geisler et al. (2011, 2012) \#177).

(144) Tympanosquamosal recess: absent, with anterior transverse ridge present (0); anterior transverse ridge absent and middle sinus inferred to be present without a large tympanosquamosal recess (1); present and enlarged, forming triangular fossa medial and anteromedial to postglenoid process (2); very large, forming large fossa bordering entire medial edge of glenoid fossa (3). (Geisler and Sanders (2003) \#178; Geisler et al. $(2011,2012)$ \#178; Murakami et al. (2012a, 2012b) \#143; modified from Lambert (2005) \#35; derived from Fraser and Purves (1960), and Fordyce (2002)).

(145) Bifurcation of tympanosquamosal recess: absent, almost undeveloped, elliptic (0); present, with a clear expansion anteriorly, invasion of mandibular fossa medially, and a depression (expansion) at the postglenoid process posteriorly (1). (Murakami et al. (2012a, 2012b) \#144; modified from de Muizon (1988); Bianucci (2005) \#11; Aguirre-Fernández et al. (2009) \#20).

(146) Fossa for the basisphenoidal sinus: absent (0); present (1). (Fraser and Purves (1960); Mead and Fordyce (2009); Murakami et al. (2012a, 2012b) \#145).

(147) Position of more-distal part of alisphenoidsquamosal suture, with skull in ventral view: anterior to external opening of foramen oval or a homologous groove (0); courses along groove for mandibular branch of trigeminal nerve, or just posterior to it (1); just medial to anterior edge of floor of squamosal fossa, foramen ovale, and/or groove situated entirely on alisphenoid (2). (Geisler and Sanders (2003) \#180; Geisler et al. $(2011,2012) \# 180$; Murakami et al. (2012a, 2012b) \#146).

(148) Groove for mandibular branch of trigeminal nerve: lateral end of groove wrapping laterally around posterior end of pterygoid sinus fossa and opening primarily anteriorly (0); directed laterally and located entirely posterior to pterygoid sinus fossa (1). (Murakami et al. (2012a, 2012b) \#147; modified from Geisler and Sanders (2003) \#181; Geisler et al. $(2011,2012)$ \#181).

(149) Suprameatal pit of squamosal: absent (0); present but shallow, situated dorsolateral to spiny process of squamosal (1); forming deep dorsolateral excavation into squamosal (2). (Geisler and Sanders (2003) \#185; Geisler et al. (2011, 2012) \#185; Murakami et al. (2012a, 2012b) \#149).

(150) Foramen spinosum: absent (0); present, located in anteromedial corner of anterior part of periotic fossa near or on squamosal-parietal suture (1). (de Muizon (1994); Geisler and Sanders (2003) \#186; Geisler et al. (2011, 2012) \#186; Murakami et al. (2012a, 2012b) \#150).

(151) Posterior portion of periotic fossa of squamosal: fossa absent (0); fossa present but shallow (1); highly compressed fossa forming narrow slit or small blind foramen (2); posteromedial portion contains large deep fossa (3). (Geisler and Sanders (2003) \#187; Geisler et al. $(2011,2012)$ \#187; Murakami et al. (2012a, 2012b) \#149 and \#151).

(152) Length of zygomatic process of squamosal as percent of greatest width of maxilla at postorbital process: $>31 \%(0) ; \leq 30 \%$ (1). (Murakami et al. (2012a, 2012b) \#152; modified from Heyning (1989) \#33, 35, \#65, 67; Geisler and Sanders (2003) \#188; Geisler et al. (2011, 2012) \#188) If the maxilla does not reach above the postorbital process, then use the frontal above the postorbital process. 
(153) External auditory meatus: wide (0); narrow (1). (Fordyce (1994) \#10; Geisler and Sanders $(2003,2012) \quad \# 189$; Lambert (2005) \#26; Geisler et al. (2011) \#189; Murakami et al. (2012a, 2012b) \#153).

(154) Vomer: posterior edge terminating on or at anterior edge of basisphenoid (0); terminating on basioccipital, covering basioccipital-basisphenoid suture ventrally (1). (Barnes (1984b); Geisler and Sanders (2003) \#190; Geisler et al. (2011, 2012) \#190; Murakami et al. (2012a, 2012b) \#154).

(155) Rectus capitus anticus muscle fossa: absent or poorly developed (0); present with welldefined anterior edge (1). (Geisler and Sanders (2003) \#192; Geisler et al. (2011, 2012) \#192; Murakami et al. (2012a, 2012b) \#155).

(156) Posteroventral-most point of basioccipital crest: rounded over (0); forming closely appressed separate flange, with narrow crease separating exoccipital dorsally from rest of basioccipital crest (1); projecting distinct flange posteriorly (2); distinct but separated by pronounced notch, interrupting basioccipital crest (3). (Geisler and Sanders (2003) \#193; Geisler et al. (2011, 2012) \#193; Murakami et al. (2012a, 2012b) \#156).

(157) Angle formed by basioccipital crests in ventral view: parallel with no angle formed (0); ca. $15-40^{\circ}(1)$; ca. $42-68^{\circ}(2)$; ca. $70-90^{\circ}$ (3); $>100^{\circ}$ (4). (Murakami et al. (2012a, 2012b) \#157; modified from Geisler and Sanders (2003) \#194; Geisler et al. (2011, 2012) \#194).

(158) Hypoglossal foramen: separated from jugular foramen, or jugular notch, by thick bone (0); separated by very thin bone or absent, in latter case hypoglossal foramen becoming confluent with jugular foramen (1). (Geisler and Sanders (2003) \#195; Geisler et al. $(2011,2012)$ \#195; Murakami et al. (2012a, 2012b) \#158).

(159) Jugular notch, gap between paroccipital process and basioccipital crest: open notch, width of opening and depth of notch about equal (0); narrow and almost slit-like, depth much greater than width of opening (1). (Geisler and Sanders (2003) \#196; Geisler et al. (2011, 2012) \#196; Murakami et al. (2012a, 2012b) \#159).
(160) Paroccipital process, skull in ventral view: posterior edge located well anterior to the posterior edge of condyle (0); posterior edge in transverse line with posterior edge of condyle (1). (Geisler and Sanders (2003) \#197; Geisler et al. (2011, 2012) \#197; Murakami et al. (2012a, 2012b) \#160).

(161) Fossa for posterior sinus in exoccipital: absent or slightly concave (0); moderately concave (1); forming deep sack-like structure (2). (Murakami et al. (2012a, 2012b) \#161; modified from de Muizon (1991); Lambert (2005) \#38).

\section{Malleus}

(162) Tuberculum of malleus: unreduced (0); highly reduced, almost indistinguishable from articular head (1). (de Muizon (1985); Messenger and McGuire (1998) \#1499; Geisler and Sanders (2003) \#198; Geisler et al. (2011, 2012) \#198; Murakami et al. (2012a, 2012b) \#162; modified from Lambert (2005) \#69. derived from Doran (1878)).

(163) Processus muscularis of malleus: shorter than manubrium of malleus (0); sub-equal or longer than manubrium (1). (Murakami et al. (2012a, 2012b) \#163; modified from de Muizon (1985; 1988); Messenger and McGuire (1998) \#1550; Geisler and Sanders (2003) \#199; Lambert (2005) \#70; Geisler et al. $(2011,2012) \# 199)$.

\section{Periotic}

(164) Length of anterior process of periotic as percent length of pars cochlearis: short, $<59 \%$ (0); long, $>60 \%$ (1). (Murakami et al. (2012a, 2012b) \#164; modified from de Muizon (1988); Heyning (1989) \#5; Messenger and McGuire (1998) \#1489; Geisler and Luo (1996) \#1; Luo and Marsh (1996) \#24; Geisler and Sanders (2003) \#203; Lambert (2005) \#39; Geisler et al. (2011, 2012) \#203; derived from Kellogg (1936); Yamada (1953); Kasuya (1973)).

(165) Apex of anterior process of periotic in dorsal view: pointed (0); dorsal edge of anterior process showing highly rounded or oblique edge due to its reduction with or without pointed apex (1); thickened by prominent dorsal tubercle giving apex rectangular section in plane of body of periotic (2). (Murakami et al. (2012a, 2012b) \#165; 
modified from Fordyce (1994) \#53; Lambert (2005) \#40).

(166) Lateral groove or depression affecting profile of periotic as viewed dorsally: no obvious vertical groove dorsal to hiatus epitympanicus (0); groove present with overall profile of periotic becoming slightly to markedly sigmoidal in dorsal view (1). (Fordyce (1994) \#35; Murakami et al. (2012a, 2012b) \#166).

(167) Anteroposterior ridge on dorsal side: undeveloped (0); developed on anterior process and body of periotic, associated with development of depression adjacent to groove for tensor tympani (1). (Fordyce (1994) \#55; Murakami et al. (2012a, 2012b) \#167).

(168) Articulation of anterior process of periotic to outer lip of tympanic bulla: contact of ventral surface of anterior process of periotic with outer lip of tympanic bulla (0); contact with thickened rim of outer lip of tympanic bulla and additionally with accessory ossicle (1); contact only with accessory ossicle (2). (Luo and Marsh (1996) \#7; Lambert (2005) \#46; Murakami et al. (2012a, 2012b) \#168).

(169) Parabullary sulcus: absent (0); strongly curved, C-shape (1); weakly curved (2); strongly curved, V-shape (3). (modified from Fordyce (1994) \#56 Anteroexternal sulcus).

(170) Parabullary ridge of periotic: absent (0); present (1); present with a fossa between anterior process and parabullary ridge (2). (modified from Murakami et al. (2012a, 2012b) \#171; Bianucci (2005) \#15).

(171) Articulation of anterior process with squamosal: extensive, most of lateral side contacting squamosal (0); large centrally-oriented ovoid region contacting squamosal, free around edges (1); small area of contact with squamosal (2); contact absent, articulation via ligaments (3). (Geisler and Sanders (2003) \#207; Geisler et al. (2011, 2012) \#207; Murakami et al. (2012a, 2012b) \#172; modified from Heyning (1997) \#32; Messenger and McGuire (1998) \#1490; derived from Heyning (1989)).

(172) Anterior bullar facet: present (0); absent (1). (de Muizon (1984, 1988, 1991); Messenger and McGuire (1998) \#1496; Lambert (2005) \#42; Murakami et al. (2012a, 2012b) \#173; modified from Fordyce (1994) \#4; derived from Kellogg (1936)).

(173) Anterior incisure: deep, pocket-like fossa with anterior groove (0); anterior groove only (1). (Geisler and Luo (1996) \#7; Luo and Marsh (1996) \#15; Geisler and Sanders (2003) \#217; Geisler et al. (2011, 2012) \#217; Murakami et al. (2012a, 2012b) \#174).

(174) Fenestra rotunda: oval to subrounded (0); shaped like teardrop with fissure directed toward aperture for cochlear aqueduct (1). (Fordyce (1994) \#22; Geisler and Sanders (2003) \#222; Lambert (2005) \#49; Geisler et al. $(2011,2012)$ \#222; Murakami et al. (2012a, 2012b) \#175).

(175) Dorsal surface of periotic in lateral view: convex dorsally (0); pyramidal process convex dorsally (1); nearly flat (2). (Murakami et al. (2012a, 2012b) \#176; modified from Luo and Marsh (1996) \#18).

(176) Relative position of dorsal depth of stapedial muscle fossa and fenestra rotunda: ventral to, or in line with, dorsal edge of fenestra rotunda (0); well dorsal to fenestra rotunda (1). (Geisler and Sanders (2003) \#223; Geisler et al. $(2011,2012)$ \#223; Murakami et al. (2012a, 2012b) \#177).

(177) Posterodorsal edge of stapedial muscle fossa: absent, rounded lip (0); present (1). (Geisler and Luo (1996) \#14; Geisler and Sanders (2003) \#217; Geisler et al. (2011, 2012) \#217; Murakami et al. (2012a, 2012b) \#178).

(178) Caudal tympanic process of periotic: low, its ventral and posterior edges drawing smooth curve (0); Elevated, its ventral and posterior edges forming a right angle in medial view (1). (Geisler and Sanders (2003) \#225; Geisler et al. $(2011,2012)$ \#225; Murakami et al. (2012a, 2012b) $\# 179)$.

(179) Position of aperture for cochlear aqueduct: dorsomedial (0); medial (1). (Lambert (2005) \#51; Murakami et al. (2012a, 2012b) \#180).

(180) Aperture for cochlear aqueduct: smaller than aperture for vestibular aqueduct (0); approximately same size as aperture for vestibular aqueduct (1); much larger than aperture for vestibular aqueduct, with narrow posterior edge (2). (Geisler and Sand- 
ers (2003) \#227; Geisler et al. (2011, 2012) \#227; Murakami et al. (2012a, 2012b) \#181; modified from de Muizon (1987); Fordyce (1994); Lambert (2005) \#52).

(181) Excavation of tegmen tympani at base of anterior process: absent (0); present, with fossa on dorsolateral side of tegmen tympani (1). (Geisler and Sanders (2003) \#231; Geisler et al. $(2011,2012)$ \#231; Murakami et al. (2012a, 2012b) \#182).

(182) Fundus of internal acoustic meatus: funnellike, smaller at blind end and wider near rim (0); tubular (1). (Luo and Marsh (1996) \#31; Geisler and Sanders (2003) \#234; Geisler et al. (2011, 2012) \#234; Murakami et al. (2012a, 2012b) \#183).

(183) Internal acoustic meatus: pyriform (0); circular (1). (de Muizon (1984); Messenger and McGuire (1998) \#1498; Bianucci (2005) \#21; Murakami et al. (2012a, 2012b) \#184).

(184) Lateral wall of internal acoustic meatus: high, with wedge-shaped area of elevated bone occurring between dorsal edge of tegmen tympani and internal acoustic meatus, the latter extending ventrally and increasing its depth (0); low, not protruding noticeably from fossa and surrounding bone (1). (Murakami et al. (2012a, 2012b) \#185; modified from Geisler and Sanders (2003) \#235; Geisler et al. $(2011,2012)$ \#235).

(185) Aperture for vestibular aqueduct, in dorsal view: at transverse level of spiral cribriform tract (0); more lateral than spiral cribriform tract (1) (Lambert (2005) \#53; Murakami et al. (2012a, 2012b) \#186).

(186) Articular rim: absent (0); present but small, forming ridge anterolateral to articulation surface of posterior process of periotic and separated from it by sulcus (1); present, sigmoidal and laterally elongated with hook-like process (2). (Geisler and Sanders (2003) \#239; Geisler et al. $(2011,2012)$ \#239; modified from Murakami et al. (2012a, 2012b) \#187; modified from de Muizon (1987); Messenger (1994); Messenger and McGuire (1998) \#1494; Fordyce (1994) \#33; Lambert (2005) \#55).

(187) Bony connection between posterior process of periotic and squamosal/occipital bones: present (0); absent (ligamentous). (1). (de Muizon (1984); Arnold and Heinsohn (1996) \#34; Messenger and McGuire
(1998) \#1491; Murakami et al. (2012a, 2012b) \#188; derived from Fraser and Purves (1960); Kasuya (1973); Heyning (1989)).

(188) Posterior process of periotic in lateral view: ventrally bent (0); in same plane as body of periotic (1). (Bianucci (2005) \#19; Murakami et al. (2012a, 2012b) \#189; modified from Arnold and Heinsohn (1996) \#28; Lambert (2005) \#54).

(189) Angle between posterior process of periotic and long axis of pars cochlearis from dorsal or ventral views: $>135^{\circ}(0)$; $\leq 135^{\circ}(1)$. (Murakami et al. (2012a, 2012b) \#190; modified from Geisler and Sanders (2003) \#246; Lambert (2005) \#54; Geisler et al. (2011, 2012) \#246; derived from Kasuya (1973); Barnes (1990); Luo and Marsh (1996)).

(190) Facet for bulla on posterior process of periotic, parallel-sided; no (0); yes (1). (modified from Fordyce (1994) \#63).

(191) Ventral surface of posterior process of periotic, along a straight path perpendicular to its long axis: flat (0); concave (1); convex (2). (Murakami et al. (2012a, 2012b) \#191; modified from Geisler and Sanders (2003) \#242; Geisler et al. $(2011,2012)$ \#242).

(192) Posterior bullar facet of periotic: with many long deep grooves and low ridges (0); with some shallow grooves and/or low ridges (1); without grooves or ridges (2). (Bianucci (2005) \#20; Murakami et al. (2012a, 2012b) \#192).

(193) Length of posterior process of periotic as percent length of pars cochlearis: long, $\geq 85 \%$ (0); short, $\leq 84 \%$ (1). (Murakami et al. (2012a, 2012b) \#193; modified from Barnes (1990); Luo and Marsh (1996) \#24; Geisler and Sanders (2003) \#245; Geisler et al. $(2011,2012) \# 245)$.

(194) Mastoid exposure of posterior process of periotic on outside of skull: exposed externally (0); not exposed, enclosed by exoccipital and squamosal (1). (Geisler and Luo (1996) \#28; Luo and Marsh (1996) \#28; Geisler and Sanders (2003) \#249; Geisler et al. $(2011,2012)$ \#249; Murakami et al. (2012a, 2012b) \#194).

\section{Tympanic Bulla}

(195) Anterior spine of tympanic bulla: absent (0); present but short (1); present and long (2). 
(de Muizon (1987); Fordyce (1994) \#45; Geisler and Sanders (2003) \#250; Lambert (2005) \#62; Geisler et al. $(2011,2012)$ \#250;Murakami et al. (2012a, 2012b) \#195; modified from Messenger and McGuire (1998) \#1484; derived from Kasuya (1973)).

(196) Anterolateral convexity of tympanic bulla with anterolateral notch: absent (0); present (1). (de Muizon (1987); Fordyce (1994) \#46; Lambert (2005) \#63; Murakami et al. (2012a, 2012b) \#196).

(197) Articulation of posterior process of tympanic bulla with squamosal: process contacting post-tympanic process of squamosal and posterior process of periotic (0); process contacting periotic only (1). (de Muizon (1984); Fordyce (1994) \#29; Arnold and Heinsohn (1996) \#34; Messenger and McGuire (1998) \#1481; Lambert (2005) \#56; Murakami et al. (2012a, 2012b) \#197; derived Kasuya (1973)).

(198) Width of tympanic bulla as percentage of its length along its long axis: wide, $\geq 65 \%(0)$; narrow and long, $\leq 64 \%$ (1). (Geisler and Sanders (2003) \#251; Bianucci (2005) \#23; Geisler et al. $(2011,2012)$ \#251; Murakami et al. (2012a, 2012b) \#198; derived from Kasuya (1973)).

(199) Accessory ossicle or homologous region on lip of bulla: not fused (0); fused to anterior process of periotic (1). (Barnes (1990); Fordyce (1994); Luo and Marsh (1996); Geisler and Sanders (2003) \#255; Geisler et al. $(2011,2012)$ \#255; Murakami et al. (2012a, 2012b) \#199).

(200) Lateral furrow of tympanic bulla: shallow groove (0); absent (1); deep, well-defined groove (2). (Murakami et al. (2012a, 2012b) \#200; modified from de Muizon (1984, 1988); Arnold and Heinsohn (1996) \#31; Messenger and McGuire (1998) \#1485; Fajardo-Mellor et al. (2006) \#17; Lambert (2008) \#17; derived from Kasuya (1973)).

(201) Sigmoid process: directed laterally to posterolaterally (0); directed anteriorly to anterolaterally (1). (Murakami et al. (2012a, 2012b) \#201; modified from Messenger and McGuire (1998) \#1486; Lambert (2005) \#67; Kasuya (1973)).

(202) Dorsomedial edge of sigmoid process: expanded anteriorly to appose lateral tuberosity of periotic (0); not articulating with squamosal or periotic (1) (Murakami et al. (2012a, 2012b) \#202; modified from Geisler and Sanders (2003) \#260; Geisler et al. $(2011,2012)$ \#260; modified from Luo and Marsh (1996) \#10).

(203) Ventral margin of tympanic bulla in lateral view: convex (0); concave (1). (Lambert (2005) \#66; Murakami et al. (2012a, 2012b) \#203).

(204) Elliptical foramen of tympanic bulla: present (0); absent or close (1). (Geisler and Sanders (2003) \#261; Geisler et al. $(2011,2012)$ \#261; Murakami et al. (2012a, 2012b) \#204; derived from Kasuya (1973)).

(205) Size of posterior process of tympanic bulla: equal to or greater than total length of tympanic bulla (0); much smaller than total length of tympanic bulla (1). (de Muizon (1984, 1991); Heyning (1989) \#23, 29; Heyning (1997) \#55, 61; Messenger and McGuire (1998) \#1482; Murakami et al. (2012a, 2012b) \#205; modified from Lambert (2005) \#57; derived from Yamada (1953); Kasuya (1973)).

(206) Surface of posterior process of tympanic bulla: spiny or irregular edges (0); cauliflower-like bony growth (1); rounded and pachyostotic (2). (de Muizon (1991); Messenger and McGuire (1998) \#1483; Murakami et al. (2012a, 2012b) \#206; derived from Kasuya (1973)).

(207) Median furrow: short extension on ventral face anterior to interprominental notch (0); anterolateral curvature of median groove to connect to long lateral furrow on outer lip (1); median groove reaching an anterior level beyond lateral furrow, and often slightly curved laterally (2); long and deep rectilinear median groove reaching at least to base of anterior tip of tympanic bulla (3). (Lambert (2005) \#64; Murakami et al. (2012a, 2012b) \#207).

(208) Median furrow on posterior side of bulla: divided by a transverse ridge originating from involucrum (0); transverse ridge absent (1). (Geisler and Sanders (2003) \#267; Geisler et al. (2011, 2012) \#267; Murakami et al. (2012a, 2012b) \#208).

(209) Posterior edge of medial prominence of involucrum: approximately in line with posterior edge of lateral prominence (0); distinctly anterior to posterior edge of lateral promi- 
nence (1). (de Muizon (1987); Geisler and Sanders (2003) \#269; Geisler et al. (2011, 2012) \#269; Murakami et al. (2012a, 2012b) \#209; derived from Kasuya (1973)).

(210) Dorsal margin of involucrum of tympanic bulla: not excavated (0); excavated just anterior to posterior process (1); excavated at mid-part of involucrum (2). (de Muizon, (1988); Messenger and McGuire, (1998) \#1487; Murakami et al. (2012a, 2012b) \#210, 211; modified from Lambert (2005) \#60; Geisler and Sanders (2003) \#271; Geisler et al. $(2011,2012)$ \#271).

(211) Ridge on inside of bulla: present, as transverse ridge extending laterally from involucrum and partially dividing cavum tympani into anterior and posterior portions (0); absent (1). (Geisler and Sanders (2003) \#272; Geisler et al. $(2011,2012)$ \#272; Murakami et al. (2012a, 2012b) \#212).

(212) Ventromedial keel of tympanic bulla: present along entire length (0); terminating approximately at level of lateral furrow or midpoint of the tympanic bulla (1); poorly defined along entire length (2). (Geisler and Sanders (2003) \#273; Geisler et al. (2011, 2012) \#273; Murakami et al. (2012a, 2012b) \#213; derived from Kasuya (1973)).

(213) Posterior end of ventromedial keel: not protruding and directed medially (0); protruding and directed medially (1). (Geisler and Sanders (2003) \#275; Geisler et al. (2011, 2012) \#275; Murakami et al. (2012a, 2012b) \#214).

\section{Hyals}

(214) Basihyal and thyrohyal connection: unfused (0); fused (1). (Murakami et al. (2012a, 2012b) \#215; modified from Bianucci (2005) \#25).

(215) Basihyal and thyrohyal shape: arched (0); angled (1). (Murakami et al. (2012a, 2012b) \#216; modified from Bianucci (2005) \#25).

\section{Vertebrae}

(216) Dorsal transverse process of atlas: developed dorsolaterally (0); fused with ventral transverse process, with length of process greater than width (1); absent or rudimentary obtuse angle (2). (Murakami et al. (2012a, 2012b) \#217; modified from de Muizon (1988); Barnes (1990)).

(217) Roof of neural canal of atlas: arched (0); convex (1); straight (2). (Murakami et al. (2012a, 2012b) \#218).

(218) Postzygapophysis of axis in anterior view: appearing as crest, elongated dorsolaterally (0); appearing as rudimentary crest (1); not appearing (2). (Murakami et al. (2012a, 2012b) \#219).

(219) Cervical vertebrae: unfused (0); atlas and axis fused (1); C1-C3 or C1-C4 fused (2); $\mathrm{C} 1-\mathrm{C} 6$ or $\mathrm{C} 1-\mathrm{C} 7$ fused (3); C2-C7 fused (4). (Murakami et al. (2012a, 2012b) \#220; modified from Arnold and Heinsohn (1996) \#9; Messenger and McGuire (1998) \#1501; Geisler and Sanders (2003) \#278, 279; Fajardo-Mellor et al. (2006) \#18; Lambert (2008) \#18; Geisler et al. (2011, 2012) \#278, 279; derived from Allen (1923); Miller (1923); Noble and Fraser (1971); de Smet (1977); Rommel (1990)).

(220) Length of cervicals $(\mathrm{C} 1-\mathrm{C} 7)$ as percent of height of vertebral body plus neural canal of atlas: long, $>150 \%$ (0); short, $<150 \%$ (1). (Murakami et al. (2012a, 2012b) \#221).

(221) Number of thoracic vertebrae: 9-11 (0); 1012 (1); 13-16 (2); 17-18 (3). (Murakami et al. (2012a, 2012b) \#222; modified from Geisler and Sanders (2003) \#281; Geisler et al. $(2011,2012)$ \#281; derived from Sanders and Barnes (2002)).

(222) Capitular articulation facets of posterior vertebrae: facets gradually shift downward on sequential vertebrae to fuse with tubercular facets (0); facets abruptly shift from a position on neural arch to a pedestal, originating from centrum on subsequent vertebra (1). (Geisler and Sanders (2003) \#282; Geisler et al. $(2011,2012)$ \#282; Murakami et al. (2012a, 2012b) \#223; derived from Flower (1868); Miller (1923)).

(223) Transverse processes of lumbar vertebrae: extend parallel to anterior and posterior borders (0); triangular (1). (de Muizon (1984; 1985; 1988); Messenger and McGuire (1998) \#1502; Geisler and Sanders (2003) \#285; Geisler et al. $(2011,2012)$ \#285; Murakami et al. (2012a, 2012b) \#224). 
(224) Transverse processes of lumbar vertebrae: oriented ventrolaterally (0); oriented laterally and horizontally (1). (Geisler and Sanders (2003) \#284; Geisler et al. (2011, 2012) \#284; Murakami et al. (2012a, $2012 b)$ \#225; derived from Sanders and Barnes (2002)).

(225) Ratio of greatest breadth of transverse process to width of centrum at anterior face in lumbar vertebrae: some or all lumbar vertebrae $>2.5$ (0); no lumbar vertebrae $>2.5$ (1). (Murakami et al. (2012a, 2012b) \#226).

(226) Number of lumbar vertebrae: 6-8 (0); 9-12 (1); 13-15 (2); 16-19 (3); 20-25 (4); >26 (5). (Murakami et al. (2012a, 2012b) \#227; modified from Geisler and Sanders (2003) \#287, (2012) \#287; Bianucci (2005) \#39; Geisler et al. (2011) \#287).

(227) Number of caudal vertebrae: 15-20 (0); 2127 (1); 28-33 (2); 34-40 (3); >41 (4). (Murakami et al. (2012a, 2012b) \#228; modified from Geisler and Sanders (2003) \#288; Bianucci (2005) \#40; Geisler et al. (2011, 2012) \#288).

\section{Sternum and Sternal Ribs}

(228) Sternum: consists of four or five parts (0); consists of two or three parts (1); consists of single bone (2). (Murakami et al. (2012a, 2012b) \#229; modified from Geisler and Sanders (2003) \#290; Geisler et al. (2011) \#290; derived from Yablokov (1964); Van Valen (1968)).

(229) Ventrolateral processes on manubrium of sternum: absent (0); present but small, occur ventral to articulation surface of first costal cartilage or rib (1). (de Muizon (1988); Messenger and McGuire (1998) \#1503; Geisler and Sanders (2003) \#289; Geisler et al. (2011, 2012) \#289; Murakami et al. (2012a, 2012b) \#230; derived from Klima et al. (1980)).

(230) Sternal ribs: unossified or ossification of fewer than five pairs (0); ossification of five pairs or more (1). (Murakami et al. (2012a, 2012b) \#231; derived from Flower (1867)).

(231) Number of two head ribs: $\geq 9(0) ; 8(1)$; $\leq 7$ (2). (Murakami et al. (2012b) \#282).

\section{Scapula}

(232) Anterodorsal part of scapula: rounded (0); rounded and anterior edge pointed (1); almost rectilinear (2). (Murakami et al. (2012a, 2012b) \#232).

(233) Ventral projection on anterior border of scapula: absent (0); present (1). (Fajardo-Mellor et al. (2006) \#26; Murakami et al. (2012a, 2012b) \#233; derived from Noble and Fraser (1971)).

(234) Anterior slope on scapula between anterior angle and midpoint of glenoid fossa with anterior and posterior margin of glenoid fossa on a plane: shallow, $<35^{\circ}(0)$; steeper, $>35^{\circ}$ (1). (modified from Murakami et al. (2012a, 2012b) \#234; modified from Bianucci (2005) \#31).

(235) Posterior slope on scapula, between scapula and midpoint of glenoid fossa with anterior and posterior margin of glenoid fossa on a plane: shallow, $<25^{\circ}(0)$; steeper, $>25^{\circ}(1)$. (modified from Murakami et al. (2012a, 2012b) \#235; modified from Bianucci (2005) \#32).

(236) Crest between infraspinous fossa and teres fossa: weakly developed (0); strongly developed (1). (Murakami et al. (2012a, 2012b) \#236).

(237) Coracoid process of scapula: not expanded distally (0); expanded distally (1); notably reduced or absent (2). (Murakami et al. (2012a, 2012b) \#237; modified from de Muizon (1987, 1994); Messenger and McGuire (1998) \#1504; Geisler and Sanders (2003) \#292; Lambert (2005) \#73; Bianucci (2005) \#33; Geisler et al. (2011) \#292; derived from True (1904)).

(238) Coracoid process of scapula, with glenoid fossa: directed horizontally (0); directed nearly anterodorsally (1); directed anteroventrally (2). (modified from Murakami et al. (2012a, 2012b) \#238; modified Barnes (1990)).

(239) Acromion of scapula: narrow and not expanded distally (0); expanded distally (1). (Murakami et al. (2012a, 2012b) \#239; modified from Bianucci (2005) \#34).

(240) Acromion of scapula, when glenoid fossa direct ventrally: directed horizontally (0); directed anterodorsally (1); directed anteroventrally (2). (Murakami et al. (2012a, 2012b) \#240; modified from Barnes (1990)).

(241) Supraspinous fossa of scapula: present (0); absent or nearly absent (1). (de Muizon 
(1987, 1994); Geisler and Sanders (2003) \#293; Lambert (2005) \#72; Geisler et al. (2011, 2012) \#293; Murakami et al. (2012a, 2012b) \#241).

\section{Forelimb (except scapula)}

(242) Ratio of length of humerus to length of radius: long, $>1.1$ (0); short, <0.8 (1). (Murakami et al. (2012a, 2012b) \#242; modified from Sanders and Barnes (2002); Geisler and Sanders (2003) \#297; Geisler et al. (2012; 2011) \#297).

(243) Location of apex of deltopectoral tuberosity of humerus: within proximal $65 \%$ of humerus (0); within distal $35 \%$ of humerus (1). (Murakami et al. (2012a, 2012b) \#243; modified from de Muizon (1988); Messenger and McGuire (1998) \#1506; Geisler and Sanders (2003) \#295; Bianucci (2005) \#35; Geisler et al. (2011, 2012) \#295).

(244) Prominent deltoid crest on anterior edge of humerus: present, forms greatest anteroposterior diameter along shaft (0); forming a knob-like tuberosity (1); neither tuberosity or crest absent (2). (Geisler and Sanders (2003) \#294; Geisler et al. (2011, 2012) \#294; Murakami et al. (2012a, 2012b) \#244; derived from Sanders and Barnes (2002)).

(245) Radial and ulnar facets of humerus in lateral view: facets forming a semicircular articulation surface (0); facets forming an obtuse angle (1). (Barnes (1990); Geisler and Sanders (2003) \#296; Geisler et al. (2011, 2012) \#296; Murakami et al. (2012a, 2012b) \#245).

(246) Olecranon process: present as a distinct process (0); present as a slightly raised proximal posterior edge (1); absent (2). (Messenger and McGuire (1998) \#1507; Geisler and Sanders (2003) \#296; Geisler et al. $(2011,2012)$ \#284; Murakami et al. (2012a, 2012b) \#246; modified from de Muizon (1984); Barnes (1990); Arnold and Heinsohn (1996) \#10; Fajardo-Mellor et al. (2006) \#28; derived from Howell (1927); Bianucci (2005) \#37).

\section{Soft Tissues}

(247) Spermaceti organ: absent (0); present (1). (Fordyce (1994) \#17; Messenger and McGuire (1998) \#1511; Geisler and Sanders (2003) \#97; Geisler et al. (2011, 2012)
\#97; Murakami et al. (2012a, 2012b) \#247; derived from Norris and Harvey (1972); Cranford et al. (1996)).

(248) Museau de singe: absent (0); present (1). (Messenger and McGuire (1998) \#1512; Murakami et al. (2012a, 2012b) \#248; derived from Norris (1964); Cranford et al. (1996)).

(249) Lateral lips of nasal plug: present (0); absent (1). (Messenger and McGuire (1998) \#1523; Murakami et al. (2012a, 2012b) \#249).

(250) Proximal sac: single frontal sac (0); sac complex, with nasofrontal sacs and vestibule (1). (Heyning (1989) \#6, 11, 17; Heyning (1997) \#33, 43, 49; Fordyce (1994) \#16; Messenger and McGuire (1998) \#1531, 1532; Lambert (2005) \#18; Murakami et al. (2012a); Murakami et al. (2012b) \#250).

(251) Posterior nasal sacs: absent (0); present (1). (Heyning (1989) \#41; Heyning (1997) \#73; Arnold and Heinsohn (1996) \#6; Messenger and McGuire (1998) \#1534; Murakami et al. (2012a, 2012b) \#251).

(252) Posterior nasal sacs: single (0); divided (1). (Messenger and McGuire (1998) \#1535; Murakami et al. (2012a) \#252).

(253) Anterior section of nasofrontal sac: absent (0); present (1). (Messenger and McGuire (1998) \#1536; Murakami et al. (2012a, 2012b) \#253).

(254) Anterior part of nasofrontal sac: smooth (0); trabeculate (1). (Messenger and McGuire (1998) \#1537; Fajardo-Mellor et al. (2006) \#35; Murakami et al. (2012a, 2012b) \#254; derived from Heyning (1989)).

(255) Vestibular sac: absent (0); present (1); hypertrophied (2). (Heyning (1989) \#28; Heyning (1997) \#60; Fordyce (1994) \#31; Arnold and Heinsohn (1996) \#1, 3; Messenger and McGuire (1998) \#1541; Lambert (2005) \#17; Fajardo-Mellor et al. (2006) \#39; Murakami et al. (2012a, 2012b) \#255).

(256) Floor of vestibular sac (nasal sac): not rigid (0); rigid (1). (Heyning (1989) \#38; Heyning (1997) \#70; Arnold and Heinsohn (1996) \#2; Messenger and McGuire (1998) \#1543; Fajardo-Mellor et al. (2006) \#38; Murakami et al. (2012a, 2012b) \#256).

(257) Vestibular sac (nasal sac): undivided (0); bilaterally divided (1). (Messenger and 
McGuire (1998) \#1544; Fajardo-Mellor et al. (2006) \#36; Murakami et al. (2012a, 2012b) \#257; derived from Heyning (1989)).

(258) Right and left sides of vestibular sac (nasal sac): same size (0); right side larger than left (1). (Heyning (1989) \#30; Heyning (1997) \#62; Messenger and McGuire (1998) \#1545; Murakami et al. (2012a, 2012b) \#258).

(259) Intrinsic muscle in vestibular sac (nasal sac): absent (0); present (1). (Messenger and McGuire (1998) \#1546; Fajardo-Mellor et al. (2006) \#37; Murakami et al. (2012a, 2012b) \#259; derived from Mead (1975)).

(260) Floor of vestibular sac (nasal sac): smooth (0); wrinkled (1). (Heyning (1997) \#70; Arnold and Heinsohn (1996) \#2; Messenger and McGuire (1998) \#1543; Murakami et al. (2012a, 2012b) \#260).

(261) Diagonal membrane: absent (0); present (1). (Messenger and McGuire (1998) \#1550; Murakami et al. (2012a, 2012b) \#261; Heyning (1989)).

(262) Spiracular cavity: slit-like (0); rounded (1). (Messenger and McGuire (1998) \#1552; Murakami et al. (2012a, 2012b) \#262).

(263) Pars posteroexternus muscle: absent (0); present (1). (Messenger and McGuire (1998) \#1553; Murakami et al. (2012a, 2012b) \#263).

(264) Pars intermedius muscle: absent (0); present (1). (Messenger and McGuire (1998) \#1554; Murakami et al. (2012a, 2012b) \#264).

(265) Pars posterointerus muscle: absent (0); present (1). (Messenger and McGuire (1998) \#1556; Murakami et al. (2012a, 2012b) \#265).

(266) Pars anterointerus muscle: one insertion (0); two insertions (1). (Messenger and McGuire (1998) \#1557; Murakami et al. (2012a, 2012b) \#266).

(267) Blowhole shape: longitudinal slit, may be slightly sigmoidal or angled (0); crescent, with apices pointed anteriorly (1); crescent, with apices pointed posteriorly, may be skewed (2); rectangular (3). (Murakami et al. (2012a, 2012b) \#267; modified from Messenger and McGuire (1998) \#1525).

(268) Soft tissues of nasal passages distal to bony external nares: separated for most of their length but confluent just proximal to blowhole (0); confluent (1). (Heyning (1989); Fordyce (1994) \#20; Messenger and McGuire (1998) \#1529; Geisler and Sanders (2003) \#95; Lambert (2005) \#16; Geisler et al. $(2011,2012)$ \#95; Murakami et al. (2012a, 2012b) \#268).

(269) Distal sac: absent (0); present, situated immediately distal to museau de singe (1). (Murakami et al. (2012a, 2012b) \#269; modified from Heyning (1989) \#12; Heyning (1997) \#44; Fordyce (1994) \#14; Messenger and McGuire (1998) \#1533; Geisler and Sanders (2003, 2012) \#99; Lambert (2005) \#19; Geisler et al. (2011) \#99).

(270) Blowhole ligament: absent (0); present (1). (Heyning (1989) \#15; Heyning (1997) \#44; Fordyce (1994) \#13; Messenger and McGuire (1998) \#1527; Geisler and Sanders (2003) \#101; Lambert (2005) \#20; Geisler et al. $(2011,2012)$ \#101; Murakami et al. (2012a, 2012b) \#270).

(271) Blowhole ligament: not appressed against skull (0); appressed against skull (1). (Messenger and McGuire (1998) \#1528; Murakami et al. (2012a, 2012b) \#271).

(272) Cartilage on blowhole ligament: absent (0); present (1). (Messenger and McGuire (1998) \#1529; Murakami et al. (2012a, 2012b) \#272).

(273) Premaxillary sac: absent (0); present (1). (Heyning (1989) \#16; Heyning (1997) \#48; Messenger and McGuire (1998) \#1538; Geisler and Sanders (2003) \#105; Geisler et al. $(2011,2012) \# 105$; Murakami et al. (2012a, 2012b) \#273).

(274) Accessory sac: absent (0); present, forms small diverticulum of inferior vestibule and extends anterolaterally around the attachment of blowhole ligament to the premaxilla (1). (Messenger and McGuire (1998) \#1549; Geisler and Sanders (2003) \#106; Fajardo-Mellor et al. (2006) \#40; Geisler et al. $(2011,2012)$ \#106; Murakami et al. (2012a, 2012b) \#274; derived from Schenkkan (1971); Mead (1975); Heyning (1989)).

(275) Esophageal forestomach: present (0); absent (1). (Geisler and Sanders (2003) \#300; Geisler et al. $(2011,2012)$ \#300; Murakami et al. (2012a, 2012b) \#275; derived from Mead (1989); Rice and Wolman (1990)). 
(276) External throat grooves: absent (0); one pair converged anteriorly (1); irregular in number and shape (2). (Murakami et al. (2012a) \#276; modified from Messenger and McGuire (1998) \#1512, 1513; Geisler and Sanders (2003) \#301; Geisler et al. (2011, 2012) \#301).

(277) Dorsal fin: present (0); dorsal hump (1); absent (2). (Murakami et al. (2012a) \#277; modified from Messenger and McGuire (1998) \#1562; Geisler and Sanders (2003, 2012) \#304; derived from Leatherwood and Reeves (1983); Jefferson and Newcomer (1993); Reeves et al. (2002)).

(278) Shape of flipper: fan shaped (0); rounded at tip (1); sharply pointed at tip (2); entire flipper rounded (3). (Murakami et al. (2012a) \#278; modified from Fajardo-Mellor et al. (2006) \#31; Lambert (2008) \#25; derived from Leatherwood and Reeves (1983); Brownell et al. (1987)).

\section{Newly added characters}

(279) Intra-premaxillary foramen on posterior dorsal surface of skull, which is bounded by premaxilla and maxilla: absent (0); present (1).

(280) Shape of restricted area between postorbital ridge of frontal and subtemporal crest from ventral view: anteroposteriorly long elliptical (0); wide fan-shape (1); narrow fanshape (2), rhombus (3).

(281) Temporal fossa shape in lateral view: height lower than anteroposterior length (0); higher (1); nearly equilateral square (2); lower and its posterior end is rounded (3).

(282) Anterior zygomatic process end of squmosal in lateral view: tapered (0); squared (1).

(283) Basioccipital width compared with maximum width of skull in ventral view: narrow, less than $50 \%(0)$, wider larger than $51 \%(1)$.

(284) Occipital condyles; on pedicle (0); lacking pedicle, unified with occipital (1).

(285) Incisors relatively delicate and procumbent: no (0); yes (1). (Fordyce (1994) \#42).

(286) Crown of heterodont teeth: long $(>10 \mathrm{~mm})$ (0); short $(<10 \mathrm{~mm})$ (1). (Fordyce (1994) \#58).

(287) Large incisor tusk: absent (0); present (1).

(288) Profile of anterior process of periotic ventrally deflected in lateral view: no, has crudely rectangular profile (0); smoothly deflected (1); abruptly deflected (2). (Fordyce (1994) \#25).

(289) Cochlear aqueduct on periotic large with a thin edge: no (0); yes (1). (Fordyce (1994) \#28).

(290) Thickness dorsoventral of pars cochlearis on periotic; thick (0) flat (1) (Gutstein et al. (2014)).

(291) Profie of cochlear on periotic in dorsoventral; rounded (0), sub-rectangular (1), squared (2). (modified from Fordyce (1994) \#61; Bianucci et al. (2013) \#2).

(292) Acromion process of scapula lies on anterior edge, with loss of supraspinous fossa: no (0); yes (1). (de Muizon (1987); Fordyce (1994) \#48). 


\section{APPENDIX 5.}

\section{List of coding modifications.}

List of modifications to the original codings and character descriptions of Tanaka and Fordyce (2014). The initial number refers to the character number in Appendix 4. Character numbers are identified by a hatch \#. For some characters, a new state (generally 2 ) was added to indicate the hitherto uncoded situation in the outgroup taxon.

(3) Premaxillae mediolateral proportion: not compressed mediolaterally (0); compressed mediolaterally at anterior of rostrum (1).

Platanista gangetica 0 to 1

(34) Antorbital process of maxilla in dorsal view: triangular (0); robust and globose or rectilinear (1); absent (2); formed by lacrimal (3).

The qualifier "of maxilla in dorsal view" is added in the character description.

A new state, absent (2), is added for Archaeoceti, and a new state, formed by lacrimal (3), is added for Archaeodelphis and Xenorophus, and codings are changed as below.

Georgiacetus vogtlensis - to 2

Zygorhiza kochii - to 2

Archaeodelphis patrius 2 to 3

Xenorophus sloanii 2 to 3

(44) Ventromedial edge of internal opening of infraorbital foramen: formed by maxilla (0); formed by maxilla and palatine and/or pterygoid (1); formed by palatine and/or pterygoid (2).

Otekaikea marplesi 1 to 0

(55) Premaxillary foramen locating: medial (0); midpoint to lateral (1) absent (2)

A state (2) "absent" is added for the Archaeoceti.

Georgiacetus vogtlensis - to 2

Zygorhiza kochii - to 2

(57) Posterolateral sulcus: deep (0); shallow or absent (1); presence of additional posterolateral sulcus (longitudinal striation) (2) presence of additional posterolateral sulcus or changing into longitudinal striation (3).

Two Archaeoceti codings were changed because of uncertain homology.

Georgiacetus vogtlensis 1 to ?

Zygorhiza kochii 1 to ?

Otekaikea marplesi 1 to ? (damaged)

In addition, based on Murakami et al. (2014) (\# 55, see Supplementary 5), state (2) was changed from "presence of additional posterolateral sulcus (longitudinal striation) (2)", state (3) was added and codings are changed as below.

Archaeophocaena teshioensis 1 to 2

Australithax intermedia 1 to 2

Haborophocoena toyoshimai 1 to 2

Lomacetus ginsburgi 1 to 2

Piscolithax boreios 1 to 2

Piscolithax longirostris 1 to 2

Piscolithax tedfordi 1 to 2

Salumiphocaena stocktoni 1 to 2

Septemtriocetus bosselaersi 1 to 2

Phocoena spinipinnis 2 to 3

Phocoena dioptrica 2 to 3

Phocoena phocoena 2 to 3

Phocoenoides dalli 2 to 3

Neophocaena phocaenoides 2 to 3

Miophocaena nishinoi 2 to 3

(90) Nasals: fossae on nasals absent (0); smoothsurfaced fossa on anterior to anterolateral surface (1) anteromedially depressed (2).

State (2) was added for the nasals of Simocetus rayi, which "is sculputured anteromedially" (see Fordyce (2002)) like steps.

(97) Vertex: absent (0); present (1); highly developed (2).

Character name is changed from "synvertex", because the term has been used for elevated vertex of the Ziphiidae (here, state 2 is equivalent to the synvertex).

Codings for the Delphinoidea were changed from 0 to 1.

(102) Roof of temporal fossa formed by: frontals (0); frontals, but with large opening through maxillae and/or premaxillae exposing margins of window formed by a frontal ring (1) absent (2)

State (2) is added for the Archaeoceti and archaic odontocetes (Simocetus rayi) with an open unroofed temporal fossa.

Georgiacetus vogtlensis - to 2

Zygorhiza kochii - to 2

Archaeodelphis patrius - to 2

(111) Emargination of posterior edge of zygomatic process by sternomastoid muscle fossa, skull in lateral view: absent, posterior edge forming nearly right angle with dorsal edge of zygomatic process of squamosal (0); shallow emargination (1); deep emargination (2). 
Character description is changed from "sternomastoid muscle fossa" to "neck muscle fossa" (see description of the squamosal).

Squalodelphis fabianii 2 to 1

Agorophius pygmaeus 0 to 1

(142) Falciform process of squamosal: plate-like with anteroposteriorly wide base (0); rodlike with narrow base (1); poorly developed or absent (2).

Otekaikea marplesi 0 to ?

(154) Vomer: posterior edge terminating on or at anterior edge of basisphenoid (0); terminating on basioccipital, covering basioccipital-basisphenoid suture ventrally (1).

Waipatia maerewhenua 1 to 0

Otekaikea marplesi 1 to 0
Notocetus vanbenedeni 1 to 0

Pomatodelphis inaequalis 1 to 0

Papahu taitapu 1 to 0

Squaloziphius emlongi 1 to 0

Prosqualodon davidis 1 to ?

(202) Dorsomedial edge of sigmoid process: expanded anteriorly to appose lateral tuberosity of periotic (0); not articulating with squamosal or periotic (1).

Character description is changed.

(238) Coracoid process of scapula, with glenoid fossa: directed horizontally (0); directed nearly anterodorsally (1); directed anteroventrally (2).

"directed ventrally" in the character description is deleted. 


\section{APPENDIX 6.}

Specimen list for newly added characters.

\section{Specimens which were used for codings of newly added characters.}

Institutional abbreviations - ALMNH, Alabama Museum of Natural History, Tuscaloosa, USA; AMNH, American Museum of Natural History, New York, USA; AMP, Ashoro Museum of Paleontology, Ashoro, Hokkaido, Japan; BMMH, British Museum Natural History, UK; CBM, Natural History Museum and Institute, Chiba, Japan; CMM, Calvert Marine Museum, Solomons, Maryland, USA; GSM, Georgia Southern Museum, Statesboro, USA; HMNH, Haboro Museum of Natural History, Haboro, Hokkaido, Japan; IGUP, Instituto di Geologia del' Universita di Padova, Italy; IRSNB, Institut Royal des Sciences Naturelles de Belgique, Brussels, Belgium; MCZ, Museum of Comparative Zoology, Harvard University, Cambridge, Massachusetts, USA; MLP, Museo de La Plata, La Plata, Argentina; MNHN, Museum National d'Histoire Naturelle, Paris, France; NHMW, Natural History Museum. Vienna. Austria; NMNZ, Museum of New Zealand Te Papa Tongarewa, Wellington, New Zealand; NMV, Museum Victoria, Melbourne, Australia; NSMT, National Science Museum of Tokyo, Japan: OM, Otago Museum, Dunedin, New Zealand; OU, Geology Museum, University of Otago, Dunedin, New Zealand; PIN, Paleontological Institute, Moscow; SMNK, Staatliches Museum für Naturkunde, Karlsruhe, Germany; UCMP, University of California Museum of Paleontology, Berkeley, USA; UCR, Department of Geological Science, University of California at Riverside, USA; USNM, United States National Museum of Natural History, Washington DC, USA; YPM, Peabody Museum, Yale University, New Haven, Connecticut, USA.

\section{List of the specimens}

Agorophius pygmaeus: photos of MCZ 8761 from True (1904)

Albireo whistleri: Photos of UCR 14589 (skull, periotic) from Barnes (2008)

Archaeodelphis patrius: photos of MCZ 15749

Archaeophocaena teshioensis: photos and illustrations of NMV 56 (skull) from Murakami et al. (2012b).

Atocetus iquensis: photos of MNHN PPI 113 (skull), 115 (periotic) and 114 (bulla) from de Muizon (1988)
Australithax intermedia: photos and illustrations of MNHN PPI 65 (skull) and 111 and 112 (periotics) from de Muizon (1988)

Berardius bairdii: AMP exhibition (skull and skeleton), earbone photos from Kasuya (1973)

Brachydelphis mazeasi: photos of MNHN PPI 121 (skull) and 126 (periotic) from de Muizon (1988)

Cephalorhynchus hectori: OU 22712 (skull and scapulae)

Delphinapterus leucas: NSMT M34189 (skull and skeleton) and photos of AMNH 1800017 (periotic and bulla) from Kasuya (1973)

Delphinus delphis: Skull of NMNZ 2852.

Denebola brachycephala: photos of UCR 21245 from Barnes (1984a)

Georgiacetus vogtlensis: photos of GSM 350 from Hulbert et al. (1998)

Globicephala macrorhynchus: Skeleton of CBM.

Haborophocoena toyoshimai: photos and illustrations of HMNH 110-1 (skull, periotic and bulla) from Ichishima and Kimura (2005)

Hadrodelphis calvertense: photos and illustrations of CMM V 11 (skull, periotic and bulla) from Dawson (1996)

Inia geoffrensis: USNM 49582, 396166, 395614 (ear bones in situ), photos from Gutstein et al (2014)

Kentriodon pernix: OU cast and Kellogg (1927) figures of USNM 8060 (periotic and bulla), OU skull cast of USNM 10670

Kogia sp.: an OM skull and earbones

Lipotes vexillifer: photos, illustrations from Miller (1918) and Zhou et al. (1979), OU cast of AMNH specimens (periotic and bulla)

Mesoplodon grayi: OM A.64.1

Miophocaena nishinoi: photos and illustrations of NMV 6 (skull and periotic) from Murakami et al. (2012b).

Monodon monoceros: NSMT M33766 (skull and skeleton) and photos of SDNHM 7096 and AMNH 73318 (periotic and bulla) from Kasuya (1973).

Neophocaena phocaenoides: Skeleton of CBM. 
Notocetus vanbenedeni: MLP 5-5 (skull); AMNH 9485 (skull and bulla); AMNH 29026 (periotic, bulla and scapula)

Odobenocetops peruvianus: OU skull cast of SMNK Pal 2492

Orcinus orca: OU ear bones and NSM skeleton

Otekaikea marplesi: OM GL 421

Otekaikea sp.: OU 22306

Papahu taitapu: OU 22066

Parapontoporia sternbergi: photos of LACM 6238 (skull) and UCMP 88581, 88589, LACM 58901, 103975 (periotics) from Barnes (1985b)

Patriocetus kazakhstanicus: photos of PIN 3067 (skull) from Dubrovo and Sanders (2000)

Phocoena dioptrica: photos of NMV C10323 (skull).

Phocoena phocoena: illustrations of BMNH 1965.3.30.1 (1971).

Phocoena sinus: illustrations of BMNH 69.678 (1971).

Phocoena spinipinnis: illustrations of BMNH 1900.5.7.29 (1971).

Physeter macrocephalus: NSM exhibition (skull and skeleton), ZMT 612 (periotic and bulla)

Piscolithax boreios: illustrations of UCR 15975 (skull) from Barnes (1984a).

Piscolithax tedfordi: illustrations of UCR 15972 (skull) from Barnes (1984a).

Platanista gangetica: NSMT M 24856; NSMT M 24862

Pliopontos littoralis: photos of MNHN SAS 931 from de Muizon (1983)

Pomatodelphis inaequalis: photos of $15750 \mathrm{MCZ}$ (Type skull) from Allen 1921; a photo of USNM 187414 (bulla) from de Muizon (1987)

Pontoporia blainvillei: USNM 48942

Prosqualodont davidi: photos and illustrations of the type from Flynn (1948) and OU cast of the type

Pseudorca crassidens: Skull NSM
Pterophocaena nishinoi: photos of NMV 7 (skull, periotic and bulla) from Murakami et al. (2012a)

Salumiphocaena stocktoni: illustrations of UCMP 34576 (skull and earbones) from Wilson (1973).

Septemtriocetus bosselaersi: photos and illustrations of IRSNB M. 1928 (skull) from Lambert (2008).

Simocetus rayi: OU cast of USNM 256517

Squalodelphis fabianii: OU cast (IGUP Type skull, mandible and ear bones in situ), photos of IGUP 26378 (periotic and bulla) from de Muizon (1987)

Squalodon calvertensis: OU skull cast of USNM exhibition and OU periotic cast of USNM 10484.

Stenella attenuata: Skeleton of CBM.

Eodelphinus kabatensis: photos of NMN 68037 (skull and ear bones) from Murakami et al. (2014)

Steno bredanensis: Skull of NMNZ 1736.

Tasmacetus shepherdi: OU exhibition (skull, periotic and bulla)

Tursiops truncatus: OU 21820

Microcetus hectori NMNZ Ma 653 (skull and mandible)

Microcetus ambiguus photos of type teeth

Microcetus sharkovi Dubrovo in Dubrovo and Sharkov (1971) OU cast of skull and mandible

Waipatia maerewhenua: OU 22095

Xenorophus sloanii: USNM 11049 (skull)

Xiphiacetus bossi: USNM 8842 (skull and skeleton) and 10711 (skull)

Zarhachis flagellator: USNM 10911

Ziphius cavirostris: OU 22724 (skull, periotic and bulla)

Zygorhiza kochii: OU cast (a skull of USNM V 11962), OU cast (a periotic of ALMNH 2000.1.2.1), OU 22125 (skull, periotic and bulla) 


\section{APPENDIX 7.}

Complete strict consensus tree of the equally weighted analysis.

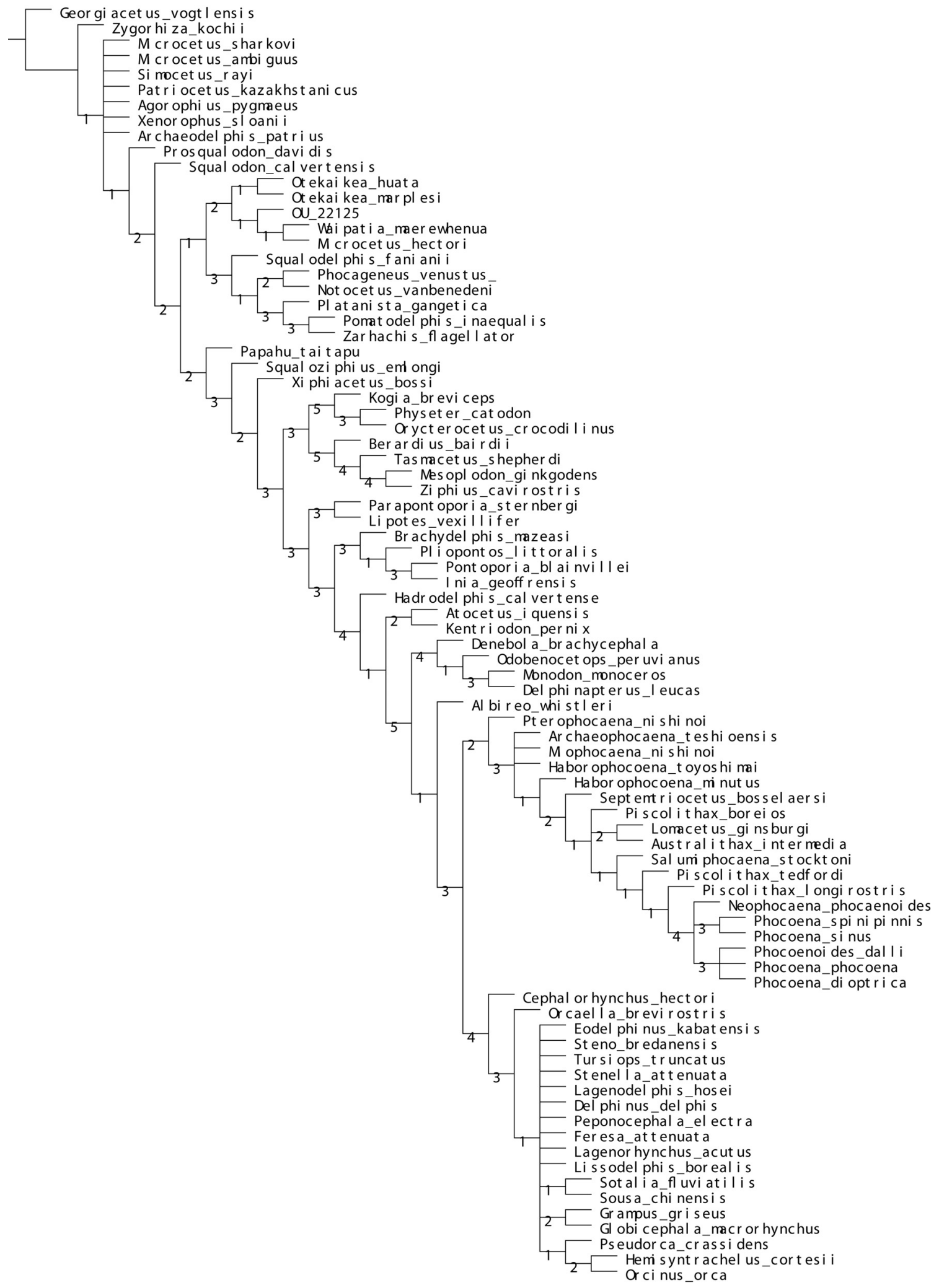




\section{APPENDIX 8.}

Complete strict consensus tree of the implied weighting analysis.

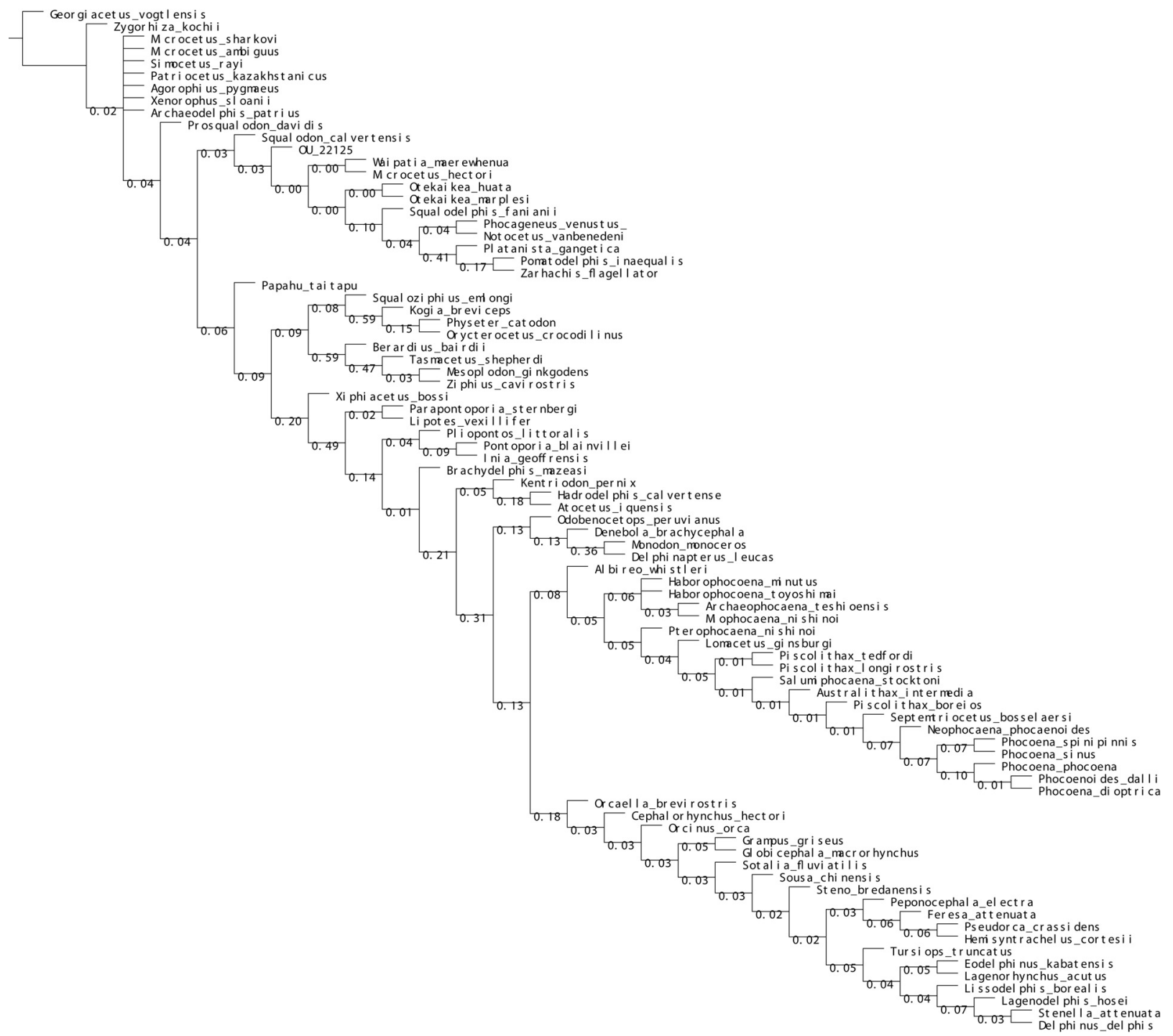

